\title{
Presenting Turkish Inappropriate Medication Use in the Elderly (TIME) Criteria Set in Turkish
}

\author{
(1) Gülistan Bahat1', (1) Birkan İlhan2, (1) Tuğba Erdoğan1, (1) Meltem Halil3, (1) Sumru Savaş4, (1) Zekeriya Ülger5, (1) Filiz Akyüz6, \\ (1) Ahmet Kaya Bilge7, (1) Sibel Çakır8, (1) Kutay Demirkan99, (1) Mustafa Erelel10, (1) Kerim Güler11, (1) Haşmet Hanağası ${ }^{12,}$ \\ (1) Belgin İzgi13, (1) Ateş Kadıoğlu14, (1) Ayşe Karan15, (1) Işın Baral Kulaksızoğlu8, (1) Ali Mert16, (1) Savaş Öztürk17, (1) İlhan Satman18, \\ (D) Mehmet Şükrü Sever17, (1) Tufan Tükek11, (1) Yağız Üresin19, (1) Önay Yalçın20, (1) Nilüfer Yeşilot'12, (1) Meryem Merve Ören21, \\ (D) Mehmet Akif Karan 1 \\ 1 Istanbul University, İstanbul Faculty of Medicine, Department of Geriatrics Medicine, Division of Geriatrics, Istanbul, Turkey \\ 2istanbul Şişli Hamidiye Etfal Training and Research Hospital, Clinic of Internal Medicine, Division of Geriatrics, İstanbul, Turkey \\ ${ }^{3}$ Hacettepe University Faculty of Medicine, Department of Internal Medicine, Division of Geriatric Medicine, Ankara, Turkey \\ ${ }^{4}$ Ege University Faculty of Medicine, Department of Internal Medicine, Division of Geriatrics, Izmir, Turkey \\ 5 Kırıkkale University Faculty of Medicine, Department of Internal Medicine, Kırıkkale, Turkey

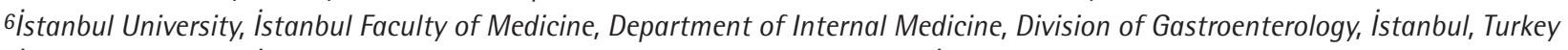 \\ 7istanbul University, İstanbul Faculty of Medicine, Department of Cardiology, Istanbul, Turkey \\ 8istanbul University, İstanbul Faculty of Medicine, Department of Psychiatry, İstanbul, Turkey \\ ${ }_{9}^{9}$ Hacettepe University Faculty of Pharmacy, Department of Clinical Pharmacy, Ankara, Turkey \\ 10 istanbul University, İstanbul Faculty of Medicine, Department of Pulmonary Medicine, Istanbul, Turkey \\ 11 istanbul University, İstanbul Faculty of Medicine, Department of Internal Medicine, istanbul, Turkey \\ 12 istanbul University, Istanbul Faculty of Medicine, Department of Neurology, istanbul, Turkey \\ 13istanbul University, Istanbul Faculty of Medicine, Department of Ophthalmology, Istanbul, Turkey

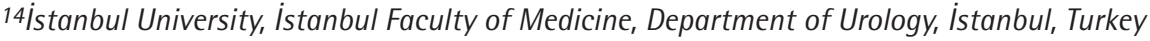 \\ 15istanbul University, istanbul Faculty of Medicine, Department of Physical Therapy and Rehabilitation, Istanbul, Turkey \\ 16istanbul Medipol University Faculty of Medicine, Department of Infectious Diseases and Clinical Microbiology, Istanbul, Turkey \\ 17istanbul University, Istanbul Faculty of Medicine, Department of Nephrology, Istanbul, Turkey \\ 18istanbul University, İstanbul Faculty of Medicine, Department of Internal Medicine, Division of Endocrinology, Istanbul, Turkey \\ 19istanbul University, Istanbul Faculty of Medicine, Department of Pharmacology, Istanbul, Turkey \\ 20Istanbul University, İstanbul Faculty of Medicine, Department of Obstetrics and Gynecology, Istanbul, Turkey \\ 21 istanbul University, istanbul Faculty of Medicine, Department of Public Health, Istanbul, Turkey
}

Keywords: Elderly, inappropriate medication use, polypharmacy, prescribing, TIME criteria

Address for Correspondence: Tuğba Erdoğan, İstanbul University, İstanbul Faculty of Medicine, Department of Geriatrics Medicine, Division of Geriatrics, İstanbul, Turkey

Phone: +90 2125324208 E-mail: tubaobekli@hotmail.com ORCID: orcid.org/0000-0001-8690-0189

Received: 18.06.2021 Accepted: 30.06 .2021

Cite this article as: Bahat G, İlhan B, Erdoğan T, Halil M, Savaş S, Ülger Z, Akyüz F, Bilge AK, Çakır S, Demirkan K, Erelel M, Güler K, Hanağası H, İzgi B, Kadıoğlu A, Karan A, Baral Kulaksızoğlu I, Mert A, Öztürk S, Satman I, Sever MŞ, Tükek T, Üresin Y, Yalçın Ö, Yeşilot N, Ören MM, Karan MA. Presenting Turkish Inappropriate Medication Use in the Elderly (TIME) Criteria Set in Turkish. Eur J Geriatr Gerontol 2021;3(2):40-100

๑Copyright 2021 by the Academic Geriatrics Society / European Journal of Geriatrics and Gerontology published by Galenos Publishing House. 


\section{Introduction}

Older adults are mostly exposed to polypharmacy and inappropriate medication use (IMU) due to the increasing incidence of chronic diseases and geriatric syndromes with aging. Polypharmacy and IMU use are well-known risk factors for adverse drug reactions $(1,2)$.

Although the prevalence and negative consequences of polypharmacy and IMU in older adults have been known for many years, inappropriate drug use in many older adults continues even in first-line treatment. Consideration of pharmacokinetic/pharmacodynamic changes, functional impairment of organs, and the drugs most commonly associated with adverse outcomes can help reduce polypharmacy and inappropriate drug use in older adults. In this context, strategies are developed to prevent inappropriate drug use and polypharmacy in older adults worldwide. Explicit (criteria-based) screening tools and implicit (judgmental) assessment methods are among the tools developed to assist in the management of drug therapy in older adults. Explicit tools provide the user algorithmic approaches that include lists of drugs to avoid or specific indicators of inappropriate drug use (3). They provide information and guidance on optimal drug use. Implicit approaches evaluate the patient with a much broader concept. Research data, clinical conditions, and patient/family preferences are also considered (4). Therefore, implicit assessments offer the most appropriate assessment for the detection of IMU but are difficult to standardize and require much more time, background knowledge, and judgment. For these reasons, explicit rather than implicit approaches have been more widely studied to guide clinicians in the management of the IMU. More than 70 tools from many different countries are described in literature for the assessment of inappropriate prescribing (5-10). Highlights from internationally accepted recommendations to reduce inappropriate drug use include the drug burden index, Beer's criteria, medication appropriateness index, assessing care of elders project, elderly complex appropriate drug use in patients [criteria to assess appropriate medication use among elderly complex patients (CRIME)] (11) STOPP/START criteria (12) among many others. The most commonly used and studied such criteria are the Beers and STOPP/START criteria.

Prescribing habits differ between the countries and so does the medications available in the market. As such, while the available explicit criteria set for assessing IMU in older adults have provided some important guidance, they had limited benefits due to lack of consideration of circumstances in the countries other than the tool was originated from. To date, there was not any criteria specifically designed from Eastern Europe to aid health care professionals in a better way for optimum prescribing.
Based on this background, we have established Turkish Inappropriate Medication Use in the Elderly (TIME) Criteria with the participation of experienced and expert in the clinical practice of elderly adults in Turkey under the leadership of Rational Drug Use Working Group of the Turkish Academic Geriatrics Society (13). We applied the methodology used to create the STOPP/ START tool and classified the criteria as the TIME-to-STOP and TIME-to-START criteria. TIME study group-comprising a national expert group of 49 academics and a national working group of 23 academics conducted the study. The academics were from a wide range of specialties dealing with the care of older adults; 17 members from geriatric medicine; four members from psychiatry; three members each from, general internal medicine, gastroenterology, neurology, cardiology, and pharmacology; two members each from endocrinology, nephrology, urology, physical therapy and rehabilitation; and one member each from clinical pharmacology, pulmonology, infectious diseases, gynecology and ophthalmology. The study was carried out in three phases. In the first phase, STOPP/START v2 and CRIME criteria were combined, and the first draft consisting of 133 criteria was created. At the end of the third phase of the study, 55 new criteria were added, 17 existing criteria were removed, and 60 criteria were modified. Accordingly, the final set of TIME criteria was composed of a total of 153 criteria (112 TIME-to-STOP and 41 TIME-to-START criteria) (13). The fourth phase was the Delphi validation process that validate the tool internationally. An internationally validated TIME criteria set was obtained through a Delphi validation study involving 11 recognized experts who took part in the study from start to finish. The validated TIME list comprised 134 criteria (101 TIME-to-STOP and 33 TIME-toSTART criteria) (14). This validation study supports the claim that the TIME set can be regarded as a widened and most up-to-date explicit tool for applications with older adults not only from Turkey and East European region, but also from the other regions across Europe. TIME Criteria mobile application was developed to facilitate the use of Turkish IMU in the elderly criteria in clinics in May 19, 2021. The TIME Criteria application is available now to help health care professionals in reviewing their older patients' medications in the context of this most update explicit IMU tool.

In Turkey, the official language is Turkish. The rate of knowing the English language in the general population is limited. According to the English proficiency index 2020 report, Turkey ranks $69^{\text {th }}$ in the list of 100 countries. With an index score of 465 points, Turkey is among the countries with "low" qualification levels. While the physicians and health care professionals are expected to have better knowledge on the English language due to their education background, a considerable proportion may have problems in following the English text with confidence. Therefore, hereby, we present the TIME criteria in Turkish language to help the healthcare professionals during their application in their everyday practice. 
The final list of TIME-to-STOP and TIME-to-START criteria in Turkish is given in Suplementary file 1 and Suplementary file 2, the final list of TIME-to-STOP and TIME-to-START criteria in Turkish with full list of references and accompanying explanations added to some criteria is given in Suplementary file 3 and Suplementary file 4, respectively. The 19 criteria that were not accepted in the international Delphi validation phase are indicated within the supplementary file. Seven criteria were rejected and 12 criteria were neither rejected nor accepted, and were therefore removed. Of note, as can be understood from the panelists' comments in the survey, some criteria were not accepted because the panelists felt they were not sufficiently familiar with the situation or medication in the criterion in their respective clinical practices and personal experiences.

\section{Conclusion}

Optimizing the medication use stands as one of the main goals in geriatrics practice. Explicit IMU criteria are important tools to help managing medication use and polypharmacy in older adults. Turkish Inappropriate Medication Use in the Elderly(TIME criteria), is an up-to-date explicit IMU tool to guide national and international health care professionals in their everyday practice.

\section{Acknowledgements}

We are grateful to the members of the expert group for their contributions in TIME criteria study. The expert group included the following persons:

Geriatricians: Sibel Akin, Sevgi Aras, Dilek Aydin, Ergun Bozoglu, Asli Curgunlu, Alper Doventas, Berrin Karadag, Selim Nalbant, Sevnaz Sahin, Ilker Tasci, Fatih Tufan, Murat Varli, Burcu Balam Yavuz. Endocrinology: Zeliha Fulden Sarac. Gastroenterology: Nese Imeryuz, Cetin Karaca. Cardiology: Berrin Umman, Huseyin Oflaz. Neurology: Hakan Gurvit. Psychiatry: Eylem Sahin Cankurtaran, Serap Oflaz. Physical therapy and rehabilitation: Nilay Dincer. Urology: Cem Akbal. Pharmacology: Turgay Celik, Zeliha Kerry.

\section{Ethics}

Peer-review: Internally peer-reviewed.

\section{Authorship Contributions}

Concept: G.B., M.A.K., Design: G.B., M.A.K., Data Collection or Processing: G.B., B.I., T.E., M.H., S.S., Z.Ü., F.A., A.K.B., S.Ç., K.D., M.E., K.G., H.H., B.I., At.K., A.K., I.B.K., A.M., S.Ö., I.S., M.Ş.S., T.T., Y.Ü., Ö.Y., N.Y., M.M.Ö., M.A.K., Analysis or Interpretation: G.B., B.I., T.E., M.A.K., Literature Search: G.B., B.I., T.E., M.H., S.S., Z.Ü., F.A., A.K.B., S.Ç., K.D., M.E., K.G., H.H., B.I., At.K., A.K., I.B.K., A.M., S.Ö., I.S., M.S.S., T.T., Y.Ü., Ö.Y., N.Y., M.M.Ö., M.A.K., Writing: G.B., B.I., T.E., M.A.K.

Conflict of Interest: No conflict of interest was declared by the authors.
Financial Disclosure: The authors declared that this study received no financial support.

\section{References}

1. Davies EA, O'Mahony MS. Adverse drug reactions in special populations the elderly. Br J Clin Pharmacol 2015;80:796-807.

2. Garfinkel D, Ilhan B, Bahat G. Routine deprescribing of chronic medications to combat polypharmacy. Ther Adv Drug Saf 2015;6:212-233.

3. Mangin $D$, Bahat $G$, Golomb BA, Mallery LH, Moorhouse $P$, Onder G, Petrovic $M$, Garfinkel D. International Group for Reducing Inappropriate Medication Use \& Polypharmacy (IGRIMUP): Position Statement and 10 Recommendations for Action. Drugs Aging 2018;35:575-587.

4. Onder G, van der Cammen TJ, Petrovic M, Somers A, Rajkumar C. Strategies to reduce the risk of iatrogenic illness in complex older adults. Age Ageing 2013;42:284-291.

5. Kaufmann $C P$, Tremp $R$, Hersberger $K E$, Lampert ML. Inappropriate prescribing: a systematic overview of published assessment tools. Eur J Clin Pharmacol 2014;70:1-11.

6. Chang CB, Lai HY, Hwang SJ, Yang SY, Wu RS, Chang LY, Lee IS, Liu HC, Chan DC. The updated PIM-Taiwan criteria: a list of potentially inappropriate medications in older people. Ther Adv Chronic Dis 2019 Oct 5;10:2040622319879602.

7. Pazan F, Kather J, Wehling M. A systematic review and novel classification of listing tools to improve medication in older people. Eur J Clin Pharmacol 2019;75:619-625.

8. Seppala U, Petrovic M, Ryg J, Bahat G, Topinkova E, Szczerbińska K, van der Cammen TJM, Hartikainen S, Ilhan B, Landi F, Morrissey Y, Mair A, GutiérrezValencia $\mathrm{M}$, Emmelot-Vonk MH, Mora MÁC, Denkinger $M$, Crome $P$, Jackson SHD, Correa-Pérez A, Knol W, Soulis G, Gudmundsson A, Ziere G, Wehling M, O'Mahony D, Cherubini A, van der Velde N. STOPPFall (Screening Tool of Older Persons Prescriptions in older adults with high fall risk): a Delphi study by the EuGMS Task and Finish Group on Fall-Risk-Increasing Drugs. Age Ageing 2021;50:1189-1199.

9. Curtin D, Gallagher $P, O^{\prime}$ Mahony D. Deprescribing in older people approaching end-of-life: development and validation of STOPPFrail version 2. Age Ageing 2021;50:465-471.

10. Rodríguez-Pérez A, Alfaro-Lara ER, Albiñana-Perez $S$, Nieto-Martín MD, Díez-Manglano J, Pérez-Guerrero C, Santos-Ramos B. Novel tool for deprescribing in chronic patients with multimorbidity: List of EvidenceBased Deprescribing for Chronic Patients criteria. Geriatr Gerontol Int 2017; 17:2200-2207.

11. Onder $G$, Landi F, Fusco D, Corsonello A, Tosato M, Battaglia M, Mastropaolo $S$, Settanni S, Antocicco M, Lattanzio F. Recommendations to prescribe in complex older adults: results of the CRIteria to assess appropriate Medication use among Elderly complex patients (CRIME) project. Drugs Aging 2014;31:33-45.

12. O'Mahony D, O'Sullivan D, Byrne $S$, O'Connor MN, Ryan C, Gallagher P. STOPP/START criteria for potentially inappropriate prescribing in older people: version 2. Age Ageing 2015;44:213-218.

13. Bahat $G$, Ilhan $B$, Erdogan $T$, Halil $M$, Savas $S$, Ulger $Z$, Akyuz F, Bilge AK, Cakir S, Demirkan K, Erelel M, Guler K, Hanagasi H, Izgi B, Kadioglu A, Karan A, Kulaksizoglu IB, Mert A, Ozturk S, Satman I, Sever MS, Tukek T, Uresin Y, Yalcin O, Yesilot N, Oren MM, Karan MA. Turkish inappropriate medication use in the elderly (TIME) criteria to improve prescribing in older adults: TIME-to-STOP/TIME-to-START. Eur Geriatr Med 2020;11:491-498.

14. Bahat G, Ilhan B, Erdogan $T$, Oren MM, Karan MA, Burkhardt $H$, Denkinger M, Garfinkel D, Cruz-Jentoft AJ, Morrissey Y, Onder G, Pazan F, Tommelein E, Topinkova E, van der Velde N, Petrovic M. International Validation of the Turkish Inappropriate Medication Use in the Elderly (TIME) Criteria Set: A Delphi Panel Study. Drugs Aging 2021;38:513-521. 


\section{TIME to STOP- YAŞLIDA KULLANIMI ÖNERILMEYEN ILAÇLAR}

Bu grup ilaçların, kriter içeriğindeki durumlarda kullanımı yaşıılarda ilaç-hastalık, ilaç-geriatrik sendrom ve/veya ilaç-ilaç etkileşimi nedeniyle "yüksek" yan etki potansiyeli taşımaktadır ve "potansiyel uygunsuz ilaç kullanımı" olarak nitelendirilmektedirler. Klinisyenler hastanın tüm özellikleriyle ilacın hastasındaki potansiyel fayda ve zararını (kar-zarar dengesini) ve hasta/bakımveren tercihleri doğrultusunda saptanan tedavi hedeflerini göz önünde bulundurarak karar vermelidir. Bu grup ilaçları klinisyenler bazı olgularda kullanmayı yine de uygun bulabilir. Kullanımı tercih edildiğinde dikkatle kullanııması, yan etki varlığı açısından klinik olarak yakın takip edilmesi gereken ilaçlardır.

\section{TIME-to-STOP Kriterleri}

\section{A: Kardiyovasküler Sistem Kriterleri}

A1. AF tedavisinde 1. basamakta digoksin kullanımı uygun değildir

A2. Digoksin'in 0,125 mg/gün'den yüksek dozda kullanımı uygun değildir (toksisite riski)

A3. Korunmuş (normal) EF'li kalp yetersizliği endikasyonuyla digoksin kullanımı uygun değildir

A4. Düşük EF'li kalp yetersizliğinde diltiazem veya verapamil kullanımı uygun değildir

A5. Bradikardi (<50/dk), tip 2 kalp bloğu veya tam kalp bloğu olanlarda hız kısıtlayıcı tedavi (beta bloker, verapamil, diltiazem, digoksin) başlanması uygun değildir

A6. Kalp yetersizliği, karaciğer yetersizliği, nefrotik sendrom veya böbrek yetersizliğinin klinik, biyokimyasal veya radyolojik bulguları olmadan ayak bileği ödemi için loop diüretiği kullanımı uygun değildir (bacak elevasyonu ve/veya kompresyon çorapları genellikle daha uygundur)

A7. Özel bir endikasyon bulunmadığı halde esansiyel HT tedavisi için ilk basamakta beta-blokerlerin kullanımı uygun değildir (kalp bloğu riskinde artış, halsizlik-yorgunluk, seksüel disfonksiyon ve inmeden korunmada az etkinlik nedeniyle; ek olarak yaşlanmayla $\beta$-adrenerjik reseptör fonksiyonunda azalma olur)

A8. Üriner inkontinansı olanlarda esansiyel HT tedavisi için ilk basamakta diüretik kullanımı uygun değildir (inkontinansı ve sıkışma hissini artırarak yaşam kalitesini bozabilir, düşmeleri artırabilir)

A9. Diğer sınıf antihipertansiflerin tolere edilemediği veya etkisiz kaldığı durumlar hariç $\mathrm{HT}$ tedavisinde alfa-1 bloker veya santral etkili antihipertansiflerin (örn. metildopa, rilmenidin, rezerpin) kullanımı uygun değildir (alfa-1 bloker antihipertansifler ile kalp yetersizliği ve kardiyovasküler olaylarda artış, ortostatik hipotansiyon, düşme, senkop, kadınlarda üriner inkontinansın kötüleşmesi; santral etkili antihipertansiflerin MSS yan etkileri, sedasyon-depresyon-parkinsonizm ve ortostatik hipotansiyon, bradikardi yan etkileri)

A10. Ortostatik hipotansiyon (sistolik kan basıncında $>=20$ $\mathrm{mmHg}$ düşüş veya diastolik kan basıncında $>=10 \mathrm{mmHg}$ düşüş) olanlarda vazodilatör antihipertansiflerin (alfa-1 blokerler)/ nitratların kullanımı uygun değildir (ortostatik hipotansiyonda artış riski)

A11. Ortostatik hipotansiyonu/bilişsel yetersizliği (örn. demans) /fonksiyonel kısıtlılığı/düşük yaşam beklentisi $(<2$ yıl)/düşme riski yüksek olan hastalarda sıkı kan basıncı kontrolu $(<140 / 90$ $\mathrm{mmHg}$ ) uygun değildir

A12. Sekonder faktörler dışlanmadan ve ilaç dışı yaklaşımlar uygulanmadan ortostatik hipotansiyon tedavisi için fludrokortizon kullanımı uygun değildir

A13. HT olgularında beta bloker ve verapamil/diltiazem kombinasyonu kullanımı uygun değildir (kalp bloğu riski)

A14. Serum potasyum düzeyi $5.5 \mathrm{mEq} / \mathrm{L}$ 'nin üzerinde olan olgularda RAS blokeri (ACE inhibitörü, ARB, direkt renin inhibitörü) veya potasyum tutucu diüretik (spironolakton, eplerenon, amilorid, triamteren) başlanması uygun değildir

A15. Serum potasyum düzeyi takip edilmeden RAS blokeri (ACEI, $A R B$, direkt renin inhibitörü) ve potasyum tutucu diüretiklerin (spironolakton, eplerenon, amilorid, triamteren) kombine edilmesi uygun değildir (tehlikeli hiperpotasemi riski)

A16. $\mathrm{GFR}<30 \mathrm{~mL} / \mathrm{dk} / 1,73 \mathrm{~m}^{2}$ olan ve serum potasyum düzeyi yakın takip edilemeyecek hastalarda, potasyum tutucu ilaçların (aldosteron antagonistleri, triamteren, amilorid, ACEI, ARB) kullanımı uygun değildir (hiperpotasemi riski)

A17. Belirgin hipopotasemi (serum $\mathrm{K}<3,0 \mathrm{mg} / \mathrm{L}$ ), hiponatremi (serum $\mathrm{Na}<130 \mathrm{mEq} / \mathrm{L}$ ), hiperkalsemi (düzeltilmiş serum $\mathrm{Ca}>10,6$ $\mathrm{mg} / \mathrm{dL}$ ) veya gut hikayesi olan hastalarda tiazid diüretiklerinin kullanımı uygun değildir

A18. Kardiyovasküler hastalığı (ciddi HT, kalp yetersizliği veya geçirilmiş $\mathrm{Mi}$, inme) olan olgularda NSAii kullanımı uygun değildir (artmış kardiyovasküler olay: Mi, inme, kalp yetersizliği ve ölüm riski)

A19. Sık hipoglisemi atakları olan DM hastalarında beta bloker kullanımı uygun değildir (hipoglisemik semptomları baskılama riski)

A20. Astım öyküsü olanlarda nonselektif beta bloker (oral veya glokom için topikal) kullanımı uygun değildir (bronkospazmda artış riski) 
A21. Primer veya sekonder kardiyovasküler korumada aspirin'in 75-150 mg/gün'den yüksek dozda kronik kullanımı uygun değildir (kanıtlanmış ek faydası yok ve kanama riskini artırıyor)

\#A22. Aspirin, klopidogrel, dipiridamol ve OAK'ların (Vitamin $\mathrm{K}$ antagonistleri, direkt trombin inhibitörü veya faktör Xa inhibitörleri) eşlik eden anlamlı kanama riski varlığında (örneğin kontrolsüz ciddi HT, kanama diyatezi, spontan anlamlı kanaması olanlarda) kullanımı uygun değildir (yüksek kanama riski)

A23. Aspirin ve klopidogrelin birlikte kullanımı için spesifik bir endikasyon yoksa, sekonder inme proflaksisinde aspirin ve klopidogrelin birlikte kullanımı uygun değildir

A24. Kronik AF veya başka bir sebeple OAK kullanan hastalarda aspirin/klopidogrel kullanımı için ek endikasyon yok ise tedaviye aspirin/klopidogrel eklenmesi uygun değildir (aspirin ile ek fayda yok)

A25. OAK'ların (vitamin $K$ antagonistleri, direkt trombin inhibitörleri veya faktör Xa inhibitörleri), devam eden risk faktörleri olmaksızın ilk kez olan derin ven trombozunda 6 aydan uzun süre kullanımı uygun değildir (kanıtlanmış ek yararı yok)

\#A26. OAK'ların (vitamin $\mathrm{K}$ antagonistleri, direkt trombin inhibitörleri veya faktör $X a$ inhibitörleri), devam eden risk faktörleri olmaksızın ilk kez olan pulmoner embolide 12 aydan uzun süre kullanımı uygun değildir (kanıtlanmış ek yararı yok)

\#A27. OAK'ların (vitamin $\mathrm{K}$ antagonistleri, direkt trombin inhibitörleri veya faktör Xa inhibitörleri) kontrendike olduğu kronik AF hastalarında, aspirin veya klopidogrel monoterapisinin kullanımı uygun değildir

A28. Dabigatran'ın GFR $<30 \mathrm{~mL} / \mathrm{dk} / 1,73 \mathrm{~m}^{2}$ olan hastalarda kullanımı uygun değildir

\#A29. Non-valvular AF'si olup malnütre olan veya besin alımı düzensiz olan hastalarda varfarin kullanımı uygun değildir

A30. Ilaç̧larını kullanmakta, yönetmekte güçlük çeken (öm. bilişsel bozukluğu olan hastalar) ve yardımcı olacak kimselerin (örn. bakıcı) olmadığı hastalarda varfarin ve digoksin gibi dar terapötik indeksi olan ilaçların kullanımı uygun değildir (hayatı tehdit edebilecek toksisite riski)

\#A31. Prasugrel'in 75 yaş ve üzeri hastalarda veya GiA/inme geçirmiş olgularda kullanımı uygun değildir

A32. Tiklopidin antitrombosit olarak kullanımı uygun değildir (klopidogrel veya tikagrelor veya prasugrel'in daha yüksek etkinliği vardır, daha çok kanıtı vardır ve daha az yan etkisi vardır)

A33. Antitrombosit-antiagregan etki için kısa etkili dipiridamol kullanımı uygun değildir (ortostatik hipotansiyon yan etkisi ve daha etkili ajanların bulunması)

A34. Yaşam beklentisi düşük olan (<2 yıl) veya ileri evre demanslı yaşlılarda primer koruma amaçlı statin kullanımı uygun değildir
A35. Asemptomatik hiperürisemi (gut veya nefrolitiazisi olmayan olgular) için allopurinol başlanması uygun değildir (fayda için kanıt yok, ksantin oksidaz inhibitörleri kullanımıyla yan etki riski) (tedavinin kardiyovasküler riski veya gut hastalığını azalttığına dair kanıt yok)

\section{B: Santral Sinir Sistemi Kriterleri}

B1. Trisiklik antidepresan kullanımı uygun değildir (yüksek antikolinerjik etki, kognitif kötüleşme, kalp iletim bozukluğu, ortostatik hipotansiyon, üriner retansiyon, prostatizmde kötüleşme, dar açılı glokomda kötüleşme)

B2. SSRI tedavisi başlanacak olgularda paroksetin, fluoksetin ve fluvaksaminin ilk basamakta tercih edilmesi uygun değildir (paroksetinin yüksek antikolinerjik etkisi, fluoksetinin uzun yarı ömrü, fluoksetin ve fluvaksaminin sık ilaç etkileşimi nedeniyle)

B3. Yakın geçmişte veya halihazırda anlamlı hiponatremi (serum $\mathrm{Na}<130 \mathrm{mEq} / \mathrm{L}$ ) hikayesi olanlarda SSRI kullanımı uygun değildir (SSRI kullanımı ile artan hiponatremi riski)

\#B4. Kontrolsüz HT varlığında SNRI kullanımı uygun değildir

B5. GFR $<30 \mathrm{~mL} / \mathrm{dk} / 1,73 \mathrm{~m}^{2}$ olanlarda duloksetin kullanımı uygun değildir (artmış GiS yan etkisi)

B6. GFR $<60 \mathrm{~mL} / \mathrm{dk} / 1,73 \mathrm{~m}^{2}$ olması durumunda pregabalin ve gabapentin'in doz azaltımı yapılmadan kullanımı uygun değildir

B7. Deliryum veya demansı olanlarda yüksek antikolinerjik etkili ilaçların (amitriptilin, paroksetin, disiklomin, L-hiyosiyamin, tioridazin, klorpromazin, klozapin, olanzapin, üriner antimuskarinikler, $\mathrm{H} 1$ reseptör blokerleri-özellikle 1. jenerasyon $\mathrm{H} 1$ reseptör blokerleri (difenhidramin, siproheptadin, feniramin), H2 reseptör blokerlerinin kullanımı uygun değildir (kognitif kötüleşme riski)

B8. Parkinson Hastalığı́nın tedavisinde antikolinerjik ajan kullanımı uygun değildir (artmış yan etki riski; daha etkin ve daha az yan etkisi olan ilaç seçenekleri var)

B9. Nöroleptiklerin ekstrapiramidal yan etkilerini tedavi etmek için antikolinerjik ilaç kullanımı uygun değildir (antikolinerjik toksisitesi riski)

B10. Demans hastalarında davranışsal ve psikolojik semptomların giderilmesinde ilaç dışı tedavilerin etkisiz kaldığı ve semptomların ciddi olduğu durumlar hariç nöroleptiklerin/ antipsikotiklerin kullanımı uygun değildir (artmış inme, kalp yetersizliği, pnömoni-infeksiyon, ölüm riski)

B11. Nöroleptiklerin/antipsikotiklerin hipnotik amaçlı kullanımı uygun değildir (artmış konfüzyon, hipotansiyon, ekstrapiramidal yan etkiler, düşme riski)

B12. Parkinsonizm veya Lewy cisimcikli demansı olanlarda nöroleptiklerin/antipsikotiklerin (ketiapin veya klozapin hariç) kullanımı uygun değildir (ağır ekstrapiramidal semptom riski) 
B13. Düşme riski yüksek olan hastalarda nöroleptiklerin/ antipsikotiklerin (ekstrapiramidal yan etki), benzodiazepinlerin (sedasyon, denge bozukluğu) ve Z tipi hipnotiklerin (ör. zopiklon, zolpidem, zaleplon) (gün içerisinde uzamış sedasyona, ataksi) kullanımı uygun değildir

B14. Benzodiazepin'lerin 4 haftadan uzun süre kullanımı uygun değildir (uzamış sedasyon, konfüzyon, denge bozukluğu, düşme, trafik kazaları riski)

B15. Benzodiazepinlerin akut ve kronik solunum yetersizliğinde $\left(\mathrm{PO}_{2}<60 \mathrm{mmHg}\right.$ ve/veya $\left.\mathrm{PCO}_{2}>50 \mathrm{mmHg}\right)$ kullanımı uygun değildir (solunum yetersizliğinde artış riski)

B16. Persistan bradikardi ( $<50 / d k), 2$. veya 3 . derece kalp bloğu veya açıklanamayan senkopu olan hastalarda, uzamış OTc olan hastalarda (kadında> 470 msn, erkekte> 450 msn) ChEi kullanımı uygun değildir (kalp iletim defekti, senkop, yaralanma riski)

B17. Esansiyel tremor tedavisi için levodopa veya dopamin agonistlerinin kullanımı uygun değildir (kanıtlanmış etkinliği yoktur)

B18. Vertigo tedavisinde betahistin, trimetazidin, dimenhidrinat gibi ilaçların aralıksız ve uzun süreli olarak kullanımı uygun değildir (kanıta dayalı faydalı etkilerinin olmaması)

\#B19. Sinnarizin kullanımı uygun değildir (ekstrapiramidal yan etkiler, sınırlı faydalanım)

B20. Pirasetam kullanımı miyoklonik konvülzüyon tedavisi dışında uygun değildir (kanıtlanmış klinik etkinlik yok, maliyet yükü ve yan etki potansiyeli nedeniyle)

B21. Epilepsinin kronik tedavisinde karbamazepin, fenitoin, fenobarbital veya valproat'ın ilk basamakta kullanımı uygun değildir (vitamin D üzerine olumsuz etkileri, enzim indüksiyonu, düşme riski nedeniyle; ayrıca daha güvenli alternatifleri var)

B22. Epilepsi hastalarında tramadol, nöroleptikler/antipsikotikler (klozapin, olanzapin, klorpromazin, tioridazin), bupropion ve maprotilin kullanımı uygun değildir.

B23. Öncesinde konvülzüyon geçirmemiş bir hastada iskemik/ hemorajik inme varlığı nedeniyle nöbet proflaksisi için antiepileptik tedavi kullanımı uygun değildir

B24. Yaşılıarda sitalopram'ın 20 mg/gün, essitalopram'ın 10 mg/ gün üzerindeki dozlarda kullanımı uygun değildir (OTc uzama riski nedeniyle)

\section{C: Gastrointestinal Sistem Kriterleri}

C1. NSAii'lerin OAK'lar (vitamin K antagonistleri, direkt trombin inhibitörleri, faktor Xa inhibitörleri) ile birlikte kullanımı uygun değildir (GiS kanama riski)

C2. Aspirin, klopidogrel, NSAii veya steroidlerin; ülser öyküsü olan hastalarda, ek antiplatelet tedavi alan hastalarda, eş zamanlı antikoagülan alan hastalarda, steroid kullanan hastalarda, dispepsi-GÖR semptomları olan hastalarda PPI verilmeden kullanımı uygun değildir

\#C3. Aspirin veya NSAil'lerin; peptik ülser (komplike veya komplike olmayan, gastrik veya duodenal) öyküsü olan hastalarda Helicobacter pylori testi yapılmadan kronik kullanım için başlanması uygun değildir

C4. PPi'ların komplike olmayan peptik ülser veya erozif peptik özofajit tedavisinde tam terapötik dozda 8-12 haftadan uzun süreli kullanımı uygun değildir (doz azaltımı veya daha kısa sürede kesme endikasyonu vardır)

C5. Çoklu ilaç kullanımı nedeniyle PPi kullanımı uygun değildir (faydası yok, potansiyel zararı var)

C6. Antikolinerjik etkili GiS antispazmotiklerinin (örn. hiyosiyamin) kullanımı uygun değildir [yaşıda artmış antikolinerjik yan etki (sersemlik, bilişsel kabiliyetlerde azalma, görme bulanıklığı, aritmi, şişkinlik-konstipasyon) ve sınırlı faydalanım]

C7. Kronik konstipasyonu olan hastalarda, bu yan etkiye sahip olmayan alternatifleri varsa, konstipasyona sebep olma intimali yüksek olan ilaçların (yüksek antikolinerjik etkili ilaçlar, oral demir, opioidler, verapamil, alüminyum antiasitleri) kullanımı uygun değildir (konstipasyonda artış riski)

C8. Yaşlılarda antiemetik tedavide ilk basamakta metoklopramid veya trimetobenzamid kullanımı uygun değildir (ekstrapiramidal yan etki, huzursuzluk yan etkisi nedeniyle)

C9. GFR $<30 \mathrm{~mL} / \mathrm{dk} / 1,73 \mathrm{~m}^{2}$ olan hastalarda laksatif veya antiasit olarak magnezyum preperatlarının kullanımı uygun değildir (hipermagnezemi riski)

\section{D: Solunum Sistemi Kriterleri}

D1. Dar açlı glokom veya üriner çıkış yolu obstrüksiyonu olan hastalarda antimuskarinik bronkodilatör ilaçların (ipratropium, tiotropium) kullanımı uygun değildir (glokomda kötüleşme ve üriner retansiyon riski)

D2. KOAH'ın veya astım bronşialenin idame tedavisinde teofilin kullanımı uygun değildir (dar terapötik indeks ve yaşlıda yüksek insomni, aritmi riski nedeniyle)

D3. Orta-ağır KOAH'ta idame tedavi için inhaler kortikosteroid yerine sistemik kortikosteroid kullanımı uygun değildir (sistemik kortikosteroidlerine uzun süre gereksiz maruziyet; etkin inhale tedaviler mevcut)

\section{E: Kas İskelet Sistemi Kriterleri ve Analjezik İlaçlar}

E1. NSAil'lerin, alternatif tedavi varken, 3 aydan uzun süreli kullanımı uygun değildir

E2. NSAii'lerin GFR $<50 \mathrm{~mL} / \mathrm{dk} / 1,73 \mathrm{~m}^{2}$ olan hastalarda kullanımı uygun değildir (renal fonksiyonlarda kötüleşme riski) 
E3. Osteoartrit tedavisinde sistemik steroid kullanımı uygun değildir (sistemik kortikosteroidler ile yan etki riski)

E4. Romatoid artritte 3 aydan uzun süreli kortikosteroid monoterapisi kullanımı uygun değildir (sistemik kortikosteroidler ile yan etki riski)

E5. Gut hastalığının kronik tedavisi için ksantin oksidaz inhibitörleri (örn. allopurinol, febuksostat) kullanımının kontrendike olmadığı durumlarda, uzun süreli NSAii veya kolşisin kullanımı uygun değildir (gut hastalığının profilaksisinde ksantin oksidaz inhibitörleri ilk seçenek ilaçlardır)

E6. Kolşisin'in GFR $<10 \mathrm{~mL} / \mathrm{dk} / 1,73 \mathrm{~m}^{2}$ olan hastalarda kullanımı uygun değildir (kolşisin toksisitesi riski)

E7. Metotreksat'ın GFR $<30 \mathrm{~mL} / \mathrm{dk} / 1,73 \mathrm{~m}^{2}$ olan hastalarda kullanımı uygun değildir

E8. Ağrı tedavisinde meperidin kullanımı uygun değildir (diğer opioidlere göre artmış nörotoksisite, deliryum riski; daha güvenilir alternatifleri var. Özellikle böbrek yetersizliği varlığında kullanımı risklidir)

E9. Uzamış salınımlı tramadol'ün $\mathrm{GFR}<30 \mathrm{~mL} / \mathrm{dk} / 1,7 \mathrm{~m}^{2}$ olan hastalarda kullanımı uygun değildir

E10. Opioidlerin kronik kullanımda eş zamanlı laksatif verilmeden kullanımı uygun değildir (ciddi konstipasyon riski)

E11. Kas iskelet sistemi ağrıları için sistemik kas gevşetici (iskelet kası) ajanların (tiyokolşikosid, tizanidin, klorzoksazon, karisoprodol, klorfenezin karbamat, siklobenzaprin, metaksalon, metokarbamol ve orfenadrin vb.) kullanımı uygun değildir (sedasyon, sersemlik, baş dönmesi, ağız kuruluğu, konstipasyon, bilişsel yan etkileri nedeniyle)

\#E12. Osteomalazi tanısı dışlanmadan osteoporoz tedavisi başlanması uygun değildir

E13. Vitamin D "idame" tedavisinde, aralıklı olarak yüksek dozda (300.000 iÜ) konvansiyonel vitamin D kullanımı uygun değildir (artmış düşme riski, kas-iskelet sistemi üzerine ek faydasının olmaması)

E14. Hiperfosfatemi ve/veya hiperkalsemi varlığında aktif (kalsitriol) (1-25(OH)2kolekalsiferol) veya konvansiyonel $(25(\mathrm{OH})$ kolekalsiferol) vitamin D kullanımı uygun değildir

E15. Üst GiS hastalığı (örn. disfaji, özofajit, peptik ülser, üst GiS kanama veya tedavi ile kontrol altına alınamamış GÖR) anamnezi olanlarda ve/veya fiziksel olarak dik duramayacak hastalarda oral bifosfonat kullanımı uygun değildir (özofajit, özofageal ülser, özofageal strüktürde relaps/alevlenme riski)

E16. Bifosfonatlar'ın GFR $<30 \mathrm{~mL} / \mathrm{dk} / 1,73 \mathrm{~m}^{2}$ olan hastalarda kullanımı uygun değildir (artmış akut böbrek yetersizliği riski)
E17. Tedavi öncesi serum kalsiyum düzeyi tayin edilmeden ve yeterli düzeyde kalsiyum/vitamin $D$ alımı sağlanmadan zoledronat, denosumab veya teriparatid kullanımı uygun değildir

\section{F: Ürogenital Sistem Kriterleri}

F1. Benign prostat hiperplazisine bağlı LUTS semptomları olan erkeklerde $P M R>150 \mathrm{~mL}$ ise mesaneye yönelik antikolinerjik ilaç kullanımı uygun değildir

F2. Kronik dar açılı glokom hastalarında mesaneye yönelik antikolinerjik ilaç kullanımı uygun değildir

F3. Prostat hiperplazisi olan (obstrüksiyon riski) veya diabetes mellitus komplikasyonları gelişmiş olan (nörojen mesane riski) veya kırılgan olan yaşılılarda (detrusor hiperaktivitesi ile birlikte azalmış kontraktilite riski) PMR tayini yapılmadan mesaneye yönelik antikolinerjik ilaç kullanımı uygun değildir (üriner retansiyon ve postrenal böbrek yetersizliği riski)

F4. Kan basıncl $<90 / 50 \mathrm{mmHg}$ veya $>170 / 100 \mathrm{mmHg}$ olan/ unstabil anginası olan/ cinsel ilişki sırasında anjinası olan/ NYHA sınıf 4 kalp yetersizliği olan/ anjina için nitrat tedavisi alan/ alfa-1 bloker tedavisi alan/geçirilmiş Mi ( $<3$ ay) öyküsü olan/ geçirilmiş inme ( $<6$ ay) öyküsü olan hastalarda fosfodiesteraz tip-5 inhibitörlerinin (örn. sildenafil, tadalafil, vardenafil) kullanımı uygun değildir

F5. Ortostatik hipotansiyonu olan hastalarda benign prostat hiperplazisine bağlı LUTS semptomlarının tedavisinde üroselektif olmayan alfa 1 blokerlerin (örn. doksazosin, terazosin) kullanımı uygun değildir (ortostatik hipotansiyonda, senkop ve düşmelerde artış)

F6. Mukozaya zarar verebilecek ürolojik girişimler hariç asemptomatik bakteriüride antibiyotik kullanımı uygun değildir

F7. Nitrofurantoin'in GFR $<30 \mathrm{~mL} / \mathrm{dk} / 1,73 \mathrm{~m}^{2}$ olan hastalarda kullanımı uygun değildir

\section{G: Endokrin Sistem Kriterleri}

G1. Yaşam beklentisi düşük ( $<5$ yıl) veya anamnezde düşme veya bilişsel yetersizliği olan hastalarda sıkı kan şekeri kontrolu ( $\mathrm{HbA1C}<\% 7)$ uygun değildir

\#G2. Kırılgan veya malnütre yaşlılarda metformin kullanımı uygun değildir (metformin'in Gis yan etkileri ve iştahsızlık etkisi nedeniyle)

G3. Metformin'in GFR $<30 \mathrm{~mL} / \mathrm{dk} / 1,73 \mathrm{~m}^{2}$ olan hastalarda kullanımı uygun değildir (laktik asidoz riski)

G4. Tip 2 DM hastalarında glibenklamid ve klorpropamid gibi uzun etkili sulfanilürelerin kullanımı uygun değildir (uzamış hipoglisemi riski)

G5. Dökümante kalp yetersizliği/kırık anamnezi/artmış kırık riski/mesane kanseri anamnezi olan veya insülin tedavisi almakta 
olan hastalarda tiazolidinedionların (rosiglitazon, pioglitazon) kullanımı uygun değildir (kalp yetersizliğinde kötüleşme, kırık ve mesane kanser riskinde artış)

G6. Kalp yetersizliği olan olgularda saksagliptin kullanımı uygun değildir

G7. Kanagliflozinin, diyabete bağlı alt ekstremite ampütasyonu komplikasyonu geçirmiş/ciddi periferik arter hastalığı olan/ tekrarlayan üriner sistem infeksiyonu/genitoüriner enfeksiyonu olan olgularda kullanımı uygun değildir

G8. SGLT-2 inhibitörlerinin GFR $<45 \mathrm{~mL} / \mathrm{dk} / 1,73 \mathrm{~m}^{2}$ olan olgularda kullanılması uygun değildir

G9. Androjen eksikliği ile ilişkili semptom ve bulguların eşlik etmediği serum testosteron düzeyi düşüklüğü varlığında androjen kullanımı uygun değildir

G10. Meme kanseri veya venöz tromboemboli öyküsü olan hastalarda sistemik östrojen kullanımı uygun değildir

G11. Intakt uterusu olan kadınlarda beraberinde progesteron kullanımı olmadan östrojen kullanımı uygun değildir (endometrial kanser riski)

G12. İştah artırıcı olarak megestrol kullanımı uygun değildir (kilo üzerine minimal etki, protrombotik yan etki)

G13. Subklinik hipotiroidisi olan yaşlılarda (TSH: 4-10 mIU/L; sT4: N), tiroid hormonu kullanımı uygun değildir (ek yararı yok, atrial fibrilasyon ve osteoporoz gibi potansiyel yan etki riski)

\section{H: Antimuskarinik-Antikolinerjik Yük}

H1. Yüksek antikolinerjik etkili ilaçların [trisiklik antidepresanlar, klorpromazin, tioridazin, klozapin, olanzapin, hiyosin, oral oksibutinin, 1. jenerasyon antihistaminikler (feniramin, klorfeniramin, hidroksizin, siproheptadin, dimenhidrinat, difenhidramin, meklizin vb.), paroksetin] kullanımı aşağıdaki durumlarda uygun değildir

Düşme/konstipasyon/dar açılı glokom/demans/deliryum/idrar retansiyonu/erkekte obstrüktif LUTS semptomları/eş zamanlı yüksek antikolinerjik etkili ilaç kullanımı

\section{J: Suplemanlar.}

J1. Kanama riski olan olgularda (antikoagülan kullanımı, NSAii kullanımı, anlamlı kanama öyküsü) gingko biloba ekstraktı kullanımı uygun değidir

J2. Sarı kantaron'un (St. John's Wort) antidepresan kullanan hastalarda (özellikle SSRi ile serotonerjik sendrom riski) ve sitokrom p450 ile metabolize olan ilaç (örn. digoksin, teofilin, varfarin, karbamazepin, fenitoin, fenobarbital) kullanan hastalarda sistemik kullanımı uygun değildir (sarı kantaron sitokrom p450 aktivasyonu yapar)

\#J3. Varfarin kullanan hastalarda supleman kullanımı uygun değildir (kanama riskinde olası artış nedeniyle)

\#Uluslararası Delfi paneli çalışmasında konsensus sağlanmayan kriterler

\section{Kısaltmalar:}

AF: Atrial fibrilasyon

ACEI: Anjiotensin konverting enzim inhibitörleri

ARB: Anjiotensin reseptör blokerleri

ChEls:Asetilkolinesteraz inhibitörleri

DM: Diabetes mellitus

EF: Ejeksiyon fraksiyonu

eGFR: Estimated Glomerular Filtrasyon hızı

GIA: Geçici iskemik atak

GÖR: Gastroözofageal reflü

GiS: Gastrointestinal sistem

H1 receptor: Histamin 1 reseptör

HT: Hipertansiyon

KOAH: Kronik obstrüktif akciğer hastalığı

LUTS: Alt üriner sistem semptomları

Mi: Miyokard infarktüsü

MSS: Merkezi sinir sistemi

NSAil: Non steroidal anti inflamatuar ilaçlar

NYHA: New York Heart Association

OAK: Oral antikoagülan

PMR: Post miksiyonel rezidü

$\mathrm{PO}_{2}$ : Parsiyel oksijen basıncı

PPI: Proton pompa inhibitörleri

OTc: düzeltilmiş QT Intervali

RAS: Renin anjiotensin sistem

SGLT-2: Sodium-glucose kotransporter-2

SNRIs: Serotonin-norepinefrin geri alım inhibitörleri

SSRIs: Selektif serotonin geri alım inhibitörleri

TSH: Tiroid stimulan hormon 


\section{TIME to START- YAŞLIDA BAŞLANMASI UYGUN OLAN ILAÇLAR}

Bu grup ilaçların, kriter içeriğindeki durumlarda kullanımının yaşlılarda endikasyonu ve potansiyel faydalanımı vardır ancak klinik pratikte sıklıkla gözden kaçabilmekte veya ileri yaş nedeniyle, geçerli ek bir sebep olmaksızın, verilmemektedir. Bu ilaçların kriter içeriğindeki durumda kullanılmaması "potansiyel uygunsuz ilaç kullanımı" olarak nitelendirilmektedirler. Klinisyenler hastanın tüm özellikleriyle ilacın hastasındaki potansiyel fayda ve zararını (kar-zarar dengesini), beklenen yaşam süresini ve hasta/bakımveren tercihleri doğrultusunda saptanan tedavi hedeflerini göz önünde bulundurarak karar vermelidir. Bu grup ilaçları klinisyenler bazı olgularda kullanmamayı uygun bulabilir.

\section{TIME-to-START Kriterleri}

\section{A: Kardiyovasküler Sistem Kriterleri}

A1. Dökümante aterosklerotik koroner arter hastalığı (geçirilmiş akut koroner sendrom/koroner anjioplasti veya stentleme/ koroner arter bypass greftleme/abdominal aort anevrizması), dökümante aterosklerotik serebrovasküler hastalık (geçirilmiş iskemik inme/GiA/ geçirilmiş karotis endarterektomi veya stentleme) veya semptomatik alt ekstremite arter hastalığı olan hastalarda sekonder korunma amaçlı antiplatelet tedavi (aspirin veya klopidogrel) başlanması uygundur

A2. Dökümante aterosklerotik koroner arter hastalığı (geçirilmiş akut koroner sendrom/koroner anjioplasti veya stentleme/ koroner arter bypass greftleme/abdominal aort anevrizması), dökümante serebrovasküler hastalık (geçirilmiş iskemik inme/ GIA/geçirilmiş karotis endarterektomi veya stentleme) veya periferik arter hastalığı olan hastalarda sekonder korunma amaçlı statin tedavisi başlanması uygundur

A3. Sistolik kan basıncı sürekli olarak $>160 \mathrm{mmHg}$ ve/veya diastolik kan basıncı sürekli olarak $>90 \mathrm{mmHg}$ olan hastalarda antihipertansif tedavi başlanması uygundur

A4. Kronik non-valvüler AF varlığında, CHA2DS2-VASc skoru göz önüne alınarak, OAK (vitamin $\mathrm{K}$ antagonistleri, direkt trombin inhibitorleri veya faktor Xa inhibitörleri) başlanması uygundur

A5. Sistolik kalp yetersizliği ( $\mathrm{EF}<=0 \% 40)$ veya ST elevasyonlu Mi varlığında ACEi tedavisi başlanması uygundur

A6. Sistolik kalp yetersizliği $(E F<=\% 40)$ veya iskemik kalp hastalığı (kronik iskemik kalp hastalığında antianjinal etki/ Mi sonrası dönemde mortalite düşürücü etki nedeniyle) varlığında beta-bloker tedavi (sistolik KY'de bisoprolol/uzamış salınımlı metoprolol süksinat/karvedilol/nebivolol; iskemik kalp hastalığnda herhangi bir beta-bloker) başlanması uygundur

\section{B Santral Sinir Sistemi Kriterleri}

B1. Majör depresif bozukluk varlığında antidepresan tedavi başlanması uygundur

B2. Fonksiyonelliği (işlevselliği) etkileyen persistan, ağır şiddette anksiyete varlığında SSRi (SSRi kontrendike ise SNRi veya pregabalin) tedavisi başlanması uygundur

\#B3. Erken-orta evre Alzheimer hastalığında ChEi tedavisi başlanması uygundur

\#B4. Orta-ileri evre Alzheimer hastalığında memantin tedavisi başlanması uygundur

\#B5. Fonksiyonelliği (işlevselliği) etkileyen esansiyel tremoru olan hastalara propranolol veya pirimidon tedavisi başlanması uygundur

B6. Fonksiyonel (işlevsel) bozukluk ve dizabiliteye sebep olan idiyopatik Parkinson hastalığı varlığında L-dopa tedavisi başlanması uygundur

B7. İdiyopatik Parkinson hastalarında açık-kapalı motor dalgalanmalar başladığında, L-dopa tedavisine MAO-B inhibitörü veya COMT inhibitörü eklenmesi uygundur

B8. Demir eksikliği ve kronik böbrek yetersizliğinin dışlandığı huzursuz bacak sendromu olan hastalarda, semptomlar yaşam kalitesini olumsuz etkiliyorsa, alfa-2-delta kalsiyum kanal blokerleri (pregabalin, gabapentin) veya dopamin agonistleri (pramipeksol/ropinirol/rotigotin) başlanması uygundur

\section{C: Gastrointestinal Sistem Kriterleri}

C1. Yaşam tarzı değişikliklerine (diyet-egzersiz) yanıtsız semptomatik konstipasyonu olan olgularda, fekal tıkaç dışlanarak, lif desteği (psilyum, metilselüloz, polikarbofil, buğday dekstrin) veya polietilenglikol başlanması uygundur

\section{D: Solunum Sistemi Kriterleri}

D1. Hafif-orta astım veya KOAH'ı olan hastalarda düzenli inhale beta2 agonist veya antikolinerjik tedavi başlanması uygundur

D2. FEV $1<\% 50$ olan ve oral steroid tedavisi gerektiren tekrarlayan alevlenmeleri olan orta-ağır astım veya KOAH hastalarında düzenli inhale kortikosteroid tedavisi başlanması uygundur

D3. Kronik hipoksemisi $\left(\mathrm{PO}_{2}<=55 \mathrm{mmHg}\right.$ veya $\left.\mathrm{SO}_{2}<=\% 88\right)$ olan hastalarda evde sürekli oksijen tedavisi başlanması uygundur

\section{E: Kas İskelet Sistemi Kriterleri ve Analjezik İlaçlar}

\#E1. Günlük diyetle vitamin D alımı <800-1000 iÜ veya elementer kalsiyum alımı <1000-1200 mg olan hastalarda replasman tedavisinin başlanması uygundur

E2. Dökümante osteoporozu olan [frajilite fraktürü ve/veya kemik mineral dansitometri T skoru (femur total, femur boyun 
veya lomber < -2,5)] hastalarda anti-rezorptif (bifosfonat, denosumab) veya anabolik ajan (parathormon anoloğu) başlanması uygundur

E3. Uzun süreli (beklenen süre $\geq 3$ ay) sistemik kortikosteroid tedavisi başlanan hastalarda: i) $\geq 7,5 \mathrm{mg} / \mathrm{gün}$ prednizolon veya eşdeğer steroid tedavisi alacaklarda, ii) eğer T skoru $<-1$ ise dozdan bağımsız steroid tedavisi alacak tüm hastalarda, bifosfonat tedavisi başlanması uygundur

E4. En az iki doz Denosumab tedavisi sonlandırıldıktan sonra uzun etkili antirezorbtif tedavi başlanması uygundur (denosumab kesilmesini takiben rebound BTM'lerde artış, KMD kaybı ve vertebral fraktür riskinde artış olur)

\#E5. Teriparatid tedavisi sonrası antirezorbtif tedavi başlanması uygundur

E6. Kronik aktif romatolojik hastalık varlığında hastalığı modifiye edici tedavi başlanması uygundur

E7. Metotreksat alan hastalarda folik asit desteği başlanması uygundur

E8. Tekrarlayan gut atağı olan hastalarda ksantin oksidaz inhibitörü (öncelikle allopürinol) başlanması uygundur

E9. Orta-ağır düzeydeki ağrı tedavisinde diğer analjeziklerin (parasetamol, NSAii veya hafif opioidler) yeterli olmadığı durumlarda güçlü etkili opioid tedavisi başlanması uygundur

E10. Kronik ağrılı olan ve uzun etkili opioid kullanan hastalarda, kaçak ağrı varlığında (breakthrough pain: Aralıklarla gelen şiddetli ağrılar) tedaviye kısa etkili opioidlerin eklenmesi uygundur (şiddetli ağrının kontrol edilememe riski)

\section{F: Endokrin Sistem Kriterleri}

F1. Diabetes mellitus'lu hastalarda aşikar proteinüri (>300 mg/ gün) veya mikroalbuminüri (>30 mg/gün) varlığında, ACEi veya ARB tedavisi başlanması uygundur

\section{G: Ürogenital Sistem Kriterleri}

\#G1. Prostatektominin endike olmadığı, orta-ağır (IPSS skoru) düzeyde semptomatik LUTS (alt uriner sistem semptomları) mevcut olan hastalarda alfa-1 reseptör blokeri kullanımı uygundur

\#G2. Prostatektominin endike olmadığı orta-ağır (IPSS skoru) düzeyde semptomatik LUTS (alt uriner sistem semptomları) mevcut olan hastalarda, prostat hacmi $>30-40 \mathrm{~mL}$ ise, alfa-1 reseptör blokerine ek olarak 5 -alfa redüktaz inhibitörü tedavisi başlanması uygundur

G3. Semptomatik atrofik vajinitte, hormon-dışı tedaviler denendikten sonra, topikal vajinal östrojen tedavisi kullanımı uygundur

\section{H: Aşılar.}

H1. Yıllık influenza aşısı yapılması uygundur

H2. 65 yaşından sonra Pnömokok aşısı (13 valan konjuge ve 23 valan polisakkarit aşıdan herbiri için bir doz) yapılması uygundur

H3. Herpes zoster aşısı yapılması uygundur (zona infeskiyonu riskinde ve postherpetik nevralji riskinde azalma sağlar)

H4. 10 yılda bir Td (tetanoz-difteri toksoidi) yapılması uygundur \#H5. Hacca gidecek olgulara meningokok aşısı yapılması uygundur

\section{I: Suplemanlar.}

I1. Malnütrisyon (MN) veya malnütrisyon riski (MNR) olan yaşlılarda beslenme danışmanlığı ve besin takviyesi diyetle alımı artırmak ve beslenme hedeflerine ulaşmak için yeterli değil ise oral nütrisyonel suplemanların (ONS) başlanması uygundur

12. Hastanede yatan MN veya MNR olan yaşlılarda ONS başlanması uygundur (besin alımı ve vücut ağırlığını artırır, komplikasyon ve tekrar başvuru riskini azaltır)

I3. Kalça kırığı olan yaşlı hastalara postoperatif dönemde ONS başlanması (nütrisyonel durumundan bağımsız olarak) uygundur (besin alımını iyileştirir ve komplikasyon riskini azaltır)

14. Bası yarası mevcut olan hastalarda yeterli protein ve enerji alımını sağlamak için 1,2-2 g/kg/gün protein, 30-35 kcal/kg/gün enerji hedeflenerek ONS başlanması uygundur

\#Uluslararası Delfi paneli çalışmasında konsensus sağlanmayan kriterler

\section{Kısaltmalar:}

AF: Atrial fibrilasyon

ACEI: Anjiotensin konverting enzim inhibitörleri

ARB: Anjiotensin reseptör blokerleri

KMD: Kemik mineral dansite

BTM: Kemik Turnover Belirteçleri

ChEi: Kolinesteraz Inhibitörü

COMT: Catechol-0-methyltransferase

$\mathrm{KOAH:} \mathrm{Kronik} \mathrm{obstrüktif} \mathrm{akciğer} \mathrm{hastalığı}$

EF: Ejeksiyon fraksiyonu

FEV1: Zorlu Ekspiratuar Volüm

IPSS: Uluslararası Prostat Semptom Skoru

LUTS: Alt üriner sistem semptomları

MAO-B: Monoamin oksidaz-B

Mi: Miyokard infarktüsü 
MN: Malnütrisyon

MNR: Malnütrisyon riski

NSAii: Non steroidal anti inflamatuar ilaç

OAK: Oral antikoagülan

ONS: Oral nütrisyonel suplemanlar
$\mathrm{PO}_{2}$ : Parsiyel oksijen basıncı

$\mathrm{SaO}_{2}$ : Oksijen satürasyonu

SNRI: Serotonin-norepinefrin geri alım inhibitörü

SSRi: Selektif serotonin geri alım inhibitörü

GiA: Geçici iskemik atak 


\section{TIME to STOP- YAŞLIDA KULLANIMI ÖNERILMEYEN ILAÇLAR}

Bu grup ilaçların, kriter içeriğindeki durumlarda kullanımı yaşlılarda ilaç-hastalık, ilaç-geriatrik sendrom ve/veya ilaç-ilaç etkileşimi nedeniyle "yüksek" yan etki potansiyeli taşımaktadır ve "potansiyel uygunsuz ilaç kullanımı" olarak nitelendirilmektedirler. Klinisyenler hastanın tüm özellikleriyle ilacın hastasındaki potansiyel fayda ve zararını (kar-zarar dengesini) ve hasta/bakımveren tercihleri doğrultusunda saptanan tedavi hedeflerini göz önünde bulundurarak karar vermelidir. Bu grup ilaçları klinisyenler bazı olgularda kullanmayı yine de uygun bulabilir. Kullanımı tercih edildiğinde dikkatle kullanılması, yan etki varlığı açısından klinik olarak yakın takip edilmesi gereken ilaçlardır.

Klinik kullanıma yardımcı olması için bazı kriterlere eklenen açıklamalar kriterden hemen sonra italik karakterde ve önek* ile verilmiştir.

Referanslar; kriterle ilgili ve mevcut ise açıklamalar ile ilgili referansları içermektedir.

\section{TIME-to-STOP Kriterleri (referanslı ve açıklamalı)}

\section{A: Kardiyovasküler Sistem Kriterleri}

A1. AF tedavisinde 1.basamakta digoksin kullanımı uygun değildir

*Digoksin kullanımı, AF olgularında, beta-bloker ve kalsiyum kanal blokerlerinin tolere edilemediği olgularda (örn. hipotansiyon) veya bu tedavilerin yeterli olmadığı durumlarda kombinasyon tedavisinde kullanılabilir.

A1(i): By the 2019 American Geriatrics Society Beers Criteria ${ }^{\circledR}$ Update Expert Panel. American Geriatrics Society 2019 Updated AGS Beers Criteria ${ }^{\circledR}$ for Potentially Inappropriate Medication Use in Older Adults. J Am Geriatr Soc. 2019Apr;67(4):674-694. doi: 10.1111/jgs.15767. Epub 2019 Jan 29.

A1(ii): Kirchhof $P$, Benussi $S$, Kotecha D, Ahlsson A, Atar D, Casadei $B$, Castella $M$, Diener HC, Heidbuchel $H$, Hendriks J, Hindricks G, Manolis AS, Oldgren J, Popescu BA, Schotten U, Van Putte B, Vardas P; ESC Scientific Document Group. 2016 ESC Guidelines for the management of atrial fibrillation developed in collaboration with EACTS. Eur Heart J. 2016 Oct 7;37(38):28932962. doi:10.1093/eurheartj/ehw210. Epub 2016 Aug 27.

A2. Digoksin'in 0,125 mg/gün'den yüksek dozda kullanımı uygun değildir (toksisite riski)

A2(i): By the 2019 American Geriatrics Society Beers Criteria ${ }^{\circledR}$ Update Expert Panel. American Geriatrics Society 2019 Updated AGS Beers Criteria ${ }^{\circledR}$ for Potentially Inappropriate Medication Use in Older Adults. J Am Geriatr Soc. 2019Apr;67(4):674-694. doi: 10.1111/jgs.15767. Epub 2019 Jan 29.
A2(ii): Digoxin: Drug information, Lexicomp Online. Son erişim tarihi 22 Ekim 2019.

A2(iii): British National Formulary vol. 76, September 2018-March 2019: p 28.

A3. Korunmuş (normal) EF'li kalp yetersizliği endikasyonuyla digoksin kullanımı uygun değildir

*Digoksin'in eşlik eden AF için endikasyonu olabilir (bkz A1).

A3(i): Jessup M, Abraham WT, Casey DE, Feldman AM, Francis GS, Ganiats TG, KonstamMA, Mancini DM, Rahko PS, Silver MA, Stevenson LW, Yancy CW.2009 focused update: ACCF/ AHA Guidelines for the Diagnosis and Management of Heart Failure in Adults: a report of the American College of Cardiology Foundation/American Heart Association Task Force on Practice Guidelines: developed in collaboration with the International Society for Heart and Lung Transplantation. Circulation 2009; 119(14): 1977-2016.

A3(ii): Cheng JW, Nayar M. A review of heart failure management in the elderly population. Am J Geriatr Pharmacother 2009; 7(5): 233-49. Review.

A3(iii): O'Mahony D, O'Sullivan D, Byrne S, O'Connor MN, Ryan C, Gallagher P. STOPP/START criteria for potentially inappropriate prescribing in older people: version 2. Age Ageing. 2015 Mar;44(2):213-8. doi: 10.1093/ageing/afu145. Epub 2014 Oct 16. Review.

A4. Düşük EF'li kalp yetersizliğinde diltiazem veya verapamil kullanımı uygun değildir

A4(i): By the 2019 American Geriatrics Society Beers Criteria ${ }^{\circledR}$ Update Expert Panel. American Geriatrics Society 2019 Updated AGS Beers Criteria ${ }^{\circledR}$ for Potentially Inappropriate Medication Use in Older Adults. J Am Geriatr Soc. 2019Apr;67(4):674-694. doi: 10.1111/jgs.15767. Epub 2019 Jan 29.

A4(ii): Ponikowski P, Voors AA, Anker SD, Bueno $\mathrm{H}$, Cleland JGF, Coats AJS, Falk V, González-Juanatey JR, Harjola VP, Jankowska EA, Jessup M, Linde C, Nihoyannopoulos P, Parissis JT, Pieske B, Riley JP, Rosano GMC, Ruilope LM, Ruschitzka F, Rutten FH, van der Meer P; ESC Scientific Document Group. 2016 ESC Guidelines for the diagnosis and treatment of acute and chronic heart failure: The Task Force for the diagnosis and treatment of acute and chronic heart failure of the European Society of Cardiology (ESC)Developed with the special contribution of the Heart Failure Association (HFA) of the ESC. Eur Heart J. 2016 Jul 14;37(27):2129-2200. doi: 10.1093/ eurheartj/ehw128. Epub 2016 May 20. Erratum in: Eur Heart J. 2016 Dec 30

A4(iii): O'Mahony D, O'Sullivan D, Byrne S, O'Connor MN, Ryan C, Gallagher P. STOPP/START criteria for potentially inappropriate prescribing in older people: version 2. Age Ageing. 
2015 Mar;44(2):213-8. doi: 10.1093/ageing/afu145. Epub 2014 Oct 16. Review.

A5. Bradikardi (<50/dk), tip 2 kalp bloğu veya tam kalp bloğu olanlarda hız kısıtlayıcı tedavi (beta-bloker, verapamil, diltiazem, digoksin) başlanması uygun değildir

*Beta-blokerler PR aralığı >240 msn olgularda görece kontrendikedir. Halihazırda beta-bloker, diltiazem, verapamil, digoksin kullanmakta olan olgularda bradikardi (<50/dk) varlığında doz azaltımı yapılmalıdır.

A5(i): British National Formulary, No. 76, September 2018-March 2019, p 145.

A5(ii): O'Mahony D, O'Sullivan D, Byrne S, O'Connor MN, Ryan C, Gallagher P. STOPP/START criteria for potentially inappropriate prescribing in older people: version 2. Age Ageing. 2015 Mar;44(2):213-8. doi: 10.1093/ageing/afu145. Epub 2014 Oct 16. Review.

A6. Kalp yetersizliği, karaciğer yetersizliği, nefrotik sendrom veya böbrek yetersizliğinin klinik, biyokimyasal veya radyolojik bulguları olmadan ayak bileği ödemi için loop diüretiği kullanımı uygun değildir (bacak elevasyonu ve/veya kompresyon çorapları genellikle daha uygundur)

A6(i): Wehling M. Morbus diureticus in the elderly: epidemic overuse of a widely applied group of drugs. J Am Med Dir Assoc 2013; 14(6): 437-42. Review.

A6(ii): Sarafidis PA, Georgianos PI, Lasaridis AN. Diuretics in clinical practice. Part I: mechanisms of action, pharmacological effects and clinical indications of diuretic compounds. Expert Opin Drug Saf 2010; 9(2):243-57. Review.

A6(iii): O'Mahony D, O'Sullivan D, Byrne S, O'Connor MN, Ryan C, Gallagher P. STOPP/START criteria for potentially inappropriate prescribing in older people: version 2. Age Ageing. 2015 Mar;44(2):213-8. doi: 10.1093/ageing/afu145. Epub 2014 Oct 16. Review.

A6(iv): British National Formulary, No. 76, September 2018-March 2019, p28.

A7. Özel bir endikasyon bulunmadığı halde esansiyel HT tedavisi için ilk basamakta beta-blokerlerin kullanımı uygun değildir (kalp bloğu riskinde artış, halsizlik-yorgunluk, seksüel disfonksiyon ve inmeden korunmada az etkinlik nedeniyle; ek olarak yaşlanmayla $\beta$-adrenerjik reseptör fonksiyonunda azalma olur)

A7(i): Whelton PK, Carey RM, Aronow WS, Casey DE Jr, Collins KJ, Dennison Himmelfarb C, DePalma SM, Gidding S, Jamerson $K A$, Jones DW, MacLaughlin EJ, Muntner P, Ovbiagele B, Smith SC Jr, Spencer CC, Stafford RS, Taler SJ, Thomas RJ, Williams KA Sr, Williamson JD, Wright JT Jr. 2017 ACC/AHA/AAPA/ABC/ ACPM/AGS/APhA/ASH/ASPC/NMA/ PCNA Guideline for the
Prevention, Detection, Evaluation, and Management of High Blood Pressure in Adults: ExecutiveSummary: A Report of the American College of Cardiology/American Heart Association Task Force on Clinical Practice Guidelines. Circulation. 2018 Oct 23;138(17):e426-e483

A7(ii): James PA, Oparil S, Carter BL, Cushman WC, DennisonHimmelfarb C, Handler J, Lackland DT, Le-Fevre ML, MacKenzie TD, Ogedegbe O, Smith SC Jr, Svetkey LP, Taler SJ, Townsend RR, Wright JT Jr, Narva AS, Ortiz E. 2014 evidence-based guideline for the management of high blood pressure in adults: report from the panel members appointed to the Eighth Joint National Committee (JNC 8). JAMA. 2014 Feb 5;311(5):507-20.

A7(iii): Alexander K P, Peterson E D, Coronary heart disease in Hazzards Geriatric Medicine and Gerontology Seventh edition. Eds. Haler J B, Ouslander J G, Studenski S, High K P, Asthana S, Ritchie C S, Supiano M A,; 2017

A7(iv): Arıcı M, Birdane A, Güler K, Yıldız BO, Altun B, Ertürk Ş, Aydoğdu S, Özbakkaloğlu M, Ersöz HÖ, Süleymanlar G, Tükek T, Tokgözoğlu L, Erdem Y; Türk Kardiyoloji Derneği (TKD); Türk İç Hastalıkları Uzmanlık Derneği (TiHUD); Türkiye Endokrinoloji ve Metabolizma Derneği (TEMD); Türk Nefroloji Derneği (TND); Türk Hipertansiyon ve Böbrek Hastalıkları Derneği. [Turkish Hypertension Consensus Report]. Turk Kardiyol Dern Ars. 2015 Jun;43(4):402-9. doi: 10.5543/ tkda.2015.16243. Turkish.

A7(v): Williams B, Mancia G, Spiering W, Agabiti Rosei E, Azizi M, Burnier M, Clement DL, Coca A, de Simone G, Dominiczak A, Kahan T, Mahfoud F, Redon J, Ruilope L, Zanchetti A, Kerins M, Kjeldsen SE, Kreutz R, Laurent S, Lip GYH, McManus R, Narkiewicz K, Ruschitzka F, Schmieder RE, Shlyakhto E, Tsioufis C, Aboyans V, Desormais I; ESC Scientific Document Group. 2018 ESC/ESH Guidelines for the management of arterial hypertension. Eur Heart J. 2018 Sep 1;39(33):3021-3104.

A8. Üriner inkontinansı olanlarda esansiyel HT tedavisi için ilk basamakta diüretik kullanımı uygun değildir (inkontinansı ve sıkışma hissini artırarak yaşam kalitesini bozabilir, düşmeleri artırabilir)

*Genel olarak yaşlılarda diüretikler volüm deplesyonu yaparak/ miksiyon sıklığını ve volümünü artırarak ve sıkışma hissine sebep olarak hayat kalitesini bozabilir ve düşme için risk faktörü olabilir. Diüretik kullanan olgular bu açılardan yakın takip edilmelidir.

A8(i): Lukacz E. Evaluation of women with urinary incontinence. In: UpToDate, Post, TW (Ed), UpToDate, Waltham, MA, 2019 Son erişim tarihi 23 Ekim 2019

A8(ii): Ekundayo 0J. The association between overactive bladder and diuretic use in the elderly. Curr Urol Rep 2009; 10(6):43440. Review. 
A8(iii): Ekundayo OJ, Markland A, Lefante C, Sui X, Goode PS, Allman RM, Ali M, Wahle C, Thornton PL, Ahmed A. Association of diuretic use and overactive bladder syndrome in older adults: a propensity score analysis. Arch Gerontol Geriatr2009; 49(1):64-8.

A8(iv): Finkelstein MM. Medical conditions, medications, and urinary incontinence. Analysis of a population-based survey. Can Fam Physician 2002; 48:96-101.

A8(v): O'Mahony D, O'Sullivan D, Byrne S, O'Connor MN, Ryan C, Gallagher P. STOPP/START criteria for potentially inappropriate prescribing in older people: version 2. Age Ageing. 2015 Mar;44(2):213-8. doi: 10.1093/ageing/afu145. Epub 2014 Oct 16. Review.

A9. Diğer sınıf antihipertansiflerin tolere edilemediği veya etkisiz kaldığı durumlar hariç $\mathrm{HT}$ tedavisinde alfa-1 bloker veya santral etkili antihipertansiflerin (örn. metildopa, rilmenidin, rezerpin) kullanımı uygun değildir (alfa-1 bloker antihipertansifler ile kalp yetersizliği ve kardiyovasküler olaylarda artış, ortostatik hipotansiyon, düşme, senkop, kadınlarda üriner inkontinansın kötüleşmesi; santral etkili antihipertansiflerin MSS yan etkileri, sedasyon-depresyon-parkinsonizm ve ortostatik hipotansiyon, bradikardi yan etkileri)

A9(i): By the 2019 American Geriatrics Society Beers Criteria ${ }^{\circledR}$ Update Expert Panel. American Geriatrics Society 2019 Updated AGS Beers Criteria ${ }^{\circledR}$ for Potentially Inappropriate Medication Use in Older Adults. J Am Geriatr Soc. 2019Apr;67(4):674-694. doi: 10.1111/jgs.15767. Epub 2019 Jan 29.

A9(ii): Marshall HJ, Beevers DG. Alpha-adrenoceptor blocking drugs and female urinary incontinence: prevalence and reversibility. Br J Clin Pharmacol. 1996 0ct;42(4):507-9

A9(iii): Major cardiovascular events in hypertensive patients randomized to doxazosinvs chlorthalidone: the antihypertensive and lipid-lowering treatment to preventheart attack trial (ALLHAT). ALLHAT Collaborative Research Group. JAMA. 2000 Apr19;283(15):1967-75.

A9(iv): O'Mahony D, O'Sullivan D, Byrne S, O'Connor MN, Ryan C, Gallagher P. STOPP/START criteria for potentially inappropriate prescribing in older people: version 2. Age Ageing. 2015 Mar;44(2):213-8. doi: 10.1093/ageing/afu145. Epub 2014 Oct 16. Review.

A10. Ortostatik hipotansiyon (sistolik kan basıncında $>=20$ $\mathrm{mmHg}$ düşüş veya diastolik kan basıncında $>=10 \mathrm{mmHg}$ düşüş) olanlarda vazodilatör antihipertansiflerin (alfa-1 blokerler)/ nitratların kullanımı uygun değildir (ortostatik hipotansiyonda artış riski)

*Ortostatik hipotansiyon varlığında vazodilatör antihipertansiflerin kullanımı, sadece ciddi süpin HT diğer antihipertansiflerle kontrol edilemediğinde, uygun olabilir.
Kullanılmaları durumunda eş zamanlı olarak ortostatik hipotansiyondan koruyucu tedbirler uygulanmalıdır. Ortostatik hipotansiyon varlığında tüm antihipertansifler doz azaltımı açısından değerlendirilmelidir.

A10(i): Aronow WS. Treating hypertension in older adults: safety considerations. Drug Saf 2009; 32(2): 111-8.

A10(ii): Verhaeverbeke I, Mets T. Drug-induced orthostatic hypotension in the elderly: avoiding its onset. Drug Saf 1997; 17(2): 105-18. Review.

A10(iii): O'Mahony D, O'Sullivan D, Byrne S, O'Connor MN, Ryan C, Gallagher P. STOPP/START criteria for potentially inappropriate prescribing in older people: version 2. Age Ageing. 2015 Mar;44(2):213-8. doi: 10.1093/ageing/afu145. Epub 2014 Oct 16. Review.

A10(iv): Brignole $M$, Moya $A$, de Lange FJ, Deharo JC, Elliott PM, Fanciulli A, Fedorowski $A$, Furlan $R$, Kenny RA, Martín $A$, Probst V, Reed MJ, Rice CP, Sutton R, Ungar A, van Dijk JG; ESC Scientific Document Group. 2018 ESC Guidelines for the diagnosis and management of syncope. Eur Heart J. 2018 Jun 1;39(21):1883-1948.

A11. Ortostatik hipotansiyonu/bilişsel yetersizliği (örn. demans) /fonksiyonel kısıtılığı/düşük yaşam beklentisi $(<2$ yıl)/düşme riski yüksek olan hastalarda sıkı kan basıncı kontrolu $(<140 / 90$ $\mathrm{mmHg}$ ) uygun değildir

A11(i): Onder $G$, Landi $F$, Fusco $D$, Corsonello $A$, Tosato $M$, Battaglia M, Mastropaolo S, Settanni S, Anto-cicco M, Lattanzio F. Recommendations to prescribe in complex older adults: results of the CRIteria to assess appropriate Medication use among Elderly complex patients (CRIME) project. Drugs Aging. 2014 Jan;31(1):33-45.Review.

A11(ii): Wu JS, Yang YC, Lu FH. Population-based study on the prevalence and risk factors of orthostatic hypotension in subjects withpre-diabetes and diabetes. Diabetes Care. 2009;32:69-74.

A11 (iii): Luukinen H, Koski K, Laippala P, Kivela“ SL. Prognosis of diastolic and systolic orthostatic hypotension in older persons. ArchIntern Med. 1999;159:273-80.

A11 (iv): Hiitola P, Enlund H, Kettunen R. Postural changes in blood pressure and the prevalence of orthostatic hypotension among home-dwelling elderly aged 75 years or older. J Hum Hypertens. 915 2009;23:33-9.

A12. Sekonder faktörler dışlanmadan ve ilaç dışı yaklaşımlar uygulanmadan ortostatik hipotansiyon tedavisi için fludrokortizon kullanımı uygun değildir

*Ortostatik hipotansiyonun yönetimine yönelik ilaç dışı yaklaşımlar şunlardır: Ayağa yavaş kalkmak, alt ekstremite direnç egzersizleri, varis çorabı giymek, yeterli sıvı alımı [2-3 
L/gün], alkolden kaçınmak, az ve sık yemek yemek, yeterli tuz alımı [6-10 g/gün], karbonhidrattan zengin yiyeceklerden uzak durulması, sıcak havada yoğun egzersizden kaçınılması, yatarken başın 30-45 derece yüksekte tutulması

A12(i): Seppi K, Weintraub D, Coelho M, Perez-Lloret S, Fox SH, Katzenschlager R,Hametner EM, Poewe W, Rascol O, Goetz CG, Sampaio C. The Movement DisorderSociety EvidenceBased Medicine Review Update: Treatments for the nonmotorsymptoms of Parkinson's disease. Mov Disord. 2011 Oct;26 Suppl 3:S42-80.

A12(ii): Kaufmann H. Treatment of orthostatic and postprandial hypotension. In: UpToDate, Post, TW (Ed), UpToDate, Waltham, MA, 2019 Son erişim tarihi 23 Ekim 2019

A12(iii): Shibao C, Lipsitz LA, Biaggioni I. ASH position paper: evaluation and treatment of orthostatic hypotension. J Clin Hypertens (Greenwich). 2013 Mar;15(3):147-53.

A13. HT olgularında beta-bloker ve verapamil/diltiazem kombinasyonu kullanımı uygun değildir (kalp bloğu riski)

*Yaşlılarda HT tedavisinde kalsiyum kanal blokerlerinden genellikle uzun etkili dihidropiridin grubu tercih edilmelidir (verapamil/diltiazem kullanımı kalp bloğu riskini artırabilir).

*Beta-blokerler'in, verapamil/diltiazem ile kombinasyonu bazı supraventriküler taşikardi olgularında uygun olabilir. Bu durumda da dikkatli kullanılmalıdır.

A13(i): Edoute $Y$, Nagachandran P, Svirski B, Ben-Ami H. Cardiovascular adverse drug reaction associated with combined beta-adrenergic and calcium entry-blocking agents. J Cardiovasc Pharmacol 2000; 35(4): 556-9.

A13(ii): Egan BM. Treatment of hypertension in older adults, particularly isolated systolic hypertension. In: UpToDate, Post, TW (Ed), UpToDate, Waltham, MA, 2019 Son erişim tarihi 23 Ekim 2019

A13(iii): O'Mahony D, O'Sullivan D, Byrne S, O'Connor MN, Ryan C, Gallagher P. STOPP/START criteria for potentially inappropriate prescribing in older people: version 2. Age Ageing. 2015 Mar;44(2):213-8. doi: 10.1093/ageing/afu145. Epub 2014 Oct 16. Review.

A14. Serum potasyum düzeyi $5.5 \mathrm{mEq} / \mathrm{L}^{\prime} n$ in üzerinde olan olgularda RAS blokeri (ACE inhibitörü, ARB, direkt renin inhibitörü) veya potasyum tutucu diüretik (spironolakton, eplerenon, amilorid, triamteren) başlanması uygun değildir

*Potasyum düzeyi $6 \mathrm{mEq} / \mathrm{L}$ 'nin üzerinde olan olgularda bu grup ilaçlar kullanılıyorsa kesilmelidir.

*ACE inhibitörü ve ARB'lerin antihipertansif amaçlı kombine kullanımı uygun değildir.
A14(i): Izzo JL Jr, Weir MR. Angiotensin-converting enzyme inhibitors. J Clin Hypertens (Greenwich) 2011; 13(9):667-75. Review.

A14(ii): Desai AS, Swedberg K, McMurray JJ, Granger CB, Yusuf $S$, Young JB, Dunlap ME, Solomon SD, Hainer JW, Olofsson B, Michelson EL, Pfeffer MA; CHARM Program Investigators. Incidence and predictors of hyperkalemia in patients with heart failure: an analysis of the CHARM Program. J Am Coll Cardiol 2007 Nov 13;50(20):1959-66.

A14(iii): Reardon LC, Macpherson DS. Hyperkalemia in outpatients using angiotensin-converting enzyme inhibitors. How much should we worry? Arch Intern Med 1998; 158(1):2632.

A14(iv): ONTARGET Investigators, Yusuf S, Teo KK, Pogue J, Dyal L, Copland I, Schumacher H, Dagenais G, Sleight P, Anderson C. Telmisartan, ramipril, or both in patients at high risk for vascular events. N Engl J Med. 2008 Apr 10;358(15):1547-59.

A14(v): O'Mahony D, O'Sullivan D, Byrne S, O'Connor MN, Ryan C, Gallagher P. STOPP/START criteria for potentially inappropriate prescribing in older people: version 2. Age Ageing. 2015 Mar;44(2):213-8. doi: 10.1093/ageing/afu145. Epub 2014 Oct 16. Review.

A15. Serum potasyum düzeyi takip edilmeden RAS blokeri (ACEI, $A R B$, direkt renin inhibitörü) ve potasyum tutucu diüretiklerin (spironolakton, eplerenon, amilorid, triamteren) kombine edilmesi uygun değildir (tehlikeli hiperpotasemi riski)

*Bu risk özellikle diabetes mellitus hastalarında, böbrek yetersizliği hastalarında, yaşlılarda ve potasyum tuzu takviyeleri kullanmakta olanlarda daha yüksektir.

A15(i): Bauersachs J, Fraccarollo D. Aldosterone antagonism in addition to angiotensin-converting enzyme inhibitors in heart failure. Minerva Cardioangiol 2003; 51(2):155-64. Review.

A15(ii): Poggio R, Grancelli HO, Miriuka SG. Understanding the risk of hyperkalaemia in heart failure: role of aldosterone antagonism. Postgrad Med J 2010; 86 (1013):136-42. Review.

A15(iii): Wrenger E, Müller R, Moesenthin M, Welte T, Frölich JC, Neumann KH. Interaction of spironolactone with ACE inhibitors or angiotensin receptor blockers: analysis of 44 cases. BMJ 2003; 327(7407):147-9.

A15(iv): Marcy TR, Ripley TL. Aldosterone antagonists in the treatment of heart failure. Am J Health Syst Pharm 2006; 63(1): 49-58.

A15(v): Tang WH, Parameswaran AC, Maroo AP, Francis GS. Aldosterone receptor antagonists in the medical management of chronic heart failure. Mayo Clin Proc 2005; 80(12): 1623-30. Review. 
A15(vi): O'Mahony D, O'Sullivan D, Byrne S, O'Connor MN, Ryan C, Gallagher P. STOPP/START criteria for potentially inappropriate prescribing in older people: version 2. Age Ageing. 2015 Mar;44(2):213-8. doi: 10.1093/ageing/afu145. Epub 2014 Oct 16. Review.

A16. $G F R<30 \mathrm{~mL} / \mathrm{dk} / 1,73 \mathrm{~m}^{2}$ olan ve serum potasyum düzeyi yakın takip edilemeyecek hastalarda, potasyum tutucu ilaçların (aldosteron antagonistleri, triamteren, amilorid, ACEi, ARB) kullanımı uygun değildir (hiperpotasemi riski)

A16(i): Kidney Disease Outcomes Quality Initiative (K/DOQI). $\mathrm{K} / \mathrm{DOOI}$ clinical practice guidelines on hypertension and antihypertensive agents in chronic kidney disease. Am J Kidney Dis. 2004 May;43(5 Suppl 1):S1-290.

A17. Belirgin hipopotasemi (serum $\mathrm{K}<3,0 \mathrm{mg} / \mathrm{L}$ ), hiponatremi (serum $\mathrm{Na}<130 \mathrm{mEq} / \mathrm{L}$ ), hiperkalsemi (düzeltilmiş serum Ca>10,6 $\mathrm{mg} / \mathrm{dL}$ ) veya gut hikayesi olan hastalarda tiazid diüretiklerinin kullanımı uygun değildir

A17(i): Sica DA, Carter B, Cushman W, Hamm L. Thiazide and loop diuretics. J Clin Hypertens (Greenwich) 2011; 13(9):639-43. Review.

A17(ii): Gurwitz JH, Kalish SC, Bohn RL, Glynn RJ, Monane M, Mogun H, Avorn J. Thiazide diuretics and the initiation of antigout therapy. J ClinEpidemiol1997; 50(8): 953-9.

A17(iii): O'Mahony D, O'Sullivan D, Byrne S, O'Connor MN, Ryan C, Gallagher P. STOPP/START criteria for potentially inappropriate prescribing in older people: version 2. Age Ageing. 2015 Mar;44(2):213-8. doi: 10.1093/ageing/afu145. Epub 2014 Oct 16. Review.

A18. Kardiyovasküler hastalığı (ciddi HT, kalp yetersizliği veya geçirilmiş Mi, inme) olan olgularda NSAii kullanımı uygun değildir (artmış kardiyovasküler olay: Mi, inme, kalp yetersizliği ve ölüm riski)

*NSAii kullanımının klinik olarak endike olduğu durumlarda, yakın klinik takip ile ve mümkün olan en düşük dozda, kısa süreli kullanım tercih edilebilir.

*NSAil'lerin hepsi kardiyovasküler açıdan riskli olmakla birlikte naproksen ve ibuprofen görece daha güvenli olabilirler.

*Aspirin kullanan hastaya NSAil'ler verilecekse, aspirinden en az 2 saat sonra uygulanması daha uygun olabilir.

A18(i): Pilotto A, Sancarlo D, Addante F, Scarcelli C, Franceschi $M$. Non-steroidal anti-inflammatory drug use in the elderly. Surg Oncol 2010; 19(3): 167-72. Review.

A18(ii): Strand V. Are COX-2 inhibitors preferable to nonselective non-steroidal anti-inflammatory drugs in patients with risk of cardiovascular events taking low-dose aspirin? Lancet 2007; 370(9605): 2138-51. Review.
A18(iii): White WB. Defining the problem of treating the patient with hypertension and arthritis pain. Am J Med. 2009; 122(5 Suppl): S3-9. Review.

A18(iv): Park KE. Qin Y, Bavry AA.Nonsteroidal anti-inflammatory drugs and their effects in the elderly. Aging Health 2012; 8(2): 167-177.

A18(v): Solomon DH. NSAIDs: Adverse cardiovascular effects. In: UpToDate, Post, TW (Ed), UpToDate, Waltham, MA, 2019 Son erişim tarihi 23 Ekim 2019

A18(vi): By the 2019 American Geriatrics Society Beers Criteria ${ }^{\circledR}$ Update Expert Panel. American Geriatrics Society 2019 Updated AGS Beers Criteria ${ }^{\circledR}$ for Potentially Inappropriate Medication Use in Older Adults. J Am Geriatr Soc. 2019Apr;67(4):674-694. doi: 10.1111/jgs.15767. Epub 2019 Jan 29.

A18(vii): O'Mahony D, O'Sullivan D, Byrne S, O'Connor MN, Ryan C, Gallagher P. STOPP/START criteria for potentially inappropriate prescribing in older people: version 2. Age Ageing. 2015 Mar;44(2):213-8. doi: 10.1093/ageing/afu145. Epub 2014 Oct 16. Review.

A19. Sık hipoglisemi atakları olan DM hastalarında beta-bloker kullanımı uygun değildir (hipoglisemik semptomları baskılama riski)

A19(i): Chelliah A, Burge MR. Hypoglycaemia in elderly patients with diabetes mellitus: causes and strategies for prevention. Drugs Aging 2004; 21(8): 511-30. Review.

A19(ii): British National Formulary vol. 76, September 2018-March 2019: p 145.

A19(iii): O'Mahony D, O'Sullivan D, Byrne S, O'Connor MN, Ryan C, Gallagher P. STOPP/START criteria for potentially inappropriate prescribing in older people: version 2. Age Ageing. 2015 Mar;44(2):213-8. doi: 10.1093/ageing/afu145. Epub 2014 Oct 16. Review.

A20. Astım öyküsü olanlarda nonselektif beta-bloker (oral veya glokom için topikal) kullanımı uygun değildir (bronkospazmda artış riski)

A20(i): O'Mahony D, O'Sullivan D, Byrne S, O'Connor MN, Ryan C, Gallagher P. STOPP/START criteria for potentially inappropriate prescribing in older people: version 2. Age Ageing. 2015 Mar;44(2):213-8. doi: 10.1093/ageing/afu145. Epub 2014 Oct 16. Review.

A20(ii): Kaiserman I, Fendyur A, Vinker S. Topical beta blockers in asthmatic patients-is it safe? Curr Eye Res. 2009 Jul;34(7):517-22.

A20(iii): McNeill RS, Ingram CG. Effect of propranolol on ventilatory function. Am J Cardiol. 1966 Sep;18(3):473-5.

A20(iv): Morales DR, Lipworth BJ, Donnan PT, Jackson C, Guthrie B. Respiratory effect of beta-blockers in people with 
asthma and cardiovascular disease: population-based nested case control study. BMC Med. 2017 Jan 27;15(1):18.

A21. Primer veya sekonder kardiyovasküler korumada aspirin'in 75-150 mg/gün'den yüksek dozda kronik kullanımı uygun değildir (kanıtlanmış ek faydası yok ve kanama riskini artırıyor)

A21(i): Task Force Members, Montalescot G, Sechtem U, Achenbach S, Andreotti F, Arden C, Budaj A, Bugiardini R, Crea F, Cuisset T, Di Mario C, Ferreira JR, Gersh BJ, Gitt AK, Hulot JS, Marx N, Opie LH, Pfisterer M, Prescott E, Ruschitzka F, Sabaté $M$, Senior $R$, Taggart DP, van der Wall EE, Vrints CJ; ESC Committee for Practice Guidelines, Zamorano JL, Achenbach $\mathrm{S}$, Baumgartner H, Bax JJ, Bueno H, Dean V, Deaton C, Erol C, Fagard R, Ferrari R, Hasdai D, Hoes AW, Kirchhof P, Knuuti J, Kolh P, Lancellotti P, Linhart A, Nihoyannopoulos P, Piepoli MF, Ponikowski $P$, Sirnes PA, Tamargo JL, Tendera M, Torbicki A, Wijns W, Windecker S; Document Reviewers, Knuuti J, Valgimigli M, Bueno H, Claeys MJ, Donner-Banzhoff N, Erol C, Frank H, Funck-Brentano C, Gaemperli O, Gonzalez-Juanatey JR, Hamilos $M$, Hasdai D, Husted S, James SK, Kervinen K, Kolh P, Kristensen SD, Lancellotti $P$, Maggioni AP, Piepoli MF, Pries AR, Romeo $F$, Rydén $L$, Simoons $M L$, Sirnes $P A$, Steg $P G$, Timmis $A$, Wijns $W$, Windecker S, Yildirir A, Zamorano JL. 2013 ESC guidelines on the management of stable coronary artery disease: the Task Force on the management of stable coronary artery disease of the European Society of Cardiology. Eur Heart J. 2013 0ct;34(38):2949-3003.

A21(ii): Hennekens CH.Aspirin for the secondary prevention of atherosclerotic cardiovascular disease. In: UpToDate, Post, TW (Ed), UpToDate, Waltham, MA, 2019 son erişim tarihi 23 October 2019

A21(iii): Cucchiara BL.Antiplatelet therapy for secondary prevention of stroke. In: UpToDate, Post, TW (Ed), UpToDate, Waltham, MA, 2019 son erişim tarihi 23 Ekim 2019

A21(iv): Spencer FA, Guyatt G, Tampi M, Golemiec B.Aspirin in the primary prevention of cardiovascular disease and cancer. In: UpToDate, Post, TW (Ed), UpToDate, Waltham, MA, 2019 son erişim tarihi 23 Ekim 2019

A21(v): Smith SC Jr, Benjamin EJ, Bonow RO, Braun LT, Creager MA, Franklin BA, Gibbons RJ, Grundy SM, Hiratzka LF, Jones DW, Lloyd-Jones DM, Minissian M, Mosca L, Peterson ED, Sacco RL, Spertus J, Stein JH, Taubert KA; World Heart Federation and the Preventive Cardiovascular Nurses Association. AHA/ACCF Secondary Prevention and Risk Reduction Therapy for Patients with Coronary and other Atherosc-lerotic Vascular Disease: 2011 update: a guideline from the American Heart Association and American College of Cardiology Foundation. Circulation. 2011 Nov 29;124(22):2458-73.
A21(vi): O'Mahony D, O'Sullivan D, Byrne S, O'Connor MN, Ryan C, Gallagher P. STOPP/START criteria for potentially inappropriate prescribing in older people: version 2. Age Ageing. 2015 Mar;44(2):213-8. doi: 10.1093/ageing/afu145. Epub 2014 Oct 16. Review.

A21(vii): Powers WJ, Rabinstein AA, Ackerson T, Adeoye OM, Bambakidis NC, Becker K, Biller J, Brown M, Demaerschalk BM, Hoh B, Jauch EC, Kidwell CS, Leslie-Mazwi TM, Ovbiagele B, Scott PA, Sheth KN, Southerland AM, Summers DV, Tirschwell DL; American Heart Association Stroke Council. 2018 Guidelines for the EarlyManagement of Patients With Acute Ischemic Stroke: A Guideline for HealthcareProfessionals From the American Heart Association/American Stroke Association.Stroke. 2018 Mar;49(3):e46-e110.

\#A22. Aspirin, klopidogrel, dipiridamol ve OAK'ların (Vitamin $\mathrm{K}$ antagonistleri, direkt trombin inhibitörü veya faktör $\mathrm{Xa}$ inhibitörleri) eşlik eden anlamlı kanama riski varlığında (örneğin kontrolsüz ciddi HT, kanama diyatezi, spontan anlamlı kanaması olanlarda) kullanımı uygun değildir (yüksek kanama riski)

A22(i): Lip GY. Implications of the CHA(2)DS(2)-VASc and HASBLED Scores for thromboprophylaxis in atrial fibrillation. Am J Med. 2011; 124(2):111-4.

A22(ii): Pisters R, Lane DA, Nieuwlaat R, de Vos CB, Crijns HJ, Lip GY. A novel user-friendly score (HAS-BLED) to assess 1-year risk of major bleeding in patients with atrial fibrillation: the Euro Heart Survey. Chest 2010; 138(5):1093-100.

A22(iii): O'Mahony D, O'Sullivan D, Byrne S, O'Connor MN, Ryan C, Gallagher P. STOPP/START criteria for potentially inappropriate prescribing in older people: version 2. Age Ageing. 2015 Mar;44(2):213-8. doi: 10.1093/ageing/afu145. Epub 2014 Oct 16. Review.

A23. Aspirin ve klopidogrelin birlikte kullanımı için spesifik bir endikasyon yoksa, sekonder inme proflaksisinde aspirin ve klopidogrelin birlikte kullanımı uygun değildir

*Aspirin +klopidogrel kombine kullanımının uygun olduğu durumlar

1. son 12 ay içinde akut koroner sendrom veya koroner girişim geçirmiş olmak (balon ve/veya stent)

2. periferik arter hastalığı nedeniyle son 1 ayda girişim geçirmiş olmak

son bir ayda stent (karotis arter stenozu/alt ekstremite arter hastalığı nedeniyle) yerleştirilmesi

son bir ayda alt ekstremiteye balon uygulaması

3. son 3 hafta-3 ay içinde inme-GiA geçirmiş olmak 
intrakranial ateroskleroza bağlı inme veya GiA olgularında 3 ay boyunca

minör inme veya GiA olgularında 3 hafta boyunca

A23(i): Diener HC, Bogousslavsky J, Brass LM, Cimminiello C, Csiba L, Kaste M, Leys D, Matias-Guiu J, Rupprecht HJ; MATCH investigators. Aspirin and clopidogrel compared with clopidogrel alone after recent ischaemic stroke or transient ischaemic attack in high-risk patients (MATCH): randomised, double-blind, placebo-controlled trial. Lancet 2004; 364(9431):331-7.

A23(ii): Bhatt DL, Fox KA, Hacke W, Berger PB, Black HR, Boden WE, Cacoub P, Cohen EA, Creager MA, Easton JD, Flather MD, Haffner SM, Hamm CW, Hankey GJ, Johnston SC, Mak KH, Mas JL, Montalescot G, Pearson TA, Steg PG, Steinhubl SR, Weber MA, Brennan DM, Fabry-Ribaudo L, Booth J, Topol EJ; CHA-RISMA Investigators. Clopidogrel and aspirin versus aspirin alone for the prevention of atherothrombotic events. N Engl J Med. 2006; 354(16):1706-17.

A23(iii): Usman $M H$, Notaro LA, Nagarakanti $R$, Brahin $E$, Dessain S, Gracely E, Ezekowitz MD. Combination antiplatelet therapy for secondary stroke prevention: enhanced efficacy or double trouble? Am J Cardiol 2009;103(8):1107-12. Review.

A23(iv): Squizzato A, Keller T, Romualdi E, Middeldorp S. Clopidogrel plus aspirin versus aspirin alone for preventing cardiovascular disease. Cochrane Database Syst Rev $2011 ;(1): C D 005158$. Review.

A23(v): Fares RR, Lansing LS, Gallati CA, Mousa SA. Antiplatelet therapy with clopidogrel and aspirin in vascular diseases: clinical evidence for and against the combination. Expert Opin Pharmacother 2008; 9(3): 377-86. Review.

A23(vi): O'Mahony D, O'Sullivan D, Byrne S, O'Connor MN, Ryan C, Gallagher P. STOPP/START criteria for potentially inappropriate prescribing in older people: version 2. Age Ageing. 2015 Mar;44(2):213-8. doi: 10.1093/ageing/afu145. Epub 2014 Oct 16. Review.

A23(vii):Valgimigli M. The ESC DAPT Guidelines 2017. Eur Heart J. 2018 Jan 14;39(3):187-188. doi: 10.1093/eurheartj/ehx768.

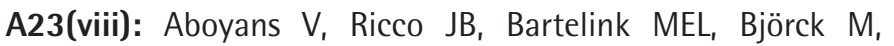
Brodmann M, Cohnert T, Collet JP, Czerny M, De Carlo M, Debus S, Espinola-Klein C, Kahan T, Kownator S, Mazzolai L, Naylor AR, Roffi M, Röther J, Sprynger M, Tendera M, Tepe G, Venermo M, Vlachopoulos C, Desormais I; ESC Scientific Document Group. 2017 ESC Guidelines on the Diagnosis and Treatment of Peripheral Arterial Diseases, in collaboration with the European Society for Vascular Surgery (ESVS): Document covering atherosclerotic disease of extracranial carotid and vertebral, mesenteric, renal, upper and lower extremity arteriesEndorsed by: the European Stroke Organization (ESO)The Task Force for the Diagnosis and Treatment of Peripheral Arterial Diseases of the European Society of Cardiology (ESC) and of the European Society for Vascular Surgery (ESVS). Eur Heart J. 2018 Mar 1;39(9):763-816. doi: 10.1093/eurheartj/ehx095.

A24. Kronik AF veya başka bir sebeple OAK kullanan hastalarda aspirin/klopidogrel kullanımı için ek endikasyon yok ise tedaviye aspirin/klopidogrel eklenmesi uygun değildir (aspirin ile ek fayda yok)

${ }^{*} O A K$ kullanımı olan hastalarda tedaviye aspirin/klopidogrel eklenmesi uygun olan durumlar şunlardır:

1. son 12 ayda akut koroner sendrom veya koroner girişim geçirmiş olmak (balon ve/veya stent)

2. periferik arter hastalığı nedeniyle son 1 ayda girişim geçirmiş olmak

son bir ayda stent (karotis arter stenozu/alt ekstremite arter hastalığı nedeniyle) yerleştirlmesi

son bir ayda alt ekstremiteye balon uygulaması

*OAK kullanan hastalarda aşağıdaki durumlarda tedaviye aspirin/klopidogrel eklenmesi uygun değildir:

1. üstteki durumlar haricinde olan periferik arter hastalı̆̆ı (karotis arter stenozu, alt ekstremite arter hastalığı, intraserebral ateroskleroz)

2. stabil koroner arter hastalığı (örneğin 12 aydan daha uzun zaman önce geçirilmiş akut koroner sendrom veya koroner girişim)

A24(i): Aboyans V, Ricco JB, Bartelink MEL, Björck M, Brodmann M, Cohnert T, Collet JP, Czerny M, De Carlo M, Debus S, Espinola-Klein C, Kahan T, Kownator S, Mazzolai L, Naylor AR, Roffi $M$, Röther J, Sprynger $M$, Tendera M, Tepe G, Venermo M, Vlachopoulos C, Desormais I; ESC Scientific Document Group. 2017 ESC Guidelines on the Diagnosis and Treatment of Peripheral Arterial Diseases, in collaboration with the European Society for Vascular Surgery (ESVS): Document covering atherosclerotic disease of extracranial carotid and vertebral, mesenteric, renal, upper and lower extremity arteriesEndorsed by: the European Stroke Organization (ESO)The Task Force for the Diagnosis and Treatment of Peripheral Arterial Diseases of the European Society of Cardiology (ESC) and of the European Society for Vascular Surgery (ESVS). Eur Heart J. 2018 Mar 1;39(9):763-816. doi: 10.1093/eurheartj/ehx095.

A24(ii): Flaker GC, Gruber M, Connolly SJ, Goldman S, Chaparro $\mathrm{S}$, Vahanian A, Halinen MO, Horrow J, Halperin JL; SPORTIF Investigators. Risks and benefits of combining aspirin with anticoagulant therapy in patients with atrial fibrillation: an exploratory analysis of stroke prevention using an oral thrombin inhibitor in atrial fibrillation (SPORTIF) trials. Am Heart J 2006; 152(5):967-73. 
A24(iii): Larson RJ, Fisher ES. Should aspirin be continued in patients started on warfarin? J Gen Intern Med 2004; 19(8):87986. Review.

A24(iv): Kirchhof $P$, Benussi $S$, Kotecha D, Ahlsson A, Atar D, Casadei B, Castella M, Diener HC, Heidbuchel H, Hendriks J, Hindricks G, Manolis AS, Oldgren J, Popescu BA, Schotten U, Van Putte B, Vardas P, Agewall S, Camm J, Baron Esquivias G,Budts W, Carerj S, Casselman F, Coca A, De Caterina R, Deftereos S, Dobrev D, Ferro JM, Filippatos G, Fitzsimons D, Gorenek B, Guenoun M, Hohnloser SH, Kolh P,Lip GY, Manolis A, McMurray J, Ponikowski P, Rosenhek R, Ruschitzka F, Savelieva I, Sharma S, Suwalski P, Tamargo JL, Taylor CJ, Van Gelder IC, Voors AA, Windecker S, Zamorano JL, Zeppenfeld K. 2016 ESC Guidelines for the management of atrial fibrillation developed in collaboration with EACTS. Europace. 2016 Nov;18(11):1609-1678.)

A24(v): XU H. Antithrombotic Therapy for Patients With Both Stable Coronary Artery Disease andAtrial Fibrillation-Expert Analysis 2014. Available at:

htt p://www. acc.org/latest-in-cardiology/ articles/2014/07/18/15/34/antithrombotic-therapy-forpatients-with-both-stable-cad-and-afib) (erişim tarihi 28 Ekim 2019)

A24(vi): O'Mahony D, O'Sullivan D, Byrne S, O'Connor MN, Ryan C, Gallagher P. STOPP/START criteria for potentially inappropriate prescribing in older people: version 2. Age Ageing. 2015 Mar;44(2):213-8. doi: 10.1093/ageing/afu145. Epub 2014 Oct 16. Review.

A24(vii): Camm AJ, Lip GY, De Caterina R, Savelieva I, Atar D, Hohnloser SH, HindricksG, Kirchhof P; ESC Committee for Practice Guidelines-CPG; Document Reviewers.2012 focused update of the ESC Guidelines for the management of atrialfibrillation: an update of the 2010 ESC Guidelines for the management of atrialfibrillation--developed with the special contribution of the European HeartRhythm Association. Europace. 2012 Oct;14(10):1385-413.

A24(viii): Smith SC Jr, Benjamin EJ, Bonow RO, et al. AHA/ACCF Secondary Prevention and Risk Reduction Therapy for Patients with Coronary and other Atherosclerotic Vascular Disease: 2011 update: a guideline from the American Heart Association and American College of Cardiology Foundation. J Am Coll Cardiol 2011;58:2432-2446.

A24(ix): Yasuda S, Kaikita K, Akao M, Ako J, Matoba T, Nakamura M, Miyauchi K, Hagiwara N, Kimura K, Hirayama A, Matsui K, Ogawa $\mathrm{H}$; AFIRE Investigators. Antithrombotic Therapy for Atrial Fibrillation with Stable Coronary Disease. N Engl J Med. 2019 Sep 19;381(12):1103-1113.

A25. OAK'ların (vitamin $\mathrm{K}$ antagonistleri, direkt trombin inhibitörleri veya faktör $\mathrm{Xa}$ inhibitörleri), devam eden risk faktörleri olmaksızın ilk kez olan derin ven trombozunda 6 aydan uzun süre kullanımı uygun değildir (kanıtlanmış ek yararı yok)

A25(i): Pinede L, Ninet J, Duhaut P, Chabaud S, DemolombeRague S, Durieu I, Nony P, Sanson C, Boissel JP; Investigators of the "Durée Optimale du Traitement AntiVitamines K" (DOTAVK) Study. Comparison of 3 and 6 months of oral anticoagulant therapy after a first episode of proximal deep vein thrombosis or pulmonary embolism and comparison of 6 and 12 weeks of therapy after isolated calf deep vein thrombosis. Circulation 2001; 103(20): 2453-60.

A25(ii): Kearon C, Akl EA, Comerota AJ, Prandoni P, Bounameaux H, Goldhaber SZ, Nelson ME, Wells PS, Gould MK, Dentali F, Crowther M, Kahn SR; American College of Chest Physicians. Antithrombotic therapy for VTE disease: Antithrombotic Therapy and Prevention of Thrombosis, 9th ed: American College of Chest Physicians Evidence-Based Clinical Practice Guidelines. Chest 2012; 141 (2 Suppl): e419S-94S.

A25(iii): Lip GYH, Hull RD. Overview of the treatment of lower extremity deep vein thrombosis (DVT). In: UpToDate, Post, TW (Ed), UpToDate, Waltham, MA, 2019 son erişim tarihi 23 Ekim 2019

A25(iv): O'Mahony D, O'Sullivan D, Byrne S, O'Connor MN, Ryan C, Gallagher P. STOPP/START criteria for potentially inappropriate prescribing in older people: version 2. Age Ageing. 2015 Mar;44(2):213-8. doi: 10.1093/ageing/afu145. Epub 2014 Oct 16. Review.

\#A26. OAK'ların (vitamin $\mathrm{K}$ antagonistleri, direkt trombin inhibitörleri veya faktör $\mathrm{Xa}$ inhibitörleri), devam eden risk faktörleri olmaksızın ilk kez olan pulmoner embolide 12 aydan uzun süre kullanımı uygun değildir (kanıtlanmış ek yararı yok)

A26(i): Kearon C, AkI EA, Comerota AJ, Prandoni P, Bounameaux H, Goldhaber SZ, Nelson ME, Wells PS, Gould MK, Dentali F, Crowther M, Kahn SR; American College of Chest Physicians. Antithrombotic therapy for VTE disease: Antithrombotic Therapy and Prevention of Thrombosis, 9th ed: American College of Chest Physicians Evidence-Based Clinical Practice Guidelines. Chest 2012; 141 (2Suppl): << potentially inappropriate prescribing in older people: version 2. Age Ageing. 2015 Mar;44(2):213-8. doi: 10.1093/ageing/afu145. Epub 2014 Oct 16. Review.

\#A27. OAK'ların (vitamin $\mathrm{K}$ antagonistleri, direkt trombin inhibitörleri veya faktör Xa inhibitörleri) kontrendike olduğu kronik AF hastalarında, aspirin veya klopidogrel monoterapisinin kullanımı uygun değildir

*Aspirin veya klopidogrel monoterapisi AF hastalarında inmenin önlenmesi için önerilmez, zararlıdır.

*Kanama riski varlı̆ı̆ nedeniyle OAK kontrendike olan hastalarda dual antiplatelet tedavi de önerilmez. 
*Bu hastalarda inme riski yüksek olan durumlarda sol atrium appendiks kapatılması önerilebilir.

A27(i): Kirchhof $P$, Benussi $S$, Kotecha D, Ahlsson A, Atar D, Casadei B, Castella M, Diener HC, Heidbuchel H, Hendriks J, Hindricks G, Manolis AS, Oldgren J, Popescu BA, Schotten U, Van Putte B, Vardas P; ESC Scientific Document Group. 2016 ESC Guidelines for the management of atrial fibrillation developed in collaboration with EACTS. Eur Heart J. 2016 Oct 7;37(38):2893-2962. doi:10.1093/eurheartj/ehw210. Epub 2016 Aug 27.

A27(ii): Själander S, Själander A, Svensson PJ, Friberg L. Atrial fibrillation patients do not benefit from acetylsalicylic acid. Europace 2014; 16:631-8.

A27(iii): Olesen JB, Lip GY, Lindhardsen J, Lane DA, Ahlehoff O, Hansen ML, Raunsø J,Tolstrup JS, Hansen PR, Gislason GH, Torp-Pedersen C. Risks of thromboembolism and bleeding with thromboprophylaxis in patients with atrial fibrillation: A net clinical benefit analysis using a 'real world' nationwide cohort study. Thromb Haemost. 2011 0ct;106(4):739-49.

A27(iv): ManningWJ, Singer DE, Lip GYH. Atrial fibrillation: Anticoagulant therapy to prevent thromboembolism. In: UpToDate, Post, TW (Ed), UpToDate, Waltham, MA, 2019 son erişim tarihi 23 Ekim 2019

A28. Dabigatran'ın GFR $<30 \mathrm{~mL} / \mathrm{dk} / 1,73 \mathrm{~m}^{2}$ olan hastalarda kullanımı uygun değildir

${ }^{*}$ GFR $<15 \mathrm{~mL} / \mathrm{dk} / 1,73 \mathrm{~m}^{2}$ ise hiçbir YOAK kullanılmamalıdır.

${ }^{*}$ GFR $\quad 15-30 \mathrm{~mL} / \mathrm{dk} / 1,73 \mathrm{~m}^{2}$ olan olgularda apiksaban, rivaroksaban ve edoksaban için sınırlı kanıt olmakla birlikte genel olarak kullanımları önerilmemektedir.

${ }^{*} G F R<30 \mathrm{~mL} / \mathrm{dk} / 1,73 \mathrm{~m}^{2}$ olan AF olgularında, düşme riski yüksek olan hastalarda veya hayatı tehdit eden kanama geçirmiş hastalarda, kanama riskini göze almak istemeyen hastalarda, INR kontrolünde zorlanacak hastalarda, kötü kontrollü HT olgularında, antikoagülan verilmeyebilir.

*Diyalize giren AF olgularında antikoagülan önerilmez [çok yüksek inme riski olmadıkça: atrial trombüs, geçirilmiş GiA-inme, kapak hastalığı: (orta ciddi MS, protez kapak)]. Antikoagülasyon endike ise varfarin önerilir.

*inme riski yüksek olan AF olgularında, OAK'ların kullanılamaması durumunda sol atrium appendiks kapatılması önerilebilir.

*Edoksaban GFR>95 $\mathrm{mL} / \mathrm{dk} / 1,73 \quad \mathrm{~m}^{2}$ olan olgularda kullanılmamalıdır.

A28(i): Hariharan S, Madabushi R. Clinical pharmacology basis of deriving dosing recommendations for dabigatran in patients with severe renal impairment. J ClinPharmacol 2012; 52(1 Suppl):119S-25S.
A28(ii): Samama MM. Use of low-molecular-weight heparins and new anticoagulants in elderly patients with renal impairment. Drugs Aging 2011; 28(3): 177-93.

A28(iii): By the 2019 American Geriatrics Society Beers Criteria ${ }^{\circledR}$ Update Expert Panel. American Geriatrics Society 2019 Updated AGS Beers Criteria ${ }^{\circledR}$ for Potentially Inappropriate Medication Use in Older Adults. J Am Geriatr Soc. 2019Apr;67(4):674-694.

A28(iv): Kirchhof $P$, Benussi $S$, Kotecha $D$, Ahlsson A, Atar D, Casadei $B$, Castella $M$, Diener $H C$, Heidbuchel $H$, Hendriks J, Hindricks G, Manolis AS, Oldgren J, Popescu BA, Schotten U, Van Putte B, Vardas P; ESC Scientific Document Group. 2016 ESC Guidelines for the management of atrial fibrillation developed in collaboration with EACTS. Eur Heart J. 2016 0ct 7;37(38):2893-2962.

A28(v): Manning WJ, Singer DE, Lip GYH. Atrial fibrillation: Anticoagulant therapy to prevent thromboembolism. In: UpToDate, Post, TW (Ed), UpToDate, Waltham, MA, 2019 son erişim tarihi 28 Ekim 2019

A28(vi): O'Mahony D, O'Sullivan D, Byrne S, O'Connor MN, Ryan C, Gallagher P. STOPP/START criteria for potentially inappropriate prescribing in older people: version 2. Age Ageing. 2015 Mar;44(2):213-8. doi: 10.1093/ageing/afu145. Epub 2014 Oct 16. Review.

A28(vii): Steffel J, Verhamme $P_{1}$ Potpara TS, Albaladejo $P_{1}$ Antz M, Desteghe L, Georg Haeusler K, Oldgren J, Reinecke $\mathrm{H}$, Roldan-Schilling V, Rowell N, Sinnaeve P, Collins R, Camm AJ, Heidbüchel H; ESC Scientific Document Group. The 2018 European Heart Rhythm Association Practical Guide on the use of non-vitamin $\mathrm{K}$ antagonist oral anticoagulants in patients with atrial fibrillation: executive summary. Europace. 2018 Aug 1;20(8):1231-1242.

\#A29. Non-valvular AF'si olup malnütre olan veya besin alımı düzensiz olan hastalarda varfarin kullanımı uygun değildir

A29(i): Onder G, Landi F, Fusco D, Corsonello A, Tosato $M$, Battaglia M, Mastropaolo S, Settanni S, Antocicco M, Lattanzio F. Recommendations to prescribe in complex older adults: results of the CRIteria to assess appropriate Medication use among Elderly complex patients (CRIME) project. Drugs Aging. 2014 Jan;31(1):33-45.Review.

A29(ii): Lurie $Y$, Loebstein R, Kurnik D, Almog S, Halkin $H$. Warfarin and vitamin $\mathrm{K}$ intake in the era of pharmacogenetics. Br J Clin Pharmacol. 2010;70:164-70. 1092.

A29(iii): Sebastian JL, Tresch DD. Use of oral anticoagulants in older patients. Drugs Aging. 2000;16:409-35. 1094.

A29(iv): Ansell J, Hirsh J, Hylek E, Jacobson A, Crowther M, Palareti G. Pharmacology and management of the vitamin K antagonists: American College of Chest Physicians Evidence- 
Based Clinical Practice Guidelines (8th Edition). Chest. 2008 Jun;133(6 Suppl):160S-198S.

A29(v):Vranckx P,Valgimigli M, Heidbuchel H. The Significance of Drug-Drug and Drug-Food Interactions of Oral Anticoagulation. Arrhythm Electrophysiol Rev. 2018 Mar;7(1):55-61.

A30. Ilaçlarını kullanmakta, yönetmekte güçlük çeken (öm. bilişsel bozukluğu olan hastalar) ve yardımcı olacak kimselerin (örn. bakıcı) olmadığı hastalarda varfarin ve digoksin gibi dar terapötik indeksi olan ilaçların kullanımı uygun değildir (hayatı tehdit edebilecek toksisite riski)

A30(i): Onder $G$, Landi $F$, Fusco $D$, Corsonello $A$, Tosato $M$, Battaglia M, Mastropaolo S, Settanni S, Antocicco M, Lattanzio F. Recommendations to prescribe in complex older adults: results of the CRIteria to assess appropriate Medication use among Elderly complex patients (CRIME) project. Drugs Aging. 2014 Jan;31(1):33-45.Review.

A30(ii): van Deelen BA, van den Bemt PM, Egberts TC, van 't Hoff A, Maas HA. Cognitive impairment as determinant for suboptimal control of oral anticoagulation treatment in elderly patients with atrial fibrillation. Drugs Aging.2005;22(4):353-60. Review.

A30(iii): Diug B, Evans S, Lowthian J, Maxwell E, Dooley M, Street A, Wolfe R, Cameron P, McNeil J. The unrecognized psychosocial factors contributing to bleeding risk in warfarin therapy. Stroke. 2011 0ct;42(10):2866-71.

A30(iv): Arlt $S_{1}$ Lindner R, Ro"sler A, von Renteln-Kruse W. Adherence to medication in patients with demen-tia: predictors and strategies for improvement. Drugs Aging. 2008;25:1033-47.

A30(v): Brauner DJ, Muir JC, Sachs GA. Treating nondementia illnesses in patients with dementia. JAMA. 2000;283:3230-5.

A30(vi): Marvanova M. Drug-induced cognitive impairment: Effect of cardiovascular agents. Ment Health Clin. 2016 Jun 29;6(4):201-206. doi: 10.9740/mhc.2016.07.201.

\#A31. Prasugrel'in 75 yaş ve üzeri hastalarda veya GïA/inme geçirmiş olgularda kullanımı uygun değildir

A31(i): Prasugrel: Drug information, Lexicomp Online.Son erişim tarihi 22 Ekim 2019.

A32. Tiklopidin antitrombosit olarak kullanımı uygun değildir (klopidogrel veya tikagrelor veya prasugrel'in daha yüksek etkinliği vardır, daha çok kanıtı vardır ve daha az yan etkisi vardır)

A32(i): Furie KL, Kasner SE, Adams RJ, Albers GW, Bush RL, Fagan SC, Halperin JL, Johnston SC, Katzan I, Kernan WN, Mitchell PH, Ovbiagele B, Palesch YY, Sacco RL, Schwamm LH, WassertheilSmoller S, Turan TN, Wentworth D; American Heart Association Stroke Council, Council on Cardiovascular Nursing, Council on
Clinical Cardiology, and Interdisciplinary Council on Quality of Care and Outcomes Research. Guidelines for the prevention of stroke in patients with stroke or transient ischemic attack: a guideline for healthcare professionals from the American heart association/American stroke association. Stroke 2011; 42(1):227-76.

A32(ii): Porto I, Giubilato S, De Maria GL, Biasucci LM, Crea F. Platelet P2Y12 receptor inhibition by thienopyridines: status and future. Expert Opin Investig Drugs 2009; 18(9):1317-32. Review.

A32(iii): O'Mahony D, O'Sullivan D, Byrne $S$, O'Connor MN, Ryan C, Gallagher P. STOPP/START criteria for potentially inappropriate prescribing in older people: version 2. Age Ageing. 2015 Mar;44(2):213-8. doi: 10.1093/ageing/afu145. Epub 2014 Oct 16. Review.

A32(iv): Li YH, Fang CY, Hsieh IC, Huang WC, Lin TH, Sung SH, Chiu CZ, Wu CJ, Shyu KG, Chang PY, Fang CC, Lu TM, Chen CP, Tai WC, Sheu CC, Wei KC, Huang YH, Wu HM, Hwang JH. 2018 Expert Consensus on the Management of Adverse Effects of Antiplatelet Therapy for Acute Coronary Syndrome in Taiwan. Acta Cardiol Sin. 2018 May;34(3):201-210.

A33. Antitrombotik antiagregan etki için kısa etkili dipiridamol kullanımı uygun değildir (ortostatik hipotansiyon yan etkisi ve daha etkili ajanların bulunması)

A33(i): By the 2019 American Geriatrics Society Beers Criteria ${ }^{\circledR}$ Update Expert Panel. American Geriatrics Society 2019 Updated AGS Beers Criteria ${ }^{\circledR}$ for Potentially Inappropriate Medication Use in Older Adults. J Am Geriatr Soc. 2019Apr;67(4):674-694.

A33(ii): Dipyridamole: Drug information, Lexicomp Online. Son erişim tarihi 22 October 2019.

A34. Yaşam beklentisi düşük olan $(<2$ yıl) veya ileri evre demanslı yaşlılarda primer koruma amaçlı statin kullanımı uygun değildir

A34(i): Onder G, Landi F, Fusco D, Corsonello A, Tosato $M$, Battaglia M, Mastropaolo S, Settanni S, Antocicco M, Lattanzio F. Recommendations to prescribe in complex older adults: results of the CRIteria to assess appropriate Medication use among Elderly complex patients (CRIME) project. Drugs Aging. 2014 Jan;31(1):33-45.Review.

A34(ii): Pignone M. Management of elevated low density lipoprotein-cholesterol (LDL-C) in primary prevention of cardiovascular disease.In: UpToDate, Post, TW (Ed), UpToDate, Waltham, MA, 2019 son erişim tarihi 23 Ekim 2019

A34(iii): Lavan AH, Gallagher P, Parsons C, O'Mahony D. STOPPFrail (Screening Tool of Older Persons Prescriptions in Frail adults with limited life expectancy) consensus validation. Age Ageing. 2017 Jul 1;46(4):600-607. 
A35. Asemptomatik hiperürisemi (gut veya nefrolitiazisi olmayan olgular) için allopurinol başlanması uygun değildir (fayda için kanıt yok, ksantin oksidaz inhibitörleri kullanımıyla yan etki riski) (tedavinin kardiyovasküler riski veya gut hastalığını azalttığına dair kanıt yok)

*Serum ürik asit düzeyi, kadınlarda> $10 \mathrm{mg} / \mathrm{dl}$ ve erkeklerde> $13 \mathrm{mg} / \mathrm{dL}$ ise kronik böbrek hastalığı riski nedeniyle ürik asit düşürücü tedavi önerilebilir.

A35(i): Feig DI, Kang DH, Johnson RJ. Uric acid and cardiovascular risk. N Engl J Med. 2008 Oct 23;359(17):1811-21. doi: 10.1056/ NEJMra0800885. Review.

A35(ii): Poon SH, Hall HA, Zimmermann B. Approach to the treatment of hyperuricemia. Med Health R I. 2009 Nov;92(11):359-62. Review.

A35(iii): Maria Lorenza Muiesan, Claudia Agabiti-Rosei, Anna Paini, Massimo Salvetti. Uric Acid and Cardiovascular Disease: An Update. European Cardiology Review 2016;11(1):54-9.

A35(iv): Luis Ruilope, César Cerezo. Uric acid and cardiovascular risk considered: an update An article from the e-journal of the ESC Council for cardiology Practice. e-Journal of Cardiology Practice. Vol. 10, № 21 - 02 Mar 2012. Available at:

https://www.escardio.org/Journals/E-Journal-of-CardiologyPractice/Volume-10/Uric-Acid-and-Cardiovascular-RiskConsidered-an-Update; son erişim tarihi 28 Ekim 2019

A35(v): Becker MA, Perez-Ruiz F. Pharmacologic uratelowering therapy and treatment of tophi in patients with gout. In: UpToDate, Post, TW (Ed), UpToDate, Waltham, MA, 2019 son erişim tarihi 28 Ekim 2019

A35(vi): Wallace SL, Singer JZ. Therapy in gout. Rheum Dis Clin North Am 1988; 14:441.

A35(vii): Becker MA, Mount DB. Asymptomatic hyperuricemia. In: UpToDate, Post, TW (Ed), UpToDate, Waltham, MA, 2019 son erişim tarihi 23 Ekim 2019

A35(viii): Fessel WJ. Renal outcomes of gout and hyperuricemia. Am J Med. 1979 Jul;67(1):74-82.

\section{B: Santral Sinir Sistemi Kriterleri}

B1. Trisiklik antidepresan kullanımı uygun değildir (yüksek antikolinerjik etki, kognitif kötüleşme, kalp iletim bozukluğu, ortostatik hipotansiyon, üriner retansiyon, prostatizmde kötüleşme, dar açılı glokomda kötüleşme)

B1(i): By the 2019 American Geriatrics Society Beers Criteria $^{\circledR}$ Update Expert Panel. American Geriatrics Society 2019 Updated AGS Beers Criteria ${ }^{\circledR}$ for Potentially Inappropriate Medication Use in Older Adults. J Am Geriatr Soc. 2019Apr;67(4):674-694.
B1(ii): Sultana J, Spina E, Trifirò G. Antidepressant use in the elderly: the role of pharmacodynamics and pharmacokinetics in drug safety. Expert Opin Drug Metab Toxicol. 2015 Jun;11(6):883-92. doi: 10.1517/17425255.2015.1021684. Epub 2015 Mar 3. Review.

B2. SSRI tedavisi başlanacak olgularda paroksetin, fluoksetin ve fluvaksaminin ilk basamakta tercih edilmesi uygun değildir (paroksetinin yüksek antikolinerjik etkisi, fluoksetinin uzun yarı ömrü, fluoksetin ve fluvaksaminin sık ilaç etkileşimi nedeniyle)

B2(i):Canadian Coalition for Seniors' Mental Health. National guidelines for seniors' mental health: The assessment and treatment of depression. Toronto, ON: Canadian Coalition for Seniors' Mental Health; 2006. Available at: https://ccsmh.ca/ wp-content/uploads/2016/03/NatIGuideline_Depression.pdf (son erişim tarihi Ekim 23, 2019).

B2(ii): Bonnie Wiese, MD, MA, FRCPC. Geriatric depression: The use of antidepressants in the elderly. BCMJ, Vol. 53, No. 47, September, 2011, Page(s) 341-347 - Clinical Articles. Available at: http://www.bcmj.org/articles/geriatric-depression-useantidepressants-elderly (son erişim tarihi Ekim 23, 2019).

B3. Yakın geçmişte veya halihazırda anlamlı hiponatremi (serum $\mathrm{Na}<130 \mathrm{mEq} / \mathrm{L}$ ) hikayesi olanlarda SSRi kullanımı uygun değildir (SSRi kullanımı ile artan hiponatremi riski)

*SSRI'Iarla hiponatremi gelişimi için risk faktörleri ileri yaş, kadın cinsiyet, eş zamanlı diüretik kullanımı, düşük vücut ağırlığı ve düşük bazal Na değeridir.

*SSRI başlanan veya doz artırımı olan hastalar hiponatremi klinik bulguları açısından bilgilendirilmelidir. Illk 4 hafta en riskli zamandır.

*Hiponatremi riski olan hastalarda, SSRI yerine mirtazapin veya bupropion tercih edilmesi uygun olabilir.

B3(i): Jacob S, Spinler SA. Hyponatremia associated with selective serotonin-reuptake inhibitors in older adults. Ann Pharmacother 2006; 40(9):1618-22. Review.

B3(ii): Draper B, Berman K. Tolerability of selective serotonin reuptake inhibitors: issues relevant to the elderly. Drugs Aging 2008; 25(6): 501-19. Review.

B3(iii): By the 2019 American Geriatrics Society Beers Criteria ${ }^{\circledR}$ Update Expert Panel. American Geriatrics Society 2019 Updated AGS Beers Criteria ${ }^{\circledR}$ for Potentially Inappropriate Medication Use in Older Adults. J Am Geriatr Soc. 2019Apr;67(4):674-694.

B3(iv): O'Mahony D, O'Sullivan D, Byrne S, O'Connor MN, Ryan C, Gallagher P. STOPP/START criteria for potentially inappropriate prescribing in older people: version 2. Age Ageing. 2015 Mar;44(2):213-8. doi: 10.1093/ageing/afu145. Epub 2014 Oct 16. Review. 
B3(v): Fabian TJ, Amico JA, Kroboth PD, et al. Paroxetineinduced hyponatremia in older adults: a 12-week prospective study. Arch Intern Med. 2004;164: 327-332.

B3(vi): Fiske A,Wetherell JL, Gatz M. Depression in older adults. Annu Rev Clin Psychol. 2009;5:363-389.

B3(vii): De Picker L,VanDen Eede F, Dumont G, et al.Antidepressants and the risk of hyponatremia: a class-byclass review of literature. Psychosomatics. 2014;55:536-547.

B3(viii): Leth-Møller KB, Hansen AH, Torstensson M, Andersen SE, Ødum L, Gislasson G,Torp-Pedersen C, Holm EA. Antidepressants and the risk of hyponatremia: a Danishregister-based population study. BMJ Open. 2016 May 18;6(5):e011200.

\#B4. Kontrolsüz HT varlığında SNRi kullanımı uygun değildir

*Venlafaksin'in HT yan etkisi duloksetin'e göre daha belirgindir.

*Venlafaksinin HT yan etkisi >300 mg/gün dozlarda daha belirgindir.

B4(i): Breeden M, Brieler J, Salas J, Scherrer JF. Antidepressants and Incident Hypertension in Primary Care Patients. J Am Board Fam Med. 2018 Jan-Feb;31(1):22-28.

B4(ii): Taylor D, Lenox-Smith A, Bradley A. A review of the suitability of duloxetine and venlafaxine for use in patients with depression in primary care with a focus on cardiovascular safety, suicide and mortality due to antidepressant overdose. Ther Adv Psychopharmacol. 2013 Jun;3(3):151-61.

B4(iii): Thase ME. Effects of venlafaxine on blood pressure: a meta-analysis of original data from 3744 depressed patients. J Clin Psychiatry. 1998 0ct;59(10):502-8.

B5. GFR $<30 \mathrm{~mL} / \mathrm{dk} / 1,73 \mathrm{~m}^{2}$ olanlarda duloksetin kullanımı uygun değildir (artmış GiS yan etkisi) *Böbrek yetmezliği durumunda diğer yaygın antidepresanların kullanımı:

Sitalopram ve essitalopram: hafif-orta böbrek yetersizliğinde doz ayarlaması gerekli değildir. Ciddi (GFR<20 mL/dk/1.73 $\mathrm{m}^{2}$ ) böbrek yetersizliğinde doz ayarlaması gerekli değildir ancak dikkatle kullanılmalıdır.

Sertralin: böbrek yetersizliğinde doz ayarlaması gerekli değildir.

Paroksetin: GFR<30 mL/dk/1,73 $\mathrm{m}^{2}$ ise hızlı salınımlı tabletlerde maksimum doz 40 mg, uzatılmış salınımlı preperatlarda maksimum doz: 50 mg/gün.

Venlafaksin: GFR< $30 \mathrm{~mL} / \mathrm{dk} / 1,73 \mathrm{~m}^{2}$ ise uzatılmış salınımlı preperatlarda doz $\% 50$ azaltılmalıdır; hızlı salınımlı preperatlarda GFR 10-75 mL/dk/1,73 $\mathrm{m}^{2}$ ise doz \%25 azaltılmalıdır.

Mirtazapin: böbrek yetersizliğinde doz ayarlaması gerekli değildir ancak orta-ciddi böbrek yetersizliğinde dikkatle kullanılmalıdır.

Agomelatin: böbrek yetersizliğinde doz ayarlaması gerekli değildir.
Vortioksetin: böbrek yetersizliğinde doz ayarlaması gerekli değildir.

B5(i): By the 2019 American Geriatrics Society Beers Criteria ${ }^{\circledR}$ Update Expert Panel. American Geriatrics Society 2019 Updated AGS Beers Criteria ${ }^{\circledR}$ for Potentially Inappropriate Medication Use in Older Adults. J Am Geriatr Soc. 2019Apr;67(4):674-694.

B5(ii): Vortioxetine: Drug information, Lexicomp Online. Son erişim tarihi 22 Ekim 2019.

B5(iii): Paroxetine: Drug information, Lexicomp Online. Son erişim tarihi 22 Ekim 2019.

B5(iv): Duloxetine: Drug information, Lexicomp Online. Son erişim tarihi 22 Ekim 2019.

B5(v): Sertraline: Drug information, Lexicomp Online. Son erişim tarihi 22 Ekim 2019.

B5(vi): Mirtazapine: Drug information, Lexicomp Online. Son erişim tarihi 22 Ekim 2019.

B5(vii): Venlafaxine: Drug information, Lexicomp Online. Son erişim tarihi 22 Ekim 2019.

B5(viii): Escitalopram: Drug information, Lexicomp Online. Son erişim tarihi 22 Ekim 2019.

B5(ix): Citalopram: Drug information, Lexicomp Online. Son erişim tarihi 22 Ekim 2019.

B6. GFR $<60 \mathrm{~mL} / \mathrm{dk} / 1,73 \mathrm{~m}^{2}$ olması durumunda pregabalin ve gabapentin'in doz azaltımı yapılmadan kullanımı uygun değildir

B6(i): By the 2019 American Geriatrics Society Beers Criteria ${ }^{\circledR}$ Update Expert Panel. American Geriatrics Society 2019 Updated AGS Beers Criteria ${ }^{\circledR}$ for Potentially Inappropriate Medication Use in Older Adults. J Am Geriatr Soc. 2019Apr;67(4):674-694.

B6(ii):Pregabalin: Drug information, Lexicomp Online. Son erişim tarihi 22 Ekim 2019.

B7. Deliryum veya demansı olanlarda yüksek antikolinerjik etkili ilaçların (amitriptilin, paroksetin, disiklomin, L-hiyosiyamin, tioridazin, klorpromazin, klozapin, olanzapin, üriner antimuskarinikler, $\mathrm{H} 1$ reseptör blokerleri-özellikle 1. jenerasyon $\mathrm{H} 1$ reseptör blokerleri (difenhidramin, siproheptadin, feniramin), H2 reseptör blokerlerinin kullanımı uygun değildir (kognitif kötüleşme riski)

*Parkinson demansı ve Lewy cisimcikli demans gibi ekstrapiramidal sistem bulguları (parkinsonizm bulguları) olan hastalarda demansın/deliryumun ciddi davranışsal semptomlarının tedavisi için klinik pratikte klozapin kullanımı gerekebilmektedir. Bu durumda mümkün olan en kısa süreli, en düşük dozda ve yakın kognitif fonksiyon takibi ile kullanılmalıdır.

*Parkinson demansı ve Lewy cisimcikli demans gibi ekstrapiramidal sistem bulguları (parkinsonizm bulguları) olan 
hastalarda ciddi davranışsal sepmtomlar nedeniyle nöroleptik kullanımı gerekli olması durumunda klozapin tedavisinden önce ilk basamakta ketiapin tedavisinin kullanımı uygundur.

*Tedavi düşünüldüğünde, Klozapin/ketiapin tedavileri $12,5 \mathrm{mg}$ dozunda başlanarak, yan etkiler yakından izlenmeli, lüzum halinde 12,5-25 mg dozlarında artırılmalıdır. Semptom kontrolü sağlandıktan sonra birkaç hafta içinde azaltılarak kesilmesi denenmelidir.

B7(i): Pagoria D, O'Connor RC, Guralnick ML. Antimuscarinic drugs: review of the cognitive impact when used to treat overactive bladder in elderly patients. Curr Urol Rep 2011; 12 (5): 351-7. Review.

B7(ii): Gerretsen P, Pollock BG. Drugs with anticholinergic properties: a current perspective on use and safety. Expert Opin Drug Saf 2011; 10(5): 751-65. Review.

B7(iii): O'Mahony D, O'Sullivan D, Byrne S, O'Connor MN, Ryan C, Gallagher P. STOPP/START criteria for potentially inappropriate prescribing in older people: version 2. Age Ageing. 2015 Mar;44(2):213-8. doi: 10.1093/ageing/afu145. Epub 2014 Oct 16. Review.

B7(iv): McKeith IG, Boeve BF, Dickson DW, et al., Diagnosis and management of dementia with Lewy bodies: Fourth consensus report of the DLB Consortium. Neurology. 2017 Jul 4;89(1):88100.

B7(v): By the 2019 American Geriatrics Society Beers Criteria ${ }^{\circledR}$ Update Expert Panel. American Geriatrics Society 2019 Updated AGS Beers Criteria ${ }^{\circledR}$ for Potentially Inappropriate Medication Use in Older Adults. J Am Geriatr Soc. 2019 Apr;67(4):674-694.

B8. Parkinson Hastalığı'nın tedavisinde antikolinerjik ajan kullanımı uygun değildir (artmış yan etki riski; daha etkin ve daha az yan etkisi olan ilaç seçenekleri var)

B8(i): Spindler MA, Tarsy D.Initial pharmacologic treatment of Parkinson disease. In: UpToDate, Post, TW (Ed), UpToDate, Waltham, MA, 2019 Son erişim tarihi 23 Ekim 2019.

B8(ii): Cummings JL. Behavioral complications of drug treatment of Parkinson's disease. J Am Geriatr Soc. 1991 Jul;39(7):708-16. Review.

B9. Nöroleptiklerin ekstrapiramidal yan etkilerini tedavi etmek için antikolinerjik ilaç kullanımı uygun değildir (antikolinerjik toksisitesi riski)

B9(i): Heinik J. Effects of trihexyphenidyl on MMSE and CAMCOG scores of medicated elderly patients with schizophrenia. Int Psychogeriatr 1998; 10(1): 103-8.

B9(ii): Drimer T, Shahal B, Barak Y. Effects of discontinuation of long-term anticholinergic treatment in elderly schizophrenia patients. Int ClinPsychopharmacol 2004; 19(1):27-9.
B9(iii): O'Mahony D, O'Sullivan D, Byrne S, O'Connor MN, Ryan C, Gallagher P. STOPP/START criteria for potentially inappropriate prescribing in older people: version 2. Age Ageing. 2015 Mar;44(2):213-8. doi: 10.1093/ageing/afu145. Epub 2014 Oct 16. Review.

B9(iv): By the 2019 American Geriatrics Society Beers Criteria ${ }^{\circledR}$ Update Expert Panel. American Geriatrics Society 2019 Updated AGS Beers Criteria ${ }^{\circledR}$ for Potentially Inappropriate Medication Use in Older Adults. J Am Geriatr Soc. 2019 Apr;67(4):674-694.

B10. Demans hastalarında davranışsal ve psikolojik semptomların giderilmesinde ilaç dışı tedavilerin etkisiz kaldığı ve semptomların ciddi olduğu durumlar hariç nöroleptiklerin/ antipsikotiklerin kullanımı uygun değildir (artmış inme, kalp yetersizliği, pnömoni-infeksiyon, ölüm riski)

*Demans hastalarında davranışsal ve psikolojik semptomların giderilmesinde ilaç dışı tedavilerin etkisiz kaldığı ve semptomların ciddi olduğu durumlarda nöroleptikle/antipsikotikler kullanılabilir ancak bu durumda semptom kontrolünü sağlayan en düşük dozda ve en kısa süre ile kullanılmalıdır.

*Demans hastalarında davranışsal ve psikolojik semptomların giderilmesinde öncelikli yaklaşım optimum demans tedavisinin (ChEi/memantin) verilmesidir. Takiben seçilmiş SSRi'lar (özellikle sitalopram) denenebilir.

*Sertralin, trazadon ve melatoninin demans hastalarında davranışsal ve psikolojik semptomların giderilmesinde etkinliği ile ilgili çelişkili bilgiler vardır.

B10(i): Desmidt T, Hommet C, Camus V. Pharmacological treatments of behavioral and psychological symptoms of dementia in Alzheimer's disease: role of acetylcholinesterase inhibitors and memantine. Geriatr Psychol Neuropsychiatr Vieil. 2016 Sep 1;14(3):300-6. doi: 10.1684/pnv.2016.0621. Review.

B10(ii): Campbell N, Ayub A, Boustani MA, Fox C, Farlow M, Maidment I, Howards R. Impact of cholines-terase inhibitors on behavioral and psychological symptoms of Alzheimer's disease: a meta-analysis. Clin Interv Aging. 2008;3(4):719-28.

B10(iii): Tible OP, Riese F, Savaskan E, von Gunten A. Best practice in the management of behavioural and psychological symptoms of dementia. Ther Adv Neurol Disord. 2017 Aug;10(8):297-309. doi: 10.1177/1756285617712979. Epub 2017 Jun 19. Review.

B10(iv): Press D, Alexander M.Management of neuropsychiatric symptoms of dementia. In: UpToDate, Post, TW (Ed), UpToDate, Waltham, MA, 2019 Son erişim tarihi 23 Ekim 2019.

B10(v): Corbett A, Smith J, Creese B, Ballard C. Treatment of behavioral and psychological symptoms of Alzheimer's disease. Curr Treat Options Neurol. 2012 Apr;14(2):113-25. doi: 10.1007/ s11940-012-0166-9. 
B10(vi): Whitney M. Buterbaugh, Todd Jamrose, Jonathon Lazzara, Lindsay Honaker, and Christopher J. Thomas (2014) Review of antidepressants in the treatmentof behavioral and psychiatric symptoms in dementia (BPSD)Mental Health Clinician: July 2014, Vol. 4, pp 183-188.

B10(vii): Henry G, Williamson D, Tampi RR. Efficacy and tolerability of antidepressants in the treatment of behavioral and psychological symptoms of dementia, a literature review of evidence. Am J Alzheimers Dis Other Demen. 2011 May;26(3):169-83. doi: 10.1177/1533317511402051. Epub 2011 Mar 23. Review.

B10(viii): Seitz DP, Adunuri N, Gill SS, Gruneir A, Herrmann $\mathrm{N}$, Rochon P. Antidepressantsfor agitation and psychosis in dementia. Cochrane DatabaseSyst Rev. 2011 Feb16;(2):CD008191. doi: 10.1002/14651858.CD008191.pub2. Review.

B10(ix): Hersch EC, Falzgraf S. Management of the behavioral and psychological symptoms of dementia. Clin Interv Aging. 2007;2(4):611-21.

B10(x): Sultzer DL, Gray KF, Gnay I, Berisford MA, Mahler ME. A double-blind comparison of trazodone and haloperidol for treatment of agitation in patients with dementia. Am J Geriatr Psychiatry. 1997 Winter;5(1):60-9.

B10(xi): Pazan F, Weiss C, Wehling M; FORTA. The EURO-FORTA (Fit fOR The Aged) List: International Consensus Validation of a Clinical Tool for Improved Drug Treatment in Older People. Drugs Aging. 2018 Jan;35(1):61-71.

B10(xii): Martinon-Torres G, Fioravanti M, Grimley EJ. Trazodone for agitation indementia. Cochrane Database Syst Rev. 2004 Oct 18;(4):CD004990. Review.

B10(xiii): Alagiakrishnan K. Melatonin based therapies for delirium and dementia. Discov Med. 2016 May;21(117):363-71. Review.

B10(xiv): De Jonghe A, Korevaar JC, Van Munster BC, De Rooij SE. Effectiveness of melatonin treatment on circadian rhythm disturbances in dementia. Are there implications for delirium? A systematic review. Int J Geriatr Psychiatry 2010; 25(12):1201- 1208.

B10(xv): Jansen SL, Forbes DA, Duncan V, Morgan DG: Melatonin for cognitive impairment. Cochrane Database Syst Rev 2006; Jan 25 (1):CD003802. Review.

B10(xvi): Rabins P, Rovner B, Rummans T, Schneider L, Tariot P. Guideline Watch (October 2014): Practice Guideline for the Treatment of Patients with Alzheimer's Disease and Other Dementias. Available at: https://psychiatryonline.org/pb/assets/ raw/sitewide/practice_guidelines/guidelines/alzheimerwatch. pdf (son erişim tarihi 28 Ekim 2019)

B10(xvii): O'Mahony D, O'Sullivan D, Byrne S, O'Connor MN, Ryan C, Gallagher P. STOPP/START criteria for potentially inappropriate prescribing in older people: version 2. Age Ageing. 2015 Mar;44(2):213-8. doi: 10.1093/ageing/afu145. Epub 2014 Oct 16. Review.

B11. Nöroleptiklerin/antipsikotiklerin hipnotik amaçı kullanımı uygun değildir (artmış konfüzyon, hipotansiyon, ekstrapiramidal yan etkiler, düşme riski)

*Yaşlıda insomni tedavisinde öncelikle uyku hijyeni düzenlemesi ve bilişsel davranışcı terapiler uygulanmalıdır.

*Yaşlıda insomni tedavisinde farmakolojik tedaviye ihtiyaç duyulması halinde melatonin, melatonin reseptor agonisti ramelteon kullanılabilir. Eşlik eden depresyon varsa sedatif etkili antidepresanların (mirtazapin, trazadon, agomelatin) kullanımı değerlendirilebilir.

B11(i): British National Formulary vol. 76, September 2018-March 2019: $p 28$.

B11(ii): RD McEvoy, KS Nyfort-Hansen. Sleep disorders in the elderly: the pros and cons of prescribing. In: Prescribing for Elderly Patients, eds. S. Jackson, P. Jansen, A. Mangoni. WileyBlackwell 2009, pp 45-52.

B11(iii): Alexopoulos GS, Streim J, Carpenter D, Docherty JP. Expert Consensus Panel for Using Antipsychotic Drugs in Older Patients. Using antipsychotic agents in older patients. J Clin Psychiatry 2004; 65 Suppl 2:5-99; discussion 100-102; quiz 103-4. Review.

B11(iv): O'Mahony D, O'Sullivan D, Byrne S, O'Connor MN, Ryan C, Gallagher P. STOPP/START criteria for potentially inappropriate prescribing in older people: version 2. Age Ageing. 2015 Mar;44(2):213-8. doi: 10.1093/ageing/afu145. Epub 2014 Oct 16. Review.

B11(v): Schroeck JL, Ford J, Conway EL, Kurtzhalts KE, Gee ME, Vollmer KA, Mergenhag KA. Review of Safety and Efficacy of Sleep Medicines in Older Adults. Clin Ther. 2016 Nov;38(11):23402372.

B12. Parkinsonizm veya Lewy cisimcikli demansı olanlarda nöroleptiklerin/antipsikotiklerin (ketiapin veya klozapin hariç) kullanımı uygun değildir (ağır ekstrapiramidal semptom riski)

B12(i): Mena MA, de Yébenes JG. Drug-induced parkinsonism. Expert Opin Drug Saf 2006; 5(6):759-71. Review.

B12(ii): Eng ML, Welty TE. Management of hallucinations and psychosis in Parkinson's disease. Am J Geriatr Pharmacother 2010; 8(4):316-30. Review.

B12(iii): O'Mahony D, O'Sullivan D, Byrne S, O'Connor MN, Ryan C, Gallagher P. STOPP/START criteria for potentially inappropriate prescribing in older people: version 2. Age Ageing. 2015 Mar;44(2):213-8. doi: 10.1093/ageing/afu145. Epub 2014 Oct 16. Review. 
B12(iv): McKeith IG, Boeve BF, Dickson DW, Halliday G, Taylor JP, Weintraub D, Aarsland D, Galvin J, Attems J, Ballard CG, Bayston A, Beach TG, Blanc F, Bohnen N, Bonanni L, Bras J, Brundin P, Burn D, Chen-Plotkin A, Duda JE, El-Agnaf O, Feldman $H$, Ferman TJ, Ffytche D, Fujishiro H, Galasko D, Goldman JG, Gomperts SN, Graff-Radford NR, Honig LS, Iranzo A, Kantarci K, Kaufer D, Kukull W, Lee VMY, Leverenz JB, Lewis S, Lippa C, Lunde A, Masellis M, Masliah E, McLean P, Mollenhauer B, Montine TJ, Moreno E, Mori E, Murray M, O'Brien JT, Orimo S, Postuma RB, Ramaswamy $S$, Ross OA, Salmon DP, Singleton A, Taylor A, Thomas A, Tiraboschi P, Toledo JB, Trojanowski JQ, Tsuang D, Walker Z, Yamada M, Kosaka K. Diagnosis and management of dementia with Lewy bodies: Fourth consensus report of the DLB Consortium. Neurology. 2017 Jul 4;89(1):88100.

B13. Düşme riski yüksek olan hastalarda nöroleptiklerin/ antipsikotiklerin (ekstrapiramidal yan etki), benzodia-zepinlerin (sedasyon, denge bozukluğu) ve Z tipi hipnotiklerin (ör. zopiklon, zolpidem, zaleplon) (gün içerisinde uzamış sedasyona, ataksi) kullanımı uygun değildir

*Genel olarak bu grup ilaçlar yaşlılarda düşme riskini artıran ilaçlardır. Yaşlılarda kullanımından mümkün mertebe kaçınılmalıdır.

B13(i): Huang AR, Mallet L, Rochefort CM, Eguale T, Buckeridge DL, Tamblyn R. Medication-related falls in the elderly: causative factors and preventive strategies. Drugs Aging 2012; 29(5): 35976. Review.

B13(ii): Woolcott JC, Richardson KJ, Wiens MO, Patel B, Marin J, Khan KM, Marra CA. Meta-analysis of the impact of 9 medication classes on falls in elderly persons. Arch Intern Med 2009; 169(21): 1952-60. Review. Erratum in: Arch Intern Med 2010 Mar 8;170(5):477.

B13(iii): Hill KD, Wee R. Psychotropic drug-induced falls in older people: a review of interventions aimed at reducing the problem. Drugs Aging 2012; 29(1): 15-30. Review.

B13(iv): Mets MA, Volkerts ER, Olivier B, Verster JC. Effect of hypnotic drugs on body balance and standing steadiness. Sleep Med Rev 2010; 14(4): 259-67.

B13(v): Shuto $H_{1}$ Imakyure 0, Matsumoto J, Egawa T, Jiang $Y$, Hirakawa M, Kataoka $Y$, Yanagawa T. Medication use as a risk factor for inpatient falls in an acute care hospital: a casecrossover study. Br J Clin Pharmacol 2010; 69(5): 535-42.

B13(vi): O'Mahony D, O'Sullivan D, Byrne S, O'Connor MN, Ryan C, Gallagher P. STOPP/START criteria for potentially inappropriate prescribing in older people: version 2. Age Ageing. 2015 Mar;44(2):213-8. doi: 10.1093/ageing/afu145. Epub 2014 Oct 16. Review.
B14. Benzodiazepin'lerin 4 haftadan uzun süre kullanımı uygun değildir (uzamış sedasyon, konfüzyon, denge bozukluğu, düşme, trafik kazaları riski)

${ }^{*} G e n e l$ olarak, yüksek yan etki potansiyelleri nedeniyle, benzodiazepin kullanımından kaçınılmalıdır.

*Kısa etkili benzodiazepinler klinik endikasyon varlığında dikkatle ve kısa süreli (<4 hafta) kullanılabilir (örn. demans ile ilişkili ajitasyonda lorazepam verilebilir).

*Seçilmiş hastalarda başka ilaçlarla kontrol altına alınamayan REM uykusu davranış bozukluğu için uzun etkili benzodiazepinlerden klonazepam verilebilir ancak bu durumda da yakın klinik takip edilmelidir.

*2 hafta ve üzeri kullanılan bütün benzodiazepinler "benzodiazepin geri çekilme sendromuna" yol açmamak için birden değil kademeli azaltılarak kesilmelidir.

B14(i): Madhusoodanan S, Bogunovic 0J. Safety of benzodiazepines in the geriatric population. Expert Opin Drug Saf 2004; 3(5): 485-93. Review.

B14(ii): Glass J, Lanctôt KL, Herrmann N, Sproule BA, Busto UE. Sedative hypnotics inolder people with insomnia: meta-analysis of risks and benefits. BMJ 2005; 331(7526): 1169. Review.

B14(iii): Barker MJ, Greenwood KM, Jackson M, Crowe SF. Cognitive effects of long-term benzodiazepine use: a metaanalysis. CNS Drugs 2004; 18(1):37-48.

B14(iv): Model DG, Berry DJ. Effects of chlordiazepoxide in respiratory failure due to chronic bronchitis. Lancet 1974; 2(7885): 869-70.

B14(v): Hak E, Bont J, Hoes AW, Verheij TJ. Prognostic factors for serious morbidity and mortality from community-acquired lower respiratory tract infections among the elderly in primary care. Fam Pract 2005; 22(4): 375-80.

B14(vi): O'Mahony D, O'Sullivan D, Byrne S, O'Connor MN, Ryan C, Gallagher P. STOPP/START criteria for potentially inappropriate prescribing in older people: version 2. Age Ageing. 2015 Mar;44(2):213-8. doi: 10.1093/ageing/afu145. Epub 2014 Oct 16. Review.

B14(vii): Kotagal V, Bohnen N I. Parkinson Disease and Related Disorders in Hazzards Geriatric Medicine and Gerontology Seventh edition. Eds. Halter J B, Ouslander J G, Studenski S, High K P, Asthana S, Ritchie C S, Supiano M A,; 2017 page 1431.

B14(viii): British National Formulary vol. 76, September 2018-March 2019: p 28.

B15. Benzodiazepinlerin akut ve kronik solunum yetersizliğinde $\left(\mathrm{PO}_{2}<60 \mathrm{mmHg}\right.$ ve/veya $\left.\mathrm{PCO}_{2}>50 \mathrm{mmHg}\right)$ kullanımı uygun değildir (solunum yetersizliğinde artış riski) 
B15(i): Model DG, Berry DJ. Effects of chlordiazepoxide in respiratory failure due to chronic bronchitis. Lancet 1974; 2(7885): 869-70.

B15(ii): Hak E, Bont J, Hoes AW, Verheij TJ. Prognostic factors for serious morbidity and mortality from community-acquired lower respiratory tract infections among the elderly in primary care. Fam Pract 2005; 22(4): 375-80.

B15(iii): O'Mahony D, O'Sullivan D, Byrne S, O'Connor MN, Ryan C, Gallagher P. STOPP/START criteria for potentially inappropriate prescribing in older people: version 2. Age Ageing. 2015 Mar;44(2):213-8. doi: 10.1093/ageing/afu145. Epub 2014 Oct 16. Review.

B15(iv): Overdyk FJ, Dowling O, Marino J, Oiu J, Chien HL, Erslon M, Morrison N, Harrison B, Dahan A, Gan TJ. Association of Opioids and Sedatives with Increased Risk of In-Hospital Cardiopulmonary Arrest from an Administrative Database. PLoS One. 2016 Feb 25;11(2):e0150214.

B16. Persistan bradikardi (<50/dk), 2. veya 3. derece kalp bloğu veya açıklanamayan senkopu olan hastalarda, uzamış QTc olan hastalarda (kadında> 470 msn, erkekte> 450 msn) ChEi kullanımı uygun değildir (kalp iletim defekti, senkop, yaralanma riski)

*Nabiz: 50-60/dk olan ve asemptomatik olan hastalarda ChEi başlanabilir. Tedavi başlangıcı veya doz artırımından 1 hafta sonra nabız sayısı ve semptom açısından kontrol edilmelidir.

${ }^{*}$ Eş zamanlı hız kısıtlayıcı ilaç alanlarda nabız< 50/dk değilse ve semptom yok ise, dikkatle kullanılabilir. ChEi'leri $L B B B$ veya AF olan hastalarda dikkatli kullanılmalıdır, hastalar takip edilmelidir.

${ }^{*}$ ChEi'leri KOAH veya astımı olan hastalarda dikkatle kullanılmalıdır. Bronkospazmı agreve edebilir, takip edilmelidir.

${ }^{*}$ ChEi'leri gastik ülser hikayesi olanlarda ve nonsteroid anti inflamatuar ilaç kullananlarda dikkatle kullanılmalıdır. Bu hastalar gastrointestinal kanama açısından takip edilmelidir.

B16(i): Salarbaks AM, Boomkamp-Snoeren CM, van Puijenbroek $E$, Jansen PA, van Marum RJ. [Cardiac effects of cholinesterase inhibitors: a reason for restraint?]. Tijdschr Gerontol Geriatr 2009; 40(2):79-84.

B16(ii): Fisher A.A. and Davis M.W. Prolonged OT interval, syncope, and delirium with galantamine Ann Pharmacother 2008 42; 2: 278-283.

B16(iii): Suleyman T, Tevfik P, Abdulkadir G. and Ozlem S. Complete atrioventricular block and ventricular tachyarrhythmia associated with donepezil. Emerg Med J 2006; 23(8): 641-2.

B16(iv): Bordier P, Lanusse S, Garrigue S, Reynard C, Robert $F$, Gencel $L$ and Lafitte A. Causes of syncope in patients with Alzheimer's disease treated with donepezil. Drugs Aging 2005; 22(8): 687-694.
B16(v): O'Mahony D, O'Sullivan D, Byrne S, O'Connor MN, Ryan C, Gallagher P. STOPP/START criteria for potentially inappropriate prescribing in older people: version 2. Age Ageing. 2015 Mar;44(2):213-8. doi: 10.1093/ageing/afu145. Epub 2014 Oct 16. Review.

B16(vi): Helou R, Rhalimi M. Cholinesterase inhibitors and the risk of pulmonary disorders in hospitalized dementia patients. J Popul Ther Clin Pharmacol. 2010 Fall;17(3):e379-89. Epub 2010 Oct 26.

B16(vii): Thavorn K, Gomes T, Camacho X, Yao Z, Juurlink D, Mamdani M. Upper gastrointestinal bleeding in elderly adults with dementia receiving cholinesterase inhibitors: a populationbased cohort study. J Am Geriatr Soc. 2014 Feb;62(2):382-4.

B16(viii): Rivastigmine: Drug information, Lexicomp Online. Son erişim tarihi 22 Ekim 2019.

B17. Esansiyel tremor tedavisi için levodopa veya dopamin agonistlerinin kullanımı uygun değildir (kanıtlanmış etkinliği yoktur)

B17(i): Zesiewicz TA, Elble RJ, Louis ED, Gronseth GS, Ondo WG, Dewey RB Jr, Okun MS, Sullivan KL, Weiner WJ. Evidence-based guideline update- treatment of essential tremor-report of the Quality Standards sub-committee of the American Academy of Neurology. Neurology 2011; 77(19):1752-5. Review.

B17(ii): Deuschl G, Raethjen J, Hellriegel H, Elble R. Treatment of patients with essential tremor. Lancet Neurol 2011; 10(2): 148-61. Review.

B17(iii): O'Mahony D, O'Sullivan D, Byrne S, O'Connor MN, Ryan C, Gallagher P. STOPP/START criteria for potentially inappropriate prescribing in older people: version 2. Age Ageing. 2015 Mar;44(2):213-8. doi: 10.1093/ageing/afu145. Epub 2014 Oct 16. Review.

B18. Vertigo tedavisinde betahistin, trimetazidin, dimenhidrinat gibi ilaçların aralıksız ve uzun süreli olarak kullanımı uygun değildir (kanıta dayalı faydalı etkilerinin olmaması)

B18(i): FurmanJM, Barton JJS.Treatment of vertigo. In: UpToDate, Post, TW (Ed), UpToDate, Waltham, MA, 2019 Son erişim tarihi 28 Ekim 2019.

B18(ii): Aman Nanda, Richard W. Besdine. Dizziness in Hazzards Geriatric Medicine and Gerontology Seventh edition. Eds. Halter J B, Ouslander J G, Studenski S, High K P, Asthana S, Ritchie C S, Supiano M A,; 2017 page 1086.

\#B19. Sinnarizin kullanımı uygun değildir (ekstrapiramidal yan etkiler, sınırlı faydalanım)

B19(i): Shin HW. Drug-induced parkinsonism. J Clin Neurol. 2012 Mar;8(1):15-21. 
B20. Pirasetam kullanımı miyoklonik konvülzüyon tedavisi dışında uygun değildir (kanıtlanmış klinik etkinlik yok, maliyet yükü ve yan etki potansiyeli nedeniyle)

*Pirasetam tedavisinden semptomatik fayda görüldüğüne inanılan hastalarda, kar-zarar dengesi göz önünde bulundurularak kullanılabilir.

*Pirasetamın inme sonrası akut afazi tedavisinde sınırlı yararı olabileceğine dair çalışmalar mevcuttur.

B20(i): Piracetam for Aphasia in Post-stroke Patients: A Systematic Review and Meta-analysis of Randomized Controlled Trials. CNS Drugs. 2016 Jul;30(7):575-87.

B20(ii): Wright CB. Treatment and prevention of vascular dementia. In: UpToDate, Post, TW (Ed), UpToDate, Waltham, MA, 2019 Son erişim tarihi 28 Ekim 2019.

B20(iii): Flicker L, Grimley Evans G. Piracetam for dementia or cognitive impairment. Cochrane Database Syst Rev. 2001;(2):CD001011. Review.

B21. Epilepsinin kronik tedavisinde karbamazepin, fenitoin, fenobarbital veya valproat'ın ilk basamakta kullanımı uygun değildir (vitamin D üzerine olumsuz etkileri, enzim indüksiyonu, düşme riski nedeniyle; ayrıca daha güvenli alternatifleri var)

*Yaşlılarda kronik epilepsi tedavisinde levatiresetam, Iamotrijin, gabapentin gibi yeni ajanlar tercih edilebilir.

B21(i): Snih T. Seizures and epilepsy in older adults: Treatment and prognosis. In: UpToDate, Post, TW (Ed), UpToDate, Waltham, MA, 2019 Son erişim tarihi 23 Ekim 2019.

B21 (ii): Vestergaard P, Rejnmark L, Mosekilde L. Fracture risk associated with use of antiepileptic drugs. Epilepsia. 2004 Nov;45(11):1330-7.

B21 (iii): Vestergaard P, Tigaran S, Rejnmark L, Tigaran C, Dam $M$, Mosekilde L. Fracture risk is increased in epilepsy. Acta Neurol Scand. 1999 May;99(5):269-75.

B21 (iv): Koppel BS, Harden CL, Nikolov BG, Labar DR. An analysis of lifetime fractures in women with epilepsy. Acta Neurol Scand. 2005 Apr;111(4):225-8.

B21(v): Nakken KO, Sætre E, Markhus R, Lossius MI. [Epilepsy in the elderly]. Tidsskr Nor Laegeforen. 2013 Mar 5;133(5):528-31.

B22. Epilepsi hastalarında tramadol, nöroleptikler/antipsikotikler (klozapin, olanzapin, klorpromazin, tioridazin), bupropion ve maprotilin kullanımı uygun değildir.

B22(i): By the American Geriatrics Society 2015 Beers Criteria Update Expert Panel.American Geriatrics Society 2015 Updated Beers Criteria for Potentially Inappropriate Medication Use in Older Adults. J Am Geriatr Soc. 2015 Nov;63(11):2227-46.
B22(ii): Habibi $M$, Hart $F$, Bainbridge J. The Impact of Psychoactive Drugs on Seizures and Antiepileptic Drugs. Curr Neurol Neurosci Rep. 2016 Aug;16(8):71.

B23. Öncesinde konvülzüyon geçirmemiş bir hastada iskemik/ hemorajik inme varlığı nedeniyle nöbet proflaksisi için antiepileptik tedavi kullanımı uygun değildir

B23(i): Hemphill JC 3rd, Greenberg SM, Anderson CS, Becker K, Bendok BR, Cushman M, Fung GL, Goldstein JN, Macdonald L, Mitchell PH, Scott PA, Selim MH, Woo D; American Heart Association Stroke Council; Council on Cardiovascular and Stroke Nursing; Council on Clinical Cardiology. Guidelines for the Management of Spontaneous Intracerebral Hemorrhage: A Guideline for Healthcare Professionals From the American Heart Association/American Stroke Association. Stroke. 2015Jul;46(7):2032-60.

B23(ii): Adams HP Jr, del Zoppo G, Alberts MJ, Bhatt DL, Brass L, Furlan A, Grubb RL,Higashida RT, Jauch EC, Kidwell C, Lyden PD, Morgenstern LB, Qureshi Al,Rosenwasser RH, Scott PA, Wijdicks EF; American Heart Association/American StrokeAssociation Stroke Council; American Heart Association/American StrokeAssociation Clinical Cardiology Council; American Heart Association/AmericanStroke Association Cardiovascular Radiology and Intervention Council;Atherosclerotic Peripheral Vascular Disease Working Group; Quality of CareOutcomes in Research Interdisciplinary Working Group. Guidelines for the earlymanagement of adults with ischemic stroke: a guideline from the American HeartAssociation/American Stroke Association Stroke Council, Clinical CardiologyCouncil, Cardiovascular Radiology and Intervention Council, and theAtherosclerotic Peripheral Vascular Disease and Quality of Care Outcomes inResearch Interdisciplinary Working Groups: The American Academy of Neurologyaffirms the value of this guideline as an educational tool for neurologists. Circulation. 2007 May 22;115(20):e478-534.

B24. Yaşılıarda sitalopram'ın 20 mg/gün, essitalopram'ın $10 \mathrm{mg} /$ gün üzerindeki dozlarda kullanımı uygun değildir (OTc uzama riski nedeniyle)

B24(i): Citalopram: Drug information, Lexicomp Online. Son erişim tarihi 22 Ekim 2019.

B24(ii): U.S. Food and Drug Administration. Escitalopram: Highlights Of Prescribing Information by FDA. Available at: $\quad$ https://www.accessdata.fda.gov/drugsatfda_docs/ label/2017/021323s047lbl.pdf (son erişim tarihi 28 Ekim 2019.)

B24(iii): October November reports of the European Pharmacovigilance Working Party. Drug Safety Update Vol 5 Issue 5, Dec 2011: A1. 


\section{C: Gastrointestinal Sistem Kriterleri}

C1. NSAii'lerin OAK'Iar (vitamin K antagonistleri, direkt trombin inhibitörleri, faktor Xa inhibitörleri) ile birlikte kullanımı uygun değildir (GiS kanama riski)

C1(i): Knijff-Dutmer EA, Van der Palen J, Schut G, Van de Laar MA. The influence of cyclooxygenase specificity of nonsteroidal anti-inflammatory drugs on bleeding complications in concomitant coumarine users. OJM 2003; 96(7):513-20.

C1(ii): Peng S, Duggan A. Gastrointestinal adverse effects of non-steroidal anti-inflammatory drugs. Expert Opin Drug Saf 2005; 4(2):157-69. Review.

C1(iii): O'Mahony D, O'Sullivan D, Byrne S, O'Connor MN, Ryan C, Gallagher P. STOPP/START criteria for potentially inappropriate prescribing in older people: version 2. Age Ageing. 2015 Mar;44(2):213-8. doi: 10.1093/ageing/afu145. Epub 2014 Oct 16. Review.

C1(iv): Solomon DH. Nonselective NSAIDs: Overview of adverse effects.In: UpToDate, Post, TW (Ed), UpToDate, Waltham, MA, 2019 Son erişim tarihi 28 Ekim 2019.

C1(v): Melcarne L, García-Iglesias P, Calvet X. Management of NSAID-associated peptic ulcer disease. Expert Rev Gastroenterol Hepatol. 2016 Jun;10(6):723-33.

C1(vi): Chinese Rheumatism Data Center; Chinese Systemic Lupus Erythematosus Treatment and Research Group. [Recommendation for the prevention and treatment of nonsteroidal anti-inflammatory drug-induced gastrointestinal ulcers and its complications]. Zhonghua Nei Ke Za Zhi. 2017 Jan 1;56(1):81-85.

C1(vii): Masclee GM, Valkhoff VE, Coloma PM, de Ridder $M$, Romio S, Schuemie MJ, Herings R, Gini R, Mazzaglia G, Picelli G, Scotti L, Pedersen L, Kuipers EJ, van der Lei J, Sturkenboom MC. Risk of upper gastrointestinal bleeding from different drug combinations. Gastroenterology. 2014 0ct;147(4):784-792.e9; quiz e13-4.

C2. Aspirin, klopidogrel, NSAii veya steroidlerin; ülser öyküsü olan hastalarda, ek antiplatelet tedavi alan hastalarda, eş zamanlı antikoagülan alan hastalarda, steroid kullanan hastalarda, dispepsi-GÖR semptomları olan hastalarda PPI verilmeden kullanımı uygun değildir

*Profilaksi amacıyla PPi kullanımında önerilen PPi dozu, günde 1 kez tercih edilen PPi'nin piyasadaki yüksek dozudur.

*Dispepsi dışındaki komorbid durumlarda, PPi'nin yüksek dozu ile devam etmek uygundur.

*Yukarıdaki ilaçların kullanımına eşlik eden dispepsi varlığı nedeniyle PPI endikasyonu olan olgularda bir süre PPI yüksek dozu kullanılarak takipte hastanın semptomlarının tekrarlamadığı en düşük PPI dozuna düşülmesi uygun olabilir.

*Kronik NSAii kullanan yaşılarda PPi kullanımı gereklidir. NSAii'lerin yaşlıda kronik kullanımlarında, yukarıdaki eşlik eden risk faktörleri olmasa dahi, PPi/misoprostol verilmelidir.

*Kısa süreli NSAii kullanan yaşlılarda, yukarıdaki risk faktörleri olmasa bile eş zamanlı PPi vermek uygun olabilir.

*Tek başına antiagregan dozda aspirin veya klopidogrel kullanan yaşlılarda, yukarıdaki risk faktörlerinin hiçbiri yoksa, PPi kullanımına muhtemelen gerek yoktur.

*PPI'ların klopidogrel ile birlikte kullanıldığında etkinliğinin azaldığına dair çalışmalar mevcuttur. Ancak bu konuda net bir öneri yapılamamaktadır.

*Varfarin kullanan hastalarda PPI kullanım endikasyonu varsa omeprazol dışındaki bir PPi tercih edilmelidir (omeprazol varfarin düzeyini artırır).

*PPi tedavisi yerine misoprostol veya yüksek doz H2 reseptör blokerleri de tercih edilebilir.

C2(i): Lanza FL, Chan FK, Quigley EM; Practice Parameters Committee of the American College of Gastroenterology. Guidelines for prevention of NSAID-related ulcer complications. Am J Gastroenterol 2009; 104(3):728-38.

C2(ii): Nardulli G, Lanas A. Risk of gastrointestinal bleeding with aspirin and platelet antiaggregants. Gastroenterol Hepatol 2009; 32(1):36-43. Review.

C2(iii): Zullo A, Hassan C, Campo SM, Morini S. Bleeding peptic ulcer in the elderly-risk factors and prevention strategies. Drugs Aging 2007; 24(10): 815-28. Review.

C2(iv): Abraham NS, Hlatky MA, Antman EM, Bhatt DL, Bjorkman DJ, Clark CB, Furberg CD, Johnson DA, Kahi CJ, Laine L, Mahaffey KW, Quigley EM, Scheiman J, Sperling LS, Tomaselli GF; ACCF/ ACG/AHA. ACCF/ACG/AHA 2010 expert consensus document on the concomitant use of proton pump inhibitors and thienopyridines: a focused update of the ACCF/ACG/AHA 2008 expert consensus document on reducing the gastro-intestinal risks of antiplatelet therapy and NSAID use. Am J Gastroenterol. 2010 Dec;105(12):2533-49. doi: 10.1038/ajg.2010.445. Review.

C2(v): Vaduganathan M, Cannon CP, Cryer BL, Liu Y, Hsieh WH, Doros G, Cohen M, Lanas A, Schnitzer TJ, Shook TL, Lapuerta P, Goldsmith MA, Laine L, Bhatt DL; COGENT Investigators. Efficacy and Safety of Proton-Pump Inhibitors in High-Risk Cardiovascular Subsets of the COGENT Trial. Am J Med. 2016 Sep;129(9):1002-5.

C2(vi): Vaduganathan M, Bhatt DL, Cryer BL, Liu Y, Hsieh WH, Doros G, Cohen M, Lanas A, Schnitzer TJ, Shook TL, Lapuerta P, Goldsmith MA, Laine L, Cannon CP; COGENT Investigators. 
Proton-Pump Inhibitors Reduce Gastrointestinal Events Regardless of Aspirin Dose in Patients Requiring Dual Antiplatelet Therapy. J Am Coll Cardiol. 2016 Apr 12;67(14):1661-71.

C2(vii): O'Mahony D, O'Sullivan D, Byrne S, O'Connor MN, Ryan C, Gallagher P. STOPP/START criteria for potentially inappropriate prescribing in older people: version 2. Age Ageing. 2015 Mar;44(2):213-8. doi: 10.1093/ageing/afu145. Epub 2014 Oct 16. Review.

C2(viii): Feldman M, Das S.NSAIDs (including aspirin): Primary prevention of gastroduodenal toxicity. In: UpToDate, Post, TW (Ed), UpToDate, Waltham, MA, 2019 Son erişim tarihi 28 Ekim 2019.

C2(ix): Bundhun PK, Teeluck AR, Bhurtu A, Huang WQ. Is the concomitant use of clopidogrel and Proton Pump Inhibitors still associated with increased adverse cardiovascular outcomes following coronary angioplasty?: a systematic review and meta-analysis of recently published studies (2012 - 2016). BMC Cardiovasc Disord. 2017 Jan 5;17(1):3. doi: 10.1186/s12872016-0453-6. Review.

C2(x): Celebi A, Yilmaz H. When proton pump inhibitors are compared, are there specific cases in which a certain proton pump inhibitors should be particularly preferred? Turk J Gastroenterol. 2017 Dec;28(Suppl 1):S68-S70. doi: 10.5152/ tjg.2017.17.

C2(xi): Sutfin T, Balmer K, Boström H, Eriksson S, Höglund P, Paulsen 0. Stereoselective interaction of omeprazole with warfarin in healthy men. Ther Drug Monit. 1989;11(2):176-84.

C2(xii): Satoh K, Yoshino J, Akamatsu T, Itoh T, Kato M, Kamada T, Takagi A, Chiba T,Nomura S, Mizokami Y, Murakami K, Sakamoto C,

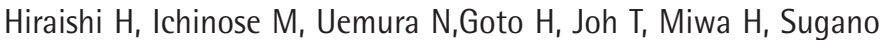
K, Shimosegawa T. Evidence-based clinical practice guidelines for peptic ulcer disease 2015. J Gastroenterol. 2016 Mar;51(3):177-94.

C2(xiii): British National Formulary vol. 76, September 2018-March 2019: p 1385.

\#C3. Aspirin veya NSAil'lerin; peptik ülser (komplike veya komplike olmayan, gastrik veya duodenal) hikayesi olan hastalarda Helicobacter pylori testi yapılmadan kronik kullanım için başlanması uygun değildir

${ }^{*} H$. pylori (+) saptanırsa eradikasyon tedavisi verilmelidir.

*Hasta bir süredir aspirin/NSAii alıyorsa, H. pylori eradikasyon tedavisinden beklenen faydalanım azdır fakat pratikte taranıp pozitif saptanması halinde genellikle eradikasyon uygulanması tercih edilmektedir.

*H. pylori prevalansı yüksek olan popülasyonlarda, anamnezde peptik ülser hikayesi olmayan olgularda da aspirin/NSAii kronik kullanımı başlanmadan önce, H. pylori için "test-tedavi" yaklaşımı uygun olabilir.
*Klopidogrel kronik kullanımı başlanacak hastalarda; anamnezde peptik ülser (komplike veya komplike olmayan, gastrik veya duodenal) hikayesi olsa dahi, H. pylori testi yapılması ve/veya $H$. pylori eradikasyon tedavisi uygulanması önerilmemektedir (teorik veya pratik uygulama).

C3(i): Feldman M, Das S. NSAIDs (including aspirin): Primary prevention of gastroduodenal toxicity. In: UpToDate, Post, TW (Ed), UpToDate, Waltham, MA, 2019 Son erişim tarihi 28 Ekim 2019.

C3(ii): Yazıcı A, Akyuz F, Issever H, Pinarbasi B, Demir K, Ozdil S, Besisik F, Boztas G, Mungan ZA, Kaymakoğlu S, Peptic ulcer disease: Whay did change in Turkey? Gastroenterology 2008;134(4):A328-329.

C3(iii): Malfertheiner P, Megraud F, O'Morain CA, Atherton J, Axon AT, Bazzoli F, Gensini GF, Gisbert JP, Graham DY, Rokkas T, El-Omar EM, Kuipers EJ; European Helicobacter Study Group. Management of Helicobacter pylori infection-the Maastricht IV/ Florence Consensus Report. Gut. 2012 May;61(5):646-64.

C3(iv): Kocazeybek B, Tokman HB. Prevalence of Primary Antimicrobial Resistance of $H$. pylori in Turkey: A Systematic Review. Helicobacter. 2016 Aug;21(4):251-60. doi: 10.1111/ hel.12272. Epub 2015 Sep 23.

C3(v): Thung I, Aramin H, Vavinskaya V, Gupta S, Park JY, Crowe SE, Valasek MA. Review article: the global emergence of Helicobacter pylori antibiotic resistance. Aliment Pharmacol Ther. 2016 Feb;43(4):514-33. doi: 10.1111/apt.13497. Epub 2015 Dec 23. Review.

C4. PPI'ların komplike olmayan peptik ülser veya erozif peptik özofajit tedavisinde tam terapötik dozda 8-12 haftadan uzun süreli kullanımı uygun değildir (doz azaltımı veya daha kısa sürede kesme endikasyonu vardır)

*8-12 haftalık terapötik doz süresi, H. pylori eradikasyonu için verilen PPI tedavi süresini içermemektedir.

*Kesilme döneminde rebound etkiden kaçınmak için PPi'lerin azaltılarak kesilmesi uygundur. (örneğin 1 hafta yarı doz, 1 hafta günaşırı doz, sonrasında kesilmesi gibi)

C4(i): British National Formulary vol. 76, September 2018-March 2019: p 78-83.

C4(ii): Gastro-oesophageal reflux disease and dyspepsia in adults: investigation and management. Clinical guideline. Published: 3 September 2014.Available at:www.nice.org.uk/ guidance/cg184 Son erişim tarihi 29 Ekim 2019.

C4(iii): O'Mahony D, O'Sullivan D, Byrne S, O'Connor MN, Ryan C, Gallagher P. STOPP/START criteria for potentially inappropriate prescribing in older people: version 2. Age Ageing. 2015 Mar;44(2):213-8. doi: 10.1093/ageing/afu145. Epub 2014 Oct 16. Review. 
C5. Çoklu ilaç kullanımı nedeniyle PPi kullanımı uygun değildir (faydası yok, potansiyel zararı var)

*PPi kullanım endikasyonları arasında "çoklu ilaç kullanımı" şeklinde bir endikasyon yoktur. Öte yandan kronik PPi kullanımı kronik böbrek yetersizliği, fraktürler, demans riskinde artış, C. difficile infeksiyonu sıklığında artış, vitamin B12 eksikliği, hipomagnezemi, enterik infeksiyonlar-bakteriyel aşırı gelişimi için risk faktörüdür.

C5(i): Xie Y. et al. Proton Pump Inhibitors and Risk of Incident CKD and Progression to ESRD. J Am Soc Nephrol.2016 Oct;27(10):3153-3163.

C5(ii): Lazarus B. et al. Proton Pump Inhibitor Use and the Risk of Chronic Kidney Disease. JAMA Intern Med. 2016 Feb;176(2):238-46.;

C5(iii): Gomm W. et al. Association of Proton Pump Inhibitors With Risk of Dementia: A Pharmacoepidemiological Claims Data Analysis. JAMA Neurol. 2016 Apr;73(4):410-6.

C5(iv): Cai D, Feng W, Jiang O. Acid-suppressive medications and risk of fracture: an updated meta-analysis. Int J Clin Exp Med. 2015 Jun 15;8(6):8893-904. eCollection 2015.

C5(v): Trifan A, Stanciu C, Girleanu I, Stoica OC, Singeap AM, Maxim R, Chiriac SA, Ciobica A, Boiculese L. Proton pump inhibitors therapy and risk of Clostridium difficile infection: Systematic review and meta-analysis. World J Gastroenterol. 2017 Sep 21;23(35):6500-6515. doi: 10.3748/wjg.v23.i35.6500. Review.

C5(vi): Scarpignato C, Gatta L, Zullo A, Blandizzi C; SIF-AIGOFIMMG Group; Italian Society of Pharmacology, the Italian Association of Hospital Gastroenterologists, and the Italian Federation of General Practitioners. Effective and safe proton pump inhibitor therapy in acidrelated diseases - A position paper addressing benefits and potential harms of acid suppression. BMC Med. 2016 Nov 9;14(1):179. Review.

C6. Antikolinerjik etkili GiS antispazmotiklerinin (örn. hiyosiyamin) kullanımı uygun değildir [yaşlıda artmış antikolinerjik yan etki (sersemlik, bilişsel kabiliyetlerde azalma, görme bulanıklığı, aritmi, şişkinlik-konstipasyon) ve sınırlı faydalanım]

C6(i): By the 2019 American Geriatrics Society Beers Criteria ${ }^{\circledR}$ Update Expert Panel. American Geriatrics Society 2019 Updated AGS Beers Criteria ${ }^{\circledR}$ for Potentially Inappropriate Medication Use in Older Adults. J Am Geriatr Soc. 2019Apr;67(4):674-694.

C6(ii): Hyoscyamine: Drug information, Lexicomp Online. Son erişim tarihi 22 Ekim 2019.

C6(iii): Wald A.Treatment of irritable bowel syndrome in adults. In: UpToDate, Post, TW (Ed), UpToDate, Waltham, MA, 2019 Son erişim tarihi 23 Ekim 2019.
C7. Kronik konstipasyonu olan hastalarda, bu yan etkiye sahip olmayan alternatifleri varsa, konstipasyona sebep olma intimali yüksek olan ilaçların (yüksek antikolinerjik etkili ilaçlar, oral demir, opioidler, verapamil, alüminyum antiasitleri) kullanımı uygun değildir (konstipasyonda artış riski)

*Verapamil dışındaki diğer kalsiyum kanal blokeri antihipertansifler de konstipasyona sebep olabilir. Ancak bu etki sirasıyla verapamil ve nifedipinde daha belirgindir.

C7(i): Meek PD, Evang SD, Tadrous M, Roux-Lirange D, Triller DM, Gumustop B. Overactive bladder drugs and constipation: a meta-analysis of randomized, placebo-controlled trials. Dig Dis Sci 2011; 56(1): 7-18. Review.

C7(ii): Müller-Lissner S. General geriatrics and gastroenterology: constipation and faecal incontinence. Best Pract Res Clin Gastroenterol 2002; 16(1): 115-33. Review.

C7(iii): Harari D, Gurwitz JH, Avorn J, Choodnovskiy I, Minaker $\mathrm{KL}$. Correlates of regular laxative use by frail elderly persons. Am J Med 1995; 99(5): 513-8.

C7(iv): Opie LH. Choosing the correct drug for the individual hypertensive patient. Drugs 1992; 44 Suppl 1: 147-55. Review.

C7(v): Opie LH. Calcium channel antagonists. Part IV: Side effects and contraindications drug interactions and combinations. Cardiovasc Drugs Ther. 1988 Jul;2(2):177-89. Review.

C7(vi): Russell RP. Side effects of calcium channel blockers. Hypertension. 1988 Mar;11(3 Pt 2):I142-4. Review.

C7(vii): Poole-Wilson PA, Kirwan BA, Vokó Z, de Brouwer S, van Dalen FJ, Lubsen J; ACTION Investigators. Safety of nifedipine GITS in stable angina: the ACTION trial. Cardiovasc Drugs Ther. 2006 Feb;20(1):45-54.

C7(viii): Acosta A, Tangalos E G, Harari D. Constipation in Hazzards Geriatric Medicine and Gerontology Seventh edition. Eds. Halter J B, Ouslander J G, Studenski S, High K P, Asthana S, Ritchie C S, Supiano M A,; 2017. Page 1956.

C7(ix): O'Mahony D, O'Sullivan D, Byrne S, O'Connor MN, Ryan C, Gallagher P. STOPP/START criteria for potentially inappropriate prescribing in older people: version 2. Age Ageing. 2015 Mar;44(2):213-8. doi: 10.1093/ageing/afu145. Epub 2014 Oct 16. Review.

C7(x): Bulpitt CJ, Connor M, Schulte M, Fletcher AE. Bisoprolol and nifedipine retard in elderly hypertensive patients: effect on quality of life. J Hum Hypertens. 2000 Mar;14(3):205-12.

C7(xi): Elliott WJ, Ram CV. Calcium channel blockers. J Clin Hypertens (Greenwich).2011 Sep;13(9):687-9.

C8. Yaşlılarda antiemetik tedavide ilk basamakta metoklopramid veya trimetobenzamid kullanımı uygun değildir (ekstrapiramidal yan etki, huzursuzluk yan etkisi nedeniyle) 
*Antiemetik olarak serotonin 5HT3 reseptor antagonist'leri yaşılıarda en güvenilir ajanlardır.

*Metoklopramid ve trimetobenzamid parkinsonizm olan hastalarda kontrendikedir.

C8(i): Glare P, Miller J, Nikolova T, Tickoo R. Treating nausea and vomiting in palliative care: a review. Clin Interv Aging. 2011;6:243-59. doi: 10.2147/CIA.S13109. Epub 2011 Sep 12. Review.

C8(ii): Stephen PJ, Williamson J. Drug-induced parkinsonism in the elderly. Lancet 1984; 2(8411): 1082-3.

C8(iii): Ganzini L, Casey DE, Hoffman WF, McCall AL. The prevalence of metoclopramide-induced tardive dyskinesia and acute extrapyramidal movement disorders. Arch Intern Med 1993; 153(12): 1469-75.

C8(iv): Pasricha PJ, Pehlivanov N, Sugumar A, Jankovic J. Drug Insight: from disturbed motility to disordered movement - a review of the clinical benefits and medicolegal risks of metoclopramide. Nat Clin Pract Gastroenterol Hepatol 2006; 3(3): 138-48. Review.

C8(v): By the 2019 American Geriatrics Society Beers Criteria ${ }^{\circledR}$ Update Expert Panel. American Geriatrics Society 2019 Updated AGS Beers Criteria ${ }^{\circledR}$ for Potentially Inappropriate Medication Use in Older Adults. J Am Geriatr Soc. 2019Apr;67(4):674-694.

C8(vi): O'Mahony D, O'Sullivan D, Byrne S, O'Connor MN, Ryan C, Gallagher P. STOPP/START criteria for potentially inappropriate prescribing in older people: version 2. Age Ageing. 2015 Mar;44(2):213-8. doi: 10.1093/ageing/afu145. Epub 2014 Oct 16. Review.

C9. GFR $<30 \mathrm{~mL} / \mathrm{dk} / 1,73 \mathrm{~m}^{2}$ olan hastalarda laksatif veya antiasit olarak magnezyum preperatlarının kullanımı uygun değildir (hipermagnezemi riski)

C9(i): Yu ASL, Gupta A.Causes, symptoms, and treatment of hypermagnesemia. In: UpToDate, Post, TW (Ed), UpToDate, Waltham, MA, 2019 Son erişim tarihi 29 Ekim 2019.

C9(ii): Navarro-González JF, Mora-Fernández C, Garcia-Pérez J. Clinical implications of disordered magnesium homeostasis in chronic renal failure and dialysis. Semin Dial. 2009 JanFeb;22(1):37-44. doi: 10.1111/j.1525-139X.2008.00530.x. Review.

C9(iii): Rao SSC. Constipation in the older adult. In: UpToDate, Post, TW (Ed), UpToDate, Waltham, MA, 2019 Son erişim tarihi 29 Ekim 2019.

C9(iv): Magnesium hydroxide: Drug information, Lexicomp Online. Son erişim tarihi 22 Ekim 2019.

C9(v): Magnesium carbonate: Drug information, Lexicomp Online. Son erişim tarihi 22 Ekim 2019.

\section{D: Solunum Sistemi Kriterleri}

D1. Dar açılı glokom veya üriner çıkış yolu obstrüksiyonu olan hastalarda antimuskarinik bronkodilatör ilaçların (ipratropium, tiotropium) kullanımı uygun değildir (glokomda kötüleşme ve üriner retansiyon riski)

*Benign prostat hiperplazisine eşlik eden obstrüktif LUTS semptomları (alt üriner traktus semptomları) yaşlı erkeklerde sıktır. Hafif düzeyde obstrüktif semptomu olan olgularda klinisyen yakın klinik takip ile antimuskarinik bronkodilatör ilaçları kullanabilir. Üriner retansiyon yan etkisi açışından PMR $>150 \mathrm{~mL}$ olan olgular özellikle risklidir ( $>150 \mathrm{~mL}$ olan olgularda kullanılması uygun değildir).

D1(i): Gupta P, O'Mahony MS. Potential adverse effects of bronchodilators in the treatment of airways obstruction in older people: recommendations for prescribing. Drugs Aging 2008; 25(5): 415-43. Review.

D1(ii): Oba Y, Zaza T, Thameem DM. Safety, tolerability and risk benefit analysis of tiotropium in COPD. Int J Chron Obstruct Pulmon Dis 2008; 3(4): 575-84. Review.

D1(iii): O'Mahony D, O'Sullivan D, Byrne S, O'Connor MN, Ryan C, Gallagher P. STOPP/START criteria for potentially inappropriate prescribing in older people: version 2. Age Ageing. 2015 Mar;44(2):213-8. doi: 10.1093/ageing/afu145. Epub 2014 Oct 16. Review.

D1(iv): Ah-Kee EY, Egong E, Shafi A, Lim LT, Yim JL. A review of drug-induced acute angle closure glaucoma for nonophthalmologists. Qatar Med J. 2015 May 10;2015(1):6. doi: 10.5339/qmj.2015.6. eCollection 2015. Review.

D1(v): Vande Griend JP, Linnebur SA. Inhaled anticholinergic agents and acute urinary retention in men with lower urinary tract symptoms or benign prostatic hyperplasia. Ann Pharmacother. 2012 Sep;46(9):1245-9. doi: 10.1345/aph.1R282. Epub 2012 Jul 31. Review.

D1(vi): Carlos Andrés Celis Preciado, Horacio Giraldo, Dario Londoño, Ingrid Rodriguez. Glaucoma risk due to antimuscarinics, not a class effect: A systematic review. European Respiratory Journal 2016 48: PA4069.

D1(vii): British National Formulary vol. 76, September 2018-March 2019: p 247.

D1(viii): Hashimoto $M$, Hashimoto $K$, Ando $F$, Kimura $Y_{\text {, }}$ Nagase K, Arai K. Prescription rate of medications potentially contributing to lower urinary tract symptoms and detection of adverse reactions by prescription sequence symmetry analysis. J Pharm Health Care Sci. 2015 Feb 15;1:7.

D2. KOAH'ın veya astım bronşialenin idame tedavisinde teofilin kullanımı uygun değildir (dar terapötik indeks ve yaşlıda yüksek insomni, aritmi riski nedeniyle) 
D2(i): Rabe KF, Hurd S, Anzueto A, Barnes PJ, Buist SA, Calverley $P$, Fukuchi $Y$, Jenkins $C$, Rodriguez-Roisin $R$, van Weel C, Zielinski J; Global Initiative for Chronic Obstructive Lung Disease. Global strategy ort he diagnosis, management, and prevention of chronic obstructive pulmonary disease: GOLD executive summary. Am J Respir Crit Care Med 2007; 176(6): 532-55. Review.

D2(ii): Ramsdell J. Use of theophylline in the treatment of COPD. Chest 1995; 107(5 Suppl): 206S-209S. Review.

D2(iii): Fragoso CAV. Diagnosis and management of asthma in older adults. In: UpToDate, Post, TW (Ed), UpToDate, Waltham, MA, 2019 Son erişim tarihi 29 Ekim 2019.

D2(iv): O'Mahony D, O'Sullivan D, Byrne S, O'Connor MN, Ryan C, Gallagher P. STOPP/START criteria for potentially inappropriate prescribing in older people: version 2. Age Ageing. 2015 Mar;44(2):213-8. Doi: 10.1093/ageing/afu145. Epub 2014 Oct 16. Review.

D2(v): By the 2019 American Geriatrics Society Beers Criteria ${ }^{\circledR}$ Update Expert Panel. American Geriatrics Society 2019 Updated AGS Beers Criteria ${ }^{\circledR}$ for Potentially Inappropriate Medication Use in Older Adults. J Am Geriatr Soc. 2019 Apr;67(4):674-694. Doi: 10.1111/jgs.15767.

D3. Orta-ağır KOAH'ta idame tedavi için inhaler kortikosteroid yerine sistemik kortikosteroid kullanımı uygun değildir (sistemik kortikosteroidlerine uzun süre gereksiz maruziyet; etkin inhale tedaviler mevcut)

D3(i): Hess MW. The 2017 Global Initiative for Chronic Obstructive Lung Disease Report and Practice Implications ort he Respiratory Therapist. Respir Care. 2017 Nov;62(11):14921500.

D3(ii): Wood-Baker R, Walters J, Walters EH. Systemic corticosteroids in chronic obstructive pulmonary disease: an overview of Cochrane systematic reviews. Respir Med 2007; 101(3): 371-7. Review.

D3(iii): O'Mahony D, O'Sullivan D, Byrne S, O'Connor MN, Ryan C, Gallagher P. STOPP/START criteria for potentially inappropriate prescribing in older people: version 2. Age Ageing. 2015 Mar;44(2):213-8. Doi: 10.1093/ageing/afu145. Epub 2014 Oct 16. Review.

\section{E: Kas İskelet Sistemi Kriterleri ve Analjezik Illaçlar}

E1. NSAii'lerin, alternatif tedavi varken, 3 aydan uzun süreli kullanımı uygun değildir

*Osteoartrit ağrısında ve basit ağrılarda (kas-iskelet sistemi, baş ağrısı vb.) öncelikle parasetamol tedavisi uygulanmalıdır (parasetamol tedavisinin metamizol, düşük doz kodein/ tramadol ile kombinasyonu düşünülebilir).
${ }^{*}$ NSAii kullanılan olgular yan etkileri açısından (nefropati, HT, kalp yetersizliği, KV olay) yakın klinik takip edilmelidir.

*NSAii kullanılması durumunda indometasin tercih edilmemelidir (yaşlıda diğer NSAii'lere kıyasla daha fazla MSS ve diğer sistem yan etkileri)

*Kronik NSAii kullanımı gereken durumlarda NSAil'lere ek olarak PPI/misoprostol kullanılmalıdır.

E1(i): Nikles CJ, Yelland M, Del Mar C, Wilkinson D. The role of paracetamol in chronic pain: an evidence-based approach. Am J Ther 2005; 12(1): 80-91. Review.

E1 (ii): Seed SM, Dunican KC, Lynch AM. Osteoarthritis: a review of treatment options. Geriatrics 2009; 64(10): 20-9. Review.

E1(iii): Jawad AS. Analgesics and osteoarthritis: are treatment guidelines reflected in clinical practice? Am J Ther 2005; 12(1): 98-103. Review.

E1(iv): By the 2019 American Geriatrics Society Beers Criteria ${ }^{\circledR}$ Update Expert Panel. American Geriatrics Society 2019 Updated AGS Beers Criteria ${ }^{\circledR}$ for Potentially Inappropriate Medication Use in Older Adults. J Am Geriatr Soc. 2019Apr;67(4):674-694.

E1 (v): O'Mahony D, O'Sullivan D, Byrne S, O'Connor MN, Ryan C, Gallagher P. STOPP/START criteria for potentially inappropriate prescribing in older people: version 2. Age Ageing. 2015 Mar;44(2):213-8. doi: 10.1093/ageing/afu145. Epub 2014 Oct 16. Review.

E2. NSAii'lerin GFR $<50 \mathrm{~mL} / \mathrm{dk} / 1,73 \mathrm{~m}^{2}$ olan hastalarda kullanımı uygun değildir (renal fonksiyonlarda kötüleşme riski)

E2(i): Harirforoosh S, Jamali F. Renal adverse effects of nonsteroidal anti-inflammatory drugs. Expert Opin Drug Saf 2009; 8(6): 669-81. Review.

E2(ii): Cheng HF, Harris RC. Renal effects of non-steroidal antiinflammatory drugs and selective cyclooxyge-nase-2 inhibitors. Curr Pharm Des 2005; 11(14): 1795-804. Review.

E2(iii): O'Mahony D, O'Sullivan D, Byrne S, O'Connor MN, Ryan C, Gallagher P. STOPP/START criteria for potentially inappropriate prescribing in older people: version 2. Age Ageing. 2015 Mar;44(2):213-8. doi: 10.1093/ageing/afu145. Epub 2014 Oct 16. Review.

E3. Osteoartrit tedavisinde sistemik steroid kullanımı uygun değildir (sistemik kortikosteroidler ile yan etki riski)

E3(i): British National Formulary vol. 76, September 2018-March 2019: p 1058.

E3(ii): Recommendations for the medical management of osteoarthritis of the hip and knee: 2000 update. American College of Rheumatology Subcommittee on Osteoarthritis Guidelines. Arthritis Rheum 2000; 43(9): 1905-15. 
E3(iii): O'Mahony D, O'Sullivan D, Byrne S, O'Connor MN, Ryan C, Gallagher P. STOPP/START criteria for potentially inappropriate prescribing in older people: version 2. Age Ageing. 2015 Mar;44(2):213-8. doi: 10.1093/ageing/afu145. Epub 2014 Oct 16. Review.

E4. Romatoid artritte 3 aydan uzun süreli kortikosteroid monoterapisi kullanımı uygun değildir (sistemik kortikosteroidler ile yan etki riski)

E4(i): Onishi S, Iwmoto M, Minota S. Management of elderlyonset rheumatoid arthritis. J Clin Immunol 2010; 33(1): 1-7.

E4(ii): American College of Rheumatology Subcommittee on Rheumatoid Arthritis Guidelines. Guidelines for the management of rheumatoid arthritis: 2002 Update. Arthritis Rheum 2002; 46(2): 28-46.

E4(iii): Soubrier M, Mathieu S, Payet S, Dubost JJ, Ristori JM. Elderlyonset rheumatoid arthritis. Joint Bone Spine 2010; 77(4): 290-6. Review.

E4(iv): O'Mahony D, O'Sullivan D, Byrne S, O'Connor MN, Ryan C, Gallagher P. STOPP/START criteria for potentially inappropriate prescribing in older people: version 2. Age Ageing. 2015 Mar;44(2):213-8. doi: 10.1093/ageing/afu145. Epub 2014 Oct 16. Review.

E4(v): Burmester GR, Pope JE. Novel treatment strategies in rheumatoid arthritis. Lancet. 2017 Jun 10;389(10086):23382348.

E4(vi): Roubille C, Richer V, Starnino T, McCourt C, McFarlane A, Fleming P, Siu S, Kraft J, Lynde C, Pope J, Gulliver W, Keeling $S$, Dutz J, Bessette L, Bissonnette R, Haraoui B. The effects of tumour necrosis factor inhibitors, methotrexate, non-steroidal anti-inflammatory drugs and corticosteroids on cardiovascular events in rheumatoid arthritis, psoriasis and psoriatic arthritis: a systematic review and meta-analysis. Ann Rheum Dis. 2015 Mar;74(3):480-9.

E5. Gut Hastalığı'nın kronik tedavisi için ksantin oksidaz inhibitörleri (örn. allopurinol, febuksostat) kullanımının kontrendike olmadığı durumlarda, uzun süreli NSAii veya kolşisin kullanımı uygun değildir (gut hastalığının profilaksisinde ksantin oksidaz inhibitörleri ilk seçenek ilaçlardır)

E5(i): De Leonardis F, Govoni M, Colina M, Bruschi M, Trotta F. Elderly-onset gout: a review. Rheumatol Int 2007; 28(1): 1-6. Review.

E5(ii): Hoskison KT, Wortmann RL. Management of gout in older adults: barriers to optimal control. Drugs Aging 2007; 24(1): 21 36. Review.

E5(iii): O'Mahony D, O'Sullivan D, Byrne S, O'Connor MN, Ryan C, Gallagher P. STOPP/START criteria for potentially inappropriate prescribing in older people: version 2. Age Ageing.
2015 Mar;44(2):213-8. doi: 10.1093/ageing/afu145. Epub 2014 Oct 16. Review.

E5(iv): British National Formulary vol. 76, September 2018-March 2019: p 1085-87.

E6. Kolşisin'in GFR< $10 \mathrm{~mL} / \mathrm{dk} / 1,73 \mathrm{~m}^{2}$ olan hastalarda kullanımı uygun değildir (kolşisin toksisitesi riski)

E6(i): Hoskison KT, Wortmann RL. Management of gout in older adults: barriers to optimal control. Drugs Aging 2007; 24(1): 21 36. Review.

E6(ii): Hanlon JT, Aspinall SL, Semla TP, Weisbord SD, Fried LF, Good CB, Fine MJ, Stone RA, Pugh MJ, Rossi MI, Handler SM. Consensus guidelines for oral dosing of primarily renally cleared medications in older adults. J Am Geriatr Soc 2009; 57(2):33540. Erratum in: J Am Geriatr Soc 2009; 57(11): 2179. Dosage error in article text.

E6(iii): O'Mahony D, O'Sullivan D, Byrne S, O'Connor MN, Ryan C, Gallagher P. STOPP/START criteria for potentially inappropriate prescribing in older people: version 2. Age Ageing. 2015 Mar;44(2):213-8. doi: 10.1093/ageing/afu145. Epub 2014 Oct 16. Review.

E6(iv): BritishNational Formulary vol. 76, September 2018-March 2019: p 1085-86.

E7. Metotreksat'ın GFR $<30 \mathrm{~mL} / \mathrm{dk} / 1,73 \mathrm{~m}^{2}$ olan hastalarda kullanımı uygun değildir

E7(i): Seyffart's Directory of Drug Dosage in Kidney Disease; (1st ed., 2011) by GünterSeyffart Publisher: Dustri-Verlag Dr. Karl Feistle GmbH \& Co. KG, Munich-Orlando; pp: 476-477.

E7(ii): Methotrexate: Drug information, Lexicomp Online. Son erişim tarihi 29 Ekim 2019.

E8. Ağrı tedavisinde meperidin kullanımı uygun değildir (diğer opioidlere göre artmış nörotoksisite, deliryum riski; daha güvenilir alternatifleri var. Özellikle böbrek yetersizliği varlığında kullanımı risklidir)

E8(i): By the 2019 American Geriatrics Society Beers Criteria ${ }^{\circledR}$ Update Expert Panel. American Geriatrics Society 2019 Updated AGS Beers Criteria ${ }^{\circledR}$ for Potentially Inappropriate Medication Use in Older Adults. J Am Geriatr Soc. 2019Apr;67(4):674-694.

E8(ii): Meperidine (pethidine): Drug information, Lexicomp Online. Son erişim tarihi 22 Ekim 2019.

E9. Uzamış salınımlı tramadol'ün $\mathrm{GFR}<30 \mathrm{~mL} / \mathrm{dk} / 1,7 \mathrm{~m}^{2}$ olan hastalarda kullanımı uygun değildir

*Hızlı salınımlı tramadol için doz azaltımı yapılmalıdır.

E9(i): By the 2019 American Geriatrics Society Beers Criteria ${ }^{\circledR}$ Update Expert Panel. American Geriatrics Society 2019 Updated 
AGS Beers Criteria ${ }^{\circledR}$ for Potentially Inappropriate Medication Use in Older Adults. J Am Geriatr Soc. 2019Apr;67(4):674-694.

E9(ii): Tramadol: Drug information, Lexicomp Online. Son erişim tarihi 22 Ekim 2019.

E10. Opioidlerin kronik kullanımda eş zamanlı laksatif verilmeden kullanımı uygun değildir (ciddi konstipasyon riski)

E10(i): Forman WB. Opioid analgesic drugs in the elderly. Clin Geriatr Med 1996; 12(3): 489-500. Review.

E10(ii): Kalso E, Edwards JE, Moore RA, McQuay HJ. Opioids in chronic non-cancer pain: systematic review of efficacy and safety. Pain 2004; 112(3): 372-80.

E10(iii): O'Mahony D, O'Sullivan D, Byrne S, O'Connor MN, Ryan C, Gallagher P. STOPP/START criteria for potentially inappropriate prescribing in older people: version 2. Age Ageing. 2015 Mar;44(2):213-8. doi: 10.1093/ageing/afu145. Epub 2014 Oct 16. Review.

E10(iv): Galicia-Castillo MC, Weiner DK. Treatment of persistent pain in older adults. In: UpToDate, Post, TW (Ed), UpToDate, Waltham, MA, 2019 Son erişim tarihi 23 Ekim 2019.

E11. Kas iskelet sistemi ağrıları için sistemik kas gevşetici (iskelet kası) ajanların (tiyokolşikosid, tizanidin, klorzoksazon, karisoprodol, klorfenezin karbamat, siklobenzaprin, metaksalon, metokarbamol ve orfenadrin vb.) kullanımı uygun değildir (sedasyon, sersemlik, baş dönmesi, ağız kuruluğu, konstipasyon, bilişsel yan etkileri nedeniyle)

*Tizanidin ile hipotansiyon riski de çok belirgindir.

E11(i): By the 2019 American Geriatrics Society Beers Criteria ${ }^{\circledR}$ Update Expert Panel. American Geriatrics Society 2019 Updated AGS Beers Criteria ${ }^{\circledR}$ for Potentially Inappropriate Medication Use in Older Adults. J Am Geriatr Soc. 2019Apr;67(4):674-694.

E11(ii): A.R Umarkar, S.R Bavaskar and P.N.Yewale. Thiocolchicoside as muscle relaxant: a review; International Journal of Pharmacy and Biological Sciences (eISSN: 2230-7605). Volume 1, Issue 3, JULY-SEPT, 2011;364-371.Available at: https:// www.ijpbs.com/ijpbsadmin/upload/ijpbs_50c8471a463c9.pdf son erişim tarihi 28 Ekim 2019.

E11(iii): Thiocolchicoside: review of adverse effects. Prescrire Int. 2016; Feb;25(168):41-3

E11(iv): Tizanidine: Drug information, Lexicomp Online. Son erişim tarihi 22 Ekim 2019.

\#E12. Osteomalazi tanısı dışlanmadan osteoporoz tedavisi başlanması uygun değildir

E12(i): Cosman F, de Beur SJ, LeBoff MS, Lewiecki EM, Tanner $B$, Randall S, Lindsay R; National Osteoporosis Foundation. Clinician's Guide to Prevention and Treatment of Osteoporosis. Osteoporos Int. 2014 Oct;25(10):2359-81.
E13. Vitamin D 'idame' tedavisinde, aralıklı olarak yüksek dozda (300.000 iÜ) konvansiyonel vitamin D kullanımı uygun değildir (artmış düşme riski, kas-iskelet sistemi üzerine ek faydasının olmaması)

*"Idame" tedavide kullanılan yüksek doz konvansiyonel vitamin D’nin olumsuz sonuçları gösterilmiştir.

*"Replasman" tedavisinde kullanılan yüksek doz konvansiyonel vitamin D ile ilişkili olumsuz sonuçlar bildirilmemiştir. Bununla birlikte, yaşlıda ilaç kullanımında genel geçerliliği olan "düşük başla-yavaş artır" ilkesi nedeniyle "replasman" vitamin D tedavisinin de tedrici yapılması uygun olabilir.

E13(i): Sanders KM, Stuart AL, Williamson EJ, Simpson JA, Kotowicz MA, Young D, Nicholson GC. Annual high-dose oral vitamin $D$ and falls and fractures in older women: a randomized controlled trial. JAMA. 2010 May 12;303(18):1815-22.

E13(ii): Bischoff-Ferrari HA, Dawson-Hughes B, Orav EJ, Staehelin HB, Meyer OW, Theiler R, Dick W, Willett WC, Egli A. Monthly High-Dose Vitamin D Treatment for the Prevention of Functional Decline: A Randomized Clinical Trial. JAMA Intern Med. 2016 Feb;176(2):175-83.

E13(iii): Smith H, Anderson F, Raphael H, Maslin P, Crozier S, Cooper C. Effect of annual intramuscular vitamin D on fracture risk in elderly men and women-a population-based, randomized, double-blind, placebo-controlled trial. Rheumatology (Oxford). 2007 Dec;46(12):1852-7.

E13(iv): Heikinheimo RJ, Inkovaara JA, Harju EJ, Haavisto MV, Kaarela RH, Kataja JM, Kokko AM, Kolho LA, Rajala SA. Annual injection of vitamin $D$ and fractures of aged bones. Calcif Tissue Int. 1992 Aug;51(2):105-10.

E13(v): Cosman F, de Beur SJ, LeBoff MS, Lewiecki EM, Tanner $B$, Randall S, Lindsay R; National Osteoporosis Foundation. Clinician's Guide to Prevention and Treatment of Osteoporosis. Osteoporos Int. 2014 Oct;25(10):2359-81. doi: 10.1007/s00198014-2794-2. Epub 2014 Aug 15. Erratum in: Osteoporos Int. 2015 Jul;26(7):2045-7.

E13(vi): Shah S, Chiang C, Sikaris K, Lu Z, Bui M, Zebaze R, Seeman E. Serum 25-Hydroxyvitamin D Insufficiency in Search of a Bone Disease. J Clin Endocrinol Metab. 2017 Jul 1;102(7):2321-2328.

E14. Hiperfosfatemi ve/veya hiperkalsemi varlığında aktif (kalsitriol) (1-25(OH)2kolekalsiferol) veya konvansiyonel $(25(\mathrm{OH})$ kolekalsiferol) vitamin D kullanımı uygun değildir

E14(i): Seyffart's Directory of Drug Dosage in Kidney Disease; (1st ed., 2011) by GünterSeyffart Publisher: Dustri-Verlag Dr. Karl Feistle GmbH \& Co. KG, Munich-Orlando; pp: 476-477.

E14(ii): Kidney Disease: Improving Global Outcomes (KDIGO) CKD-MBD Update Work Group. KDIGO 2017 Clinical Practice 
Guideline Update for the Diagnosis, Evaluation, Prevention, and Treatment of Chronic Kidney Disease-Mineral and Bone Disorder (CKD-MBD). Kidney Int Suppl. 2017;7:1-59.

E15. Üst GiS hastalığı (örn. disfaji, özofajit, peptik ülser, üst Gis kanama veya tedavi ile kontrol altına alınamamış GÖR) anamnezi olanlarda ve/veya fiziksel olarak dik duramayacak hastalarda) oral bifosfonat kullanımı uygun değildir (özofajit, özofageal ülser, özofageal strüktürde relaps/alevlenme riski)

*Oral bifosfonatlar iyi kontrol edilmiş GÖR varlığında dikkatle kullanılabilir.

E15(i): Pazianas M, Abrahamsen B. Safety of bisphosphonates. Bone 2011; 49(1): 103-10. Review.

E15(ii): Civitelli R, Napoli N, Armamento-Villareal R. Use of intravenous bisphosphonates in osteoporosis. Curr Osteoporos Rep 2007;5(1): 8-13.

E15(iii): Gaudio A, Morabito N. Pharmacological management of severe postmenopausal osteoporosis. Drugs Aging 2005; 22(5): 405-17. Review.

E15(iv): Lewiecki EM. Bisphosphonates for the treatment of osteoporosis: insights forclinicians. Ther Adv Chronic Dis. 2010 May;1(3):115-28.

E15(v): Kennel KA, Drake MT. Adverse effects of bisphosphonates: implications forosteoporosis management. Mayo Clin Proc. 2009 Jul;84(7):632-7; quiz 638.

E15(vi): O'Mahony D, O'Sullivan D, Byrne S, O'Connor MN, Ryan C, Gallagher P. STOPP/START criteria for potentially inappropriate prescribing in older people: version 2. Age Ageing. 2015 Mar;44(2):213-8. doi: 10.1093/ageing/afu145. Epub 2014 Oct 16. Review.

E15(vii): Alendronate: Drug information, Lexicomp Online. Son erişim tarihi 29 Ekim 2019.

E15(viii): Risedronate: Drug information, Lexicomp Online. Son erişim tarihi 29 Ekim 2019.

E15(ix): Ibandronate: Drug information, Lexicomp Online. Son erişim tarihi 29 Ekim 2019.

E15(x): RosenHN.The use of bisphosphonates in postmenopausal women with osteoporosis. In: UpToDate, Post, TW (Ed), UpToDate, Waltham, MA, 2019 Son erişim tarihi 22 Ekim 2019.

E16. Bifosfonatlar'ın GFR $<30 \mathrm{~mL} / \mathrm{dk} / 1,73 \mathrm{~m}^{2}$ olan hastalarda kullanımı uygun değildir (artmış akut böbrek yetersizliği riski)

*Zoledronat ve alendronat için eşik GFR değeri daha yüksektir (<35 mL/dk/1,73 $\left.\mathrm{m}^{2}\right)$.

E16(i): Cosman F, de Beur SJ, LeBoff MS, Lewiecki EM, Tanner $B$, Randall S, Lindsay $R$; National Osteoporosis Foundation.
Clinician's Guide to Prevention and Treatment of Osteoporosis. Osteoporos Int. 2014 Oct;25(10):2359-81.

E16(ii): Alendronate: Drug information, Lexicomp Online. Son erişim tarihi 22 Ekim 2019.

E16(iii): Risedronate: Drug information, Lexicomp Online. Son erişim tarihi 22 Ekim 2019.

E16(iv): Ibandronate: Drug information, Lexicomp Online. Son erişim tarihi 22 Ekim 2019.

E16(v): RosenHN.The use of bisphosphonates in postmenopausal women with osteoporosis. In: UpToDate, Post, TW (Ed), UpToDate, Waltham, MA, 2019 Son erişim tarihi 22 Ekim 2019.

E17. Tedavi öncesi serum kalsiyum düzeyi tayin edilmeden ve yeterli düzeyde kalsiyum/vitamin $D$ alımı sağlanmadan zoledronat, denosumab veya teriparatid kullanımı uygun değildir

E17(i): Denosumab: Drug information, Lexicomp Online. Son erişim tarihi 22 Ekim 2019.

E17(ii): Zoledronic acid: Drug information, Lexicomp Online. Son erişim tarihi 22 Ekim 2019.

E17(iii): Teriparatide (recombinant human parathyroid hormone [1-34]) : Drug information, Lexicomp Online. Son erişim tarihi 22 Ekim 2019.

\section{F: Ürogenital Sistem Kriterleri}

F1. Benign prostat hiperplazisine bağlı LUTS semptomları olan erkeklerde PMR>150 mL ise mesaneye yönelik antikolinerjik ilaç kullanımı uygun değildir

*Yaşlı erkeklerde, aşırı aktif mesane tedavisi için mesaneye yönelik antikolinerjik ilaç reçetelemeden önce LUTS semptomları sorgulanmalı ve tüm olgulara PMR tayini yapılmalıdır.

F1(i): McVary KT, Roehrborn CG, Avins AL, Barry MJ, Bruskewitz RC, Donnell RF, FosterHE Jr, Gonzalez CM, Kaplan SA, Penson DF, Ulchaker JC, Wei JT. Update on AUAguideline on the management of benign prostatic hyperplasia. J Urol. 2011May;185(5):1793803.

F1(ii): O'Mahony D, O'Sullivan D, Byrne S, O'Connor MN, Ryan C, Gallagher P. STOPP/START criteria for potentially inappropriate prescribing in older people: version 2. Age Ageing. 2015 Mar;44(2):213-8. doi: 10.1093/ageing/afu145. Epub 2014 Oct 16. Review.

F1(iii): S. Gravas (Chair), J.N. Cornu, M.J. Drake, M. Gacci, C. Gratzke, T.R.W. Herrmann, S. Madersbacher, C. Mamoulakis, K.A.O. Tikkinen Guidelines Associates: M. Karavitakis, I. Kyriazis, S. Malde, V. Sakkalis, R. Umbach. EAU Guidelines on Management of Non-Neurogenic Male Lower Urinary Tract Symptoms (LUTS), incl. Benign Prostatic Obstruction (BPO). European Association of Urology 2018. Page 25. 
F2. Kronik dar açılı glokom hastalarında mesaneye yönelik antikolinerjik ilaç kullanımı uygun değildir

*Mesaneye yönelik antikolinerjik ilaç başlanmadan önce glokom hikayesi sorgulanmalıdır.

*Mesaneye yönelik antikolinerjik ilaçlar dar açılı glokom lazer iridotomi ile tedavi edilmiş ise kontrendike değildir.

*Mesaneye yönelik antikolinerjik ilaçlar açık açılı glokomda da kontrendike değildir.

F2(i): O'Mahony D, O'Sullivan D, Byrne S, O'Connor MN, Ryan C, Gallagher P. STOPP/START criteria for potentially inappropriate prescribing in older people: version 2. Age Ageing. 2015 Mar;44(2):213-8. doi: 10.1093/ageing/afu145. Epub 2014 Oct 16. Review.

F2(ii): Gani J, Perlis N, Radomski SB. Urologic medications and ophthalmologic side effects: a review. Can Urol Assoc J. 2012 Feb;6(1):53-8. doi: 10.5489/cuaj.11037.

F2(iii): Kato K, Yoshida K, Suzuki K, Murase T, Gotoh M. Managing patients with an overactive bladder and glaucoma: a questionnaire survey of Japanese urologists on the use of anticholinergics. BJU Int. 2005 Jan;95(1):98-101.

F2(iv): Oxybutynin: Drug information, Lexicomp Online. Son erişim tarihi 29 Ekim 2019.

F2(v): Darifenacin: Drug information, Lexicomp Online. Son erişim tarihi 29 Ekim 2019.

F2(vi): Tolterodine: Drug information, Lexicomp Online. Son erişim tarihi 29 Ekim 2019.

F2(vii): Trospium: Drug information, Lexicomp Online. Son erişim tarihi 29 Ekim 2019.

F2(viii): Fesoterodine: Drug information, Lexicomp Online. Son erişim tarihi 29 Ekim 2019.

F2(ix): Solifenacin: Drug information, Lexicomp Online. Son erişim tarihi 29 Ekim 2019.

F3. Prostat hiperplazisi olan (obstrüksiyon riski) veya diabetes mellitus komplikasyonları gelişmiş olan (nörojen mesane riski) veya kırılgan olan yaşlılarda (detrusor hiperaktivitesi ile birlikte azalmış kontraktilite riski) PMR tayini yapılmadan mesaneye yönelik antikolinerjik ilaç kullanımı uygun değildir (üriner retansiyon ve postrenal böbrek yetersizliği riski)

F3(i): Taylor JA 3rd, Kuchel GA. Detrusor underactivity: Clinical features and pathogenesis of an underdiagnosed geriatric condition. J Am Geriatr Soc. 2006 Dec;54(12):1920-32. Review.

F3(ii): S. Gravas (Chair), J.N. Cornu, M.J. Drake, M. Gacci, C. Gratzke, T.R.W. Herrmann, S. Madersbacher, C. Mamoulakis, K.A.O. Tikkinen Guidelines Associates: M. Karavitakis, I. Kyriazis, S. Malde, V. Sakkalis, R. Umbach. EAU Guidelines on Management of Non-Neurogenic Male Lower Urinary Tract Symptoms (LUTS), incl. Benign Prostatic Obstruction (BPO). European Association of Urology 2018. Page 25.

F3(iii): Golbidi S, Laher I. Bladder dysfunction in diabetes mellitus. Front Pharmacol.2010 Nov 16;1:136. doi: 10.3389/ fphar.2010.00136. eCollection 2010.

F3(iv): O'Mahony D, O'Sullivan D, Byrne S, O'Connor MN, Ryan C, Gallagher P. STOPP/START criteria for potentially inappropriate prescribing in older people: version 2. Age Ageing. 2015 Mar;44(2):213-8. doi: 10.1093/ageing/afu145. Epub 2014 Oct 16. Review.

F4. Kan basınc $<90 / 50 \mathrm{mmHg}$ veya $>170 / 100 \mathrm{mmHg}$ olan/ unstabil anginası olan/ cinsel ilişki sırasında anjinası olan/ NYHA sınıf 4 kalp yetersizliği olan/ anjina için nitrat tedavisi alan/ alfa-1 bloker tedavisi alan/geçirilmiş Mi (< 3 ay) öyküsü olan/ geçirilmiş inme $(<6$ ay) öyküsü olan hastalarda fosfodiesteraz tip-5 inhibitörlerinin (örn. sildenafil, tadalafil, vardenafil) kullanımı uygun değildir

F4(i): Kloner RA, Hutter AM, Emmick JT, Mitchell MI, Denne J, Jackson G. Time course of the interaction between tadalafil and nitrates. J Am Coll Cardiol 2003; 42 (10): 1855-60.

F4(ii): O'Mahony D, O'Sullivan D, Byrne S, O'Connor MN, Ryan C, Gallagher P. STOPP/START criteria for potentially inappropriate prescribing in older people: version 2. Age Ageing. 2015 Mar;44(2):213-8. doi: 10.1093/ageing/afu145. Epub 2014 Oct 16. Review.

F4(iii): S. Gravas (Chair), J.N. Cornu, M.J. Drake, M. Gacci, C. Gratzke, T.R.W. Herrmann, S. Madersbacher, C. Mamoulakis, K.A.O. Tikkinen Guidelines Associates: M. Karavitakis, I. Kyriazis, S. Malde, V. Sakkalis, R. Umbach. EAU Guidelines on Management of Non-Neurogenic Male Lower Urinary Tract Symptoms (LUTS), incl. Benign Prostatic Obstruction (BPO). European Association of Urology 2018. Page 21.

F4(iv): K. Hatzimouratidis (Chair), F. Giuliano, I. Moncada, A. Muneer, A. Salonia (Vice-chair), P. Verze Guideline Associates: A. Parnham, E.C. Serefoglu. EAU Guidelines on Erectile Dysfunction, Premature Ejaculation, Penile Curvature and Priapism. European Association of Urology 2018. Page 20-21.

F5. Ortostatik hipotansiyonu olan hastalarda benign prostat hiperplazisine bağlı LUTS semptomlarının tedavisinde üroselektif olmayan alfa 1 blokerlerin (örn. doksazosin, terazosin) kullanımı uygun değildir (ortostatik hipotansiyonda, senkop ve düşmelerde artış)

*Ortostatik hipotansiyon riski en düşük üroselektif ajan silodosindir; plaseboya benzer olduğu düşünülmektedir.

*Üroselektif olmayan alfa-1 blokerlerle tedavi edilen yaşlı hastalar ortostatik hipotansiyon riski için bilgilendirilmelidir. 
F5(i): S. Gravas (Chair), J.N. Cornu, M.J. Drake, M. Gacci, C. Gratzke, T.R.W. Herrmann, S. Madersbacher, C. Mamoulakis, K.A.O. Tikkinen Guidelines Associates: M. Karavitakis, I. Kyriazis, S. Malde, V. Sakkalis, R. Umbach. EAU Guidelines on Management of Non-Neurogenic Male Lower Urinary Tract Symptoms (LUTS), incl. Benign Prostatic Obstruction (BPO). European Association of Urology 2018. Page 17.

F5(ii): Chapple CR, Montorsi F, Tammela TL, Wirth M, Koldewijn E, Fernández Fernández E; European Silodosin Study Group. Silodosin therapy for lower urinary tractsymptoms in men with suspected benign prostatic hyperplasia: results of aninternational, randomized, double-blind, placebo- and active-controlled clinical trial performed in Europe. Eur Urol. 2011 Mar;59(3):342-52.

F5(iii): Welk B, McArthur E, Fraser LA, Hayward J, Dixon S, Hwang YJ, Ordon M. The riskof fall and fracture with the initiation of a prostate-selective $\alpha$ antagonist: a population based cohort study. BMJ. 2015 Oct 26;351:h5398.

F5(iv): O'Mahony D, O'Sullivan D, Byrne S, O'Connor MN, Ryan C, Gallagher P. STOPP/START criteria for potentially inappropriate prescribing in older people: version 2. Age Ageing. 2015 Mar;44(2):213-8. doi: 10.1093/ageing/afu145. Epub 2014 Oct 16. Review.

F5(v): Cho HJ, Yoo TK. Silodosin for the treatment of clinical benign prostatic hyperplasia: safety, efficacy, and patient acceptability. Res Rep Urol. 2014 Sep 26;6:113-9. doi: 10.2147/ RRU.S41618. eCollection 2014. Review.

F5(vi): S. Gravas (Chair), T. Bach, M. Drake, M. Gacci, C. Gratzke, T.R.W. Herrmann, S. Madersbacher, C. Mamoulakis, K.A.O. Tikkinen Guidelines Associates: M. Karavitakis, S. Malde, V. Sakkalis, R. Umbach. EAU Guidelines on Management of NonNeurogenic Male Lower Urinary Tract Symptoms (LUTS), incl. Benign Prostatic Obstruction (BPO). European Association of Urology 2017; Page 14-15.

F5(vii): Chatziralli IP, Sergentanis TN. Risk factors for intraoperative floppy iris syndrome: a meta-analysis. Ophthalmology. 2011 Apr;118(4):730-5.

F5(viii): Cantrell MA, Bream-Rouwenhorst HR, Steffensmeier A, Hemerson P, Rogers M,Stamper B. Intraoperative floppy iris syndrome associated with alpha1-adrenergic receptor antagonists. Ann Pharmacother. 2008 Apr;42(4):558-63. doi:10.1345/aph.1K679. Epub 2008 Mar 25. Review.

F5(ix): Chang DF, Campbell JR. Intraoperative floppy iris syndrome associated with tamsulosin. J Cataract Refract Surg. 2005 Apr;31(4):664-73.

F5(x): Chang DF, Osher RH, Wang L, Koch DD. Prospective multicenter evaluation ofcataract surgery in patients taking tamsulosin (Flomax). Ophthalmology. 2007May;114(5):957-64.
F5(xi): Bell CM, Hatch WV, Fischer HD, Cernat G, Paterson JM, Gruneir A, Gill SS,Bronskill SE, Anderson GM, Rochon PA. Association between tamsulosin and serious ophthalmic adverse events in older men following cataract surgery. JAMA. 2009 May20;301(19):1991-6.

F5(xii): Gani J, Perlis N, Radomski SB. Urologic medications and ophthalmologic side effects: a review. Can Urol Assoc J. 2012 Feb;6(1):53-8.

F6. Mukozaya zarar verebilecek ürolojik girişimler hariç asemptomatik bakteriüride antibiyotik kullanımı uygun değildir

*Mukozaya zarar verebilecek ürolojik girişimler öncesinde asemptomatik bakteriüri taranmalı ve tedavi edilmelidir.

*Asemptomatik bakteriürinin aşağıdaki hasta gruplarında taranması ve/veya tedavi edilmesi önerilmez:

Risk faktörü olmayan hastalar

Diyabeti iyi regüle edilmiş hastalar

Bakımevinde yaşayan hastalar

Alt idrar yolu disfonksiyonu/rekonstrüksiyonu olan hastalar

Rekürren idrar yolu infeksiyonu geçiren hastalar

Artroplasti ameliyatlarından önce

Üriner katateri olan hastalar

F6(i): Lindsay E. Nicolle, Suzanne Bradley, Richard Colgan, James C. Rice, Anthony Schaeffer, Thomas M. Hooton, Infectious Diseases Society of America Guidelines for the Diagnosis and Treatment of Asymptomatic Bacteriuria in Adults, Clinical Infectious Diseases, Volume 40, Issue 5, 1 March 2005, Pages 643-654.

F6(ii): G. Bonkat (Co-chair), R. Pickard (Co-chair), R. Bartoletti, T. Cai, F. Bruyère, S.E. Geerlings, B. Köves, F. Wagenlehner Guidelines Associates: A. Pilatz, B. Pradere, R. Veeratterapillay. EAU Guidelines on Urological Infections. European Association of Urology 2018.

F7. Nitrofurantoin'in GFR $<30 \mathrm{~mL} / \mathrm{dk} / 1,73 \mathrm{~m}^{2}$ olan hastalarda kullanımı uygun değildir

*Nitrofurantoin'in üriner infeksiyonların süpresyon tedavisi amacıyla uzun süreli kullanımı yaşlılarda uygun değildir (uzun süreli kullanımda irreversibl pulmoner fibroz, karaciğer toksisitesi ve periferal nöropati riski nedeniyle)

F7(i): By the 2019 American Geriatrics Society Beers Criteria ${ }^{\circledR}$ Update Expert Panel. American Geriatrics Soci-ety 2019 Updated AGS Beers Criteria ${ }^{\circledR}$ for Potentially Inappropriate Medication Use in Older Adults. J Am Geriatr Soc. 2019Apr;67(4):674-694.

F7(ii): G. Bonkat (Co-chair), R. Pickard (Co-chair), R. Bartoletti, T. Cai, F. Bruyère, S.E. Geerlings, B. Kö-ves, F. Wagenlehner 
Guidelines Associates: A. Pilatz, B. Pradere, R. Veeratterapillay. EAU Guidelines onUro-logical Infections. European Association of Urology 2018.

\section{G: Endokrin Sistem Kriterleri}

G1. Yaşam beklentisi düşük ( $<5$ yıl) veya anamnezde düşme veya bilişsel yetersizliği olan hastalarda sıkı kan şekeri kontrolu $(\mathrm{HbA} 1 \mathrm{C}<\% 7)$ uygun değildir

G1(i): Onder $G$, Landi $F$, Fusco $D$, Corsonello $A$, Tosato $M$, Battaglia M, Mastropaolo S, Settanni S, Antocic-co M, Lattanzio F. Recommendations to prescribe in complex older adults: results of the CRIteria to assess app-ropriate Medication use among Elderly complex patients (CRIME) project. Drugs Aging. 2014 Jan;31(1):33-45.

G1(ii): Medha M. Treatment of type 2 diabetes mellitus in the older patient. In: UpToDate, Post, TW (Ed), UpToDate, Waltham, MA, 2019 Son erişim tarihi 23 Ekim 2019.

\#G2. Kırılgan veya malnütre yaşlılarda metformin kullanımı uygun değildir (metformin'in GiS yan etkileri ve iştahsızlık etkisi nedeniyle)

*Malnütrisyon riski olan olgularda metformin kullanımına karzarar dengesi göz önüne alınarak karar verilmelidir.

G2(i): Haas L. Management of diabetes mellitus medications in the nursing home. Drugs Aging. 2005;22:209-218.

G2(ii): Onder $G$, Landi $F$, Fusco $D$, Corsonello $A$, Tosato $M$, Battaglia M, Mastropaolo S, Settanni S, Anto-cicco M, Lattanzio F. Recommendations to prescribe in complex older adults: results of the CRIteria to assess appropriate Medication use among Elderly complex patients (CRIME) project. Drugs Aging. 2014 Jan;31(1):33-45.

G3(iii): Bahat G, Erdogan T, Karan MA. Need for increased awareness for avoiding metformin treatment in mal-nourished older adults with diabetes mellitus. Clinical Nutrition, 2019.

G3. Metformin'in GFR $<30 \mathrm{~mL} / \mathrm{dk} / 1,73 \mathrm{~m}^{2}$ olan hastalarda kullanımı uygun değildir (laktik asidoz riski)

*Metformin dozu, GFR: 30-45 mL/dk/1,73 $\mathrm{m}^{2}$ olan hastalarda \%50 azaltılmalıdır.

*Metformin kullanımı laktik asidoz riskini artıran diğer durumlarda da (kalp yetersizliği, karaciğer yetersizliği, şok veya kalıcı hemodinamik instabilite, KOAH, hipoksi) uygun değildir.

G3(i): Metformin: Drug information, Lexicomp Online. Son erişim tarihi 22 Ekim 2019.

G3(ii): Germino FW. Non-insulin treatment of type 2 diabetes mellitus in geriatric patients: a review. Clin Ther 2011; 33(12): 1868-82.
G3(iii): Lalau JD. Lactic acidosis induced by metformin: Incidence, management and prevention. Drug Sa-fety 2010; 33(9): 727-40.

G3(iv): O'Mahony D, O'Sullivan D, Byrne S, O'Connor MN, Ryan C, Gallagher P. STOPP/START criteria for potentially inappropriate prescribing in older people: version 2. Age Ageing. 2015 Mar;44(2):213-8.

G4. Tip 2 DM hastalarında glibenklamid ve klorpropamid gibi uzun etkili sulfanilürelerin kullanımı uygun de-ğildir (uzamış hipoglisemi riski)

G4(i): David K M. Sulfonylureas and meglitinides in the treatment of diabetes mellitus. In: UpToDate, Post, TW (Ed), UpToDate, Waltham, MA, 2019 Son erişim tarihi 29 Ekim 2019.

G4(ii): Graal MB, Wolffenbuttel BH. The use of sulphonylureas in the elderly. Drugs Aging 1999; 15(6): 471-81.

G4(iii): Langtry HD, Balfour JA. Glimepiride. A review of its use in the management of type 2 diabetes melli-tus. Drugs 1998; 55(4): 563-84.

G4(iv): O'Mahony D, O'Sullivan D, Byrne S, O'Connor MN, Ryan C, Gallagher P. STOPP/START criteria for potentially inappropriate prescribing in older people: version 2. Age Ageing. 2015 Mar;44(2):213-8.

G5. Dökümante kalp yetersizliği/kırık anamnezi/artmış kırık riski/mesane kanseri anamnezi olan veya insülin tedavisi almakta olan hastalarda tiazolidinedionların (rosiglitazon, pioglitazon) kullanımı uygun değildir (kalp yetersizliğinde kötüleşme, kırık ve mesane kanser riskinde artış)

G5(i): David K M. Thiazolidinediones in the treatment of diabetes mellitus. In: UpToDate, Post, TW (Ed), UpToDate, Waltham, MA, 2019 Son erişim tarihi 29 Ekim 2019.

G5(ii): Rosiglitazone: Drug information, Lexicomp Online. Son erişim tarihi 04 Kasım 2019.

G5(iii): Germino FW. Noninsulin treatment of type 2 diabetes mellitus in geriatric patients: a review. Clin Ther 2011; 33(12): 1868-82.

G5(iv): Lago RM, Singh PP, Nesto RW. Congestive heart failure and cardiovascular death in patients with pre-diabetes and type 2 diabetes given thiazolidinediones: a meta-analysis of randomised clinical trials. Lancet 2007; 370(9593): 1129-36.

G5(v): O'Mahony D, O'Sullivan D, Byrne S, O'Connor MN, Ryan C, Gallagher P. STOPP/START criteria for potentially inappropriate prescribing in older people: version 2. Age Ageing. 2015 Mar;44(2):213-8.

G6. Kalp yetersizliği olan olgularda saksagliptin kullanımı uygun değildir 
G6(i): LeRoith D, Biessels GJ, Braithwaite SS, Casanueva FF, Draznin B, Halter JB, Hirsch IB, McDonnell ME, Molitch ME, Murad MH, Sinclair AJ. Treatment of Diabetes in Older Adults: An Endocrine Society* Cli-nical Practice Guideline. J Clin Endocrinol Metab. 2019 May 1;104(5):1520-1574.

G6(ii): Scirica BM, Braunwald E, Raz I, Cavender MA, Morrow DA, Jarolim P, Udell JA, Mosenzon O, Im K, Umez-Eronini AA, Pollack PS, Hirshberg B, Frederich R, Lewis BS, McGuire DK, Davidson J, Steg PG, Bhatt DL; SAVOR-TIMI 53 Steering Committee and Investigators. Heart Failure, Saxagliptin, and Diabetes Mellitus: Observations from the SAVOR-TIMI 53 Randomized Trial. Circulation. 2015 Oct 13;132(15):e198.

G7. Kanagliflozinin, diyabete bağlı alt ekstremite ampütasyonu komplikasyonu geçirmiş/ciddi periferik arter hastalığı olan/ tekrarlayan üriner sistem infeksiyonu/genitoüriner enfeksiyonu olan olgularda kullanımı uygun değildir

*SGLT-2 inhibitörleri dehidratasyona, urgency inkontinansa ve diabetik ketoasidoza sebep olabileceklerinden, yaşlı hastalarda genel olarak dikkatle kullanılmalıdır.

G7(i): U.S. Food and Drug Administration. FDA confirms increased risk of leg and foot amputations with the diabetes medicine canagliflozin (Invokana, Invokamet, Invokamet XR). Available at: www.fda.gov/downloads/Drugs/DrugSafety/ UCM558427.pdf.Son erişim tarihi 30 Ekim 2019.

G7(ii): Sinclair AJ, Bode B, Harris S, Vijapurkar U, Shaw W, Desai M, Meininger G. Efficacy and Safety of Canagliflozin in Individuals Aged 75 and Older with Type 2 Diabetes Mellitus: A Pooled Analysis. J Am Geri-atr Soc. 2016 Mar;64(3):543-52.

G7(iii): Watts NB, Bilezikian JP, Usiskin K, Edwards R, Desai M, Law G, Meininger G. Effects of Canagliflo-zin on Fracture Risk in Patients With Type 2 Diabetes Mellitus. J Clin Endocrinol Metab. 2016 Jan;101(1):157-66.

G7(iv): Anthony D. Sodium-glucose co-transporter 2 inhibitors for the treatment of hyperglycemia in type 2 diabetes mellitus. In: UpToDate, Post, TW (Ed), UpToDate, Waltham, MA, 2019 Son erişim tarihi 29 Ekim 2019.

G7(v): Lupsa BC, Inzucchi SE. Use of SGLT2 inhibitors in type 2 diabetes: weighing the risks and benefits. Diabetologia. 2018 Oct;61(10):2118-2125.

G8. SGLT-2 inhibitörlerinin GFR $<45 \mathrm{~mL} / \mathrm{dk} / 1,73 \mathrm{~m}^{2}$ olan olgularda kullanılması uygun değildir

*Kanagliflozin, empagliflozin, ve ertugliflozin'in GFR< $45 \mathrm{~mL}$ dk/1,73 $\mathrm{m}^{2}$ olan olgularda öncelikle etkinlikte azalma nedeniyle kullanılması uygun değildir.

*Dapagliflozin'in GFR $<60 \mathrm{~mL} / \mathrm{dk} / 1,73 \mathrm{~m}^{2}$ olan olgularda etkisinin azalması nedeniyle kullanılması uygun değildir.
*SGLT-2 inhibitörlerinin, GFR 30-60 $\mathrm{mL} / \mathrm{dk} / 1,73 \quad \mathrm{~m}^{2}$ olan hastalarda, nefropati (idrar albümin atılımı $300 \mathrm{mg} / \mathrm{gün}$ ) tedavisi için kullanımı değerlendirilebilir.

G8(i): LeRoith D, Biessels GJ, Braithwaite SS, Casanueva FF, Draznin B, Halter JB, Hirsch IB, McDonnell ME, Molitch ME, Murad MH, Sinclair AJ. Treatment of Diabetes in Older Adults: An Endocrine Society* Cli-nical Practice Guideline. J Clin Endocrinol Metab. 2019 May 1;104(5):1520-1574.

G8(ii): George L B. Treatment of diabetic kidney disease. In: UpToDate, Post, TW (Ed), UpToDate, Waltham, MA, 2019 Son erişim tarihi 29 Ekim 2019.

G9. Androjen eksikliği ile ilişkili semptom ve bulguların eşlik etmediği serum testosteron düzeyi düşüklüğü varlığında androjen kullanımı uygun değildir.

*Hipogonadizm tanısı androjen yetersizliğinin semptom ve belirtileriyle birlikte kalıcı düşük serum testosteron düzeyi varlığında koyulur.

G9(i): O'Mahony D, O'Sullivan D, Byrne S, O'Connor MN, Ryan C, Gallagher P. STOPP/START criteria for potentially inappropriate prescribing in older people: version 2. Age Ageing. 2015 Mar;44(2):213-8. G9(ii): Bhasin S, Brito JP, Cunningham GR, Hayes FJ, Hodis HN, Matsumoto AM, Snyder PJ, Swerdloff RS, Wu FC, Yialamas MA. Testosterone Therapy in Men With Hypogonadism: An Endocrine Society Clinical Practice Guideline. J Clin Endocrinol Metab. 2018 May 1;103(5):17151744.

G9(iii): G.R. Dohle, S. Arver, C. Bettocchi, T.H. Jones, S. Kliesch. EAU Guidelines on Male Hypogonadism. In: European Association of Urology 2018, Son erişim tarihi 29 Ekim 2019.

G10. Meme kanseri veya venöz tromboemboli öyküsü olan hastalarda sistemik östrojen kullanımı uygun değil-dir

*Meme kanseri veya venöz tromboemboli öyküsü olan hastalarda vajinal östrojen; atrofik vajinit gibi ürogenital semptomların tedavisinde hormon-dışı tedavilerden sonra, kar-zarar dengesi göz önünde bulundurularak verilebilir.

G10(i): American College of Obstetricians and Gynecologists' Committee on Gynecologic Practice, Farrell R. ACOG Committee Opinion No. 659: The Use of Vaginal Estrogen in Women With a History of Estrogen-Dependent Breast Cancer. Obstet Gynecol. 2016 Mar;127(3):e93-6.

G10(ii): The NAMS 2017 Hormone Therapy Position Statement Advisory Panel. The 2017 hormone therapy position statement of The North American Menopause Society. Menopause. 2017 Jul;24(7):728-753.

G10(iii): Bergendal A, Kieler $H$, Sundström A, Hirschberg AL, Kocoska-Maras L. Risk of venous thromboem-bolism associated with local and systemic use of hormone therapy in peri- and 
postmenopausal women and in relation to type and route of administration. Menopause. 2016 Jun;23(6):593-9.

G10(iv): Calle EE, Feigelson HS, Hildebrand JS, Teras LR, Thun MJ, Rodriguez C. Postmenopausal hormone use and breast cancer associations differ by hormone regimen and histologic subtype. Cancer 2009; 115(5): 936-45. Erratum in: Cancer 2009; 115(7): 1587.

G10(v): Diergaarde B, Potter JD, Jupe ER, Manjeshwar S, Shimasaki CD, Pugh TW, Defreese DC, Gramling BA, Evans I, White E. Polymorphisms in genes involved in sex hormone metabolism, estrogen plus progestin hormone therapy use, and risk of postmenopausal breast cancer. Cancer Epidemiol Biomarkers Prev 2008; 17(7): 1751-9.

G10(vi): O'Mahony D, O'Sullivan D, Byrne S, O'Connor MN, Ryan C, Gallagher P. STOPP/START criteria for potentially inappropriate prescribing in older people: version 2. Age Ageing. 2015 Mar;44(2):213-8.

G11. Intakt uterusu olan kadınlarda beraberinde progesteron kullanımı olmadan östrojen kullanımı uygun değil-dir (endometrial kanser riski)

G11(i): Management of symptomatic vulvovaginal atrophy: 2013 position statement of The North American Menopause Society. Menopause. 2013 Sep;20(9):888-902; quiz 903-4.

G11(ii): Dick SE, DeWitt DE, Anawalt BD. Postmenopausal hormone replacement therapy and major clinical outcomes: a focus on cardiovascular disease, osteoporosis, dementia, and breast and endometrial neoplasia. Am J Manag Care 2002; 8(1): 95-104.

G11(iii): Furness S, Roberts H, Marjoribanks J, Lethaby A. Hormone therapy in postmenopausal women and risk of endometrial hyperplasia. Cochrane Database Syst Rev 2012 Aug 15;8:CD000402.

G11(iv): Marjoribanks J, Farquhar C, Roberts H, Lethaby A. Long term hormone therapy for perimenopausal and postmenopausal women. Cochrane Database Syst Rev 2012 Jul 11;7:CD004143.

G11(v): O'Mahony D, O'Sullivan D, Byrne S, O'Connor MN, Ryan C, Gallagher P. STOPP/START criteria for potentially inappropriate prescribing in older people: version 2. Age Ageing. 2015 Mar;44(2):213-8.

G11(vi): Lindahl SH. Reviewing the options for local estrogen treatment of vaginal atrophy. Int J Womens He-alth. 2014 Mar $13 ; 6: 307-12$.

G11(vii): US Preventive Services Task Force, Grossman DC, Curry SJ, Owens DK, Barry MJ, Davidson KW, Doubeni CA, Epling JW Jr, Kemper AR, Krist AH, Kurth $A E$, Landefeld CS, Mangione CM, Phipps MG, Silverstein M, Simon MA, Tseng CW. Hormone Therapy for the Primary Prevention of Chronic Conditions in
Postmenopausal Women: US Preventive Services Task Force Recommendation Statement. JAMA. 2017 Dec12;318(22):22242233.

G12. İştah artırıcı olarak megestrol kullanımı uygun değildir (kilo üzerine minimal etki, protrombotik yan etki)

G12(i): By the 2019 American Geriatrics Society Beers Criteria ${ }^{\circledR}$ Update Expert Panel. American Geriatrics Society 2019 Updated AGS Beers Criteria ${ }^{\circledR}$ for Potentially Inappropriate Medication Use in Older Adults. J Am Geriatr Soc. 2019 Apr;67(4):674-694.

G12(ii): Wen FK, Millar J, Oberst-Walsh L, Nashelsky J. Clinical Inquiry: Is megestrol acetate safe and effective for malnourished nursing home residents? J Fam Pract. 2018 Feb;67(2):112-113.

G13. Subklinik hipotiroidisi olan yaşlılarda (TSH: 4-10 mIU/L; sT4: N), tiroid hormonu kullanımı uygun değildir (ek yararı yok, atrial fibrilasyon ve osteoporoz gibi potansiyel yan etki riski)

G13(i): Stott DJ, Rodondi N, Kearney PM, Ford I, Westendorp RGJ, Mooijaart SP, Sattar N, Aubert CE, Au-jesky D, Bauer DC, Baumgartner C, Blum MR, Browne JP, Byrne S, Collet TH, Dekkers OM, den Elzen WPJ, Du Puy RS, Ellis G, Feller M, Floriani $C_{1}$ Hendry K, Hurley C, Jukema JW, Kean S, Kelly M, Krebs D, Langhorne P, McCarthy G, McCarthy V, McConnachie A, McDade M, Messow M, O'Flynn A, O'Riordan D, Poortvliet RKE, Quinn TJ, Russell A, Sinnott C, Smit JWA, Van Dorland HA, Walsh KA, Walsh EK, Watt T, Wilson R, Gussekloo J; TRUST Study Group. Thyroid Hormone Therapy for Older Adults with Subclinical Hypothyroidism. N Engl J Med. 2017 Jun 29;376(26):2534-2544.

G13(ii): Selmer C, Olesen JB, Hansen ML, von Kappelgaard LM, Madsen JC, Hansen PR, Pedersen OD, Faber J, Torp-Pedersen C, Gislason $\mathrm{GH}$. Subclinical and overt thyroid dysfunction and risk of all-cause mortality and cardiovascular events: a large population study. J Clin Endocrinol Metab. 2014 Jul;99(7):2372-82.

G13(iii): Waring AC, Arnold AM, Newman AB, Bùzková $P$, Hirsch $C$, Cappola AR. Longitudinal changes in thyroid function in the oldest old and survival: the cardiovascular health study all-stars study. J Clin Endocrinol Metab. 2012 Nov;97(11):3944-50.

G13(iv): Garber JR, Cobin RH, Gharib H, Hennessey JV, Klein I, Mechanick JI, Pessah-Pollack R, Singer PA, Woeber KA; American Association of Clinical Endocrinologists and American Thyroid Association Taskforce on Hypothyroidism in Adults. Clinical practice guidelines for hypothyroidism in adults: cosponsored by the American Association of Clinical Endocrinologists and the American Thyroid Association. Endocr Pract. 2012 Nov Dec;18(6):988-1028. Erratum in: Endocr Pract. 2013 JanFeb;19(1):175.

G13(v): Razvi S, Weaver JU, Butler TJ, Pearce SH. Levothyroxine treatment of subclinical hypothyroidism, fatal and nonfatal cardiovascular events, and mortality. Arch Intern Med. 2012 May 28;172(10):811-7. 
G13(vi): Pearce SH, Brabant G, Duntas LH, Monzani F, Peeters RP, Razvi S, Wemeau JL. 2013 ETA Guideline: Management of Subclinical Hypothyroidism. Eur Thyroid J. 2013 Dec;2(4):21528.

\section{H: Antimuskarinik-Antikolinerjik Yük}

H1. Yüksek antikolinerjik etkili ilaçların [trisiklik antidepresanlar, klorpromazin, tioridazin, klozapin, olanzapin, hiyosin, oral oksibutinin, 1. jenerasyon antihistaminikler (feniramin, klorfeniramin, hidroksizin, siproheptadin, dimenhidrinat, difenhidramin, meklizin vb.), paroksetin7 kullanımı aşağıdaki durumlarda uygun değildir

Düşme/konstipasyon/dar açılı glokom/demans/deliryum/idrar retansiyonu/erkekte obstrüktif LUTS semptomları/eş zamanlı yüksek antikolinerjik etkili ilaç kullanımı

${ }^{*}$ Genel olarak yaşlılarda yüksek antikolinerjik etkili ilaçların kullanımı tercih edilmemelidir; klinik gereklilik durumunda yan etki açısından dikkatli takip edilmelidir.

*1.kuşak antihistaminiklerin akut alerjik reaksiyon varlığında parenteral kullanımı uygundur.

H1 (i): Verhamme KM, Sturkenboom MC, Stricker BH, Bosch R. Drug-induced urinary retention: incidence, management and prevention. Drug Saf 2008; 31(5):373-88.

H1(ii): Feinberg M. The problems of anticholinergic adverse effects in older patients. Drugs Aging 1993; 3(4): 335-48.

H1(iii): Gerretsen P, Pollock BG. Drugs with anticholinergic properties: a current perspective on use and safety. Expert Opin Drug Saf 2011; 10(5): 751-65.

H1 (iv): Karimi S, Dharia SP, Flora DS, Slattum PW. Anticholinergic burden: clinical implications for seniors and strategies for clinicians. Consult Pharm 2012; 27(8): 564-82.

H1(v): O'Mahony D, O'Sullivan D, Byrne S, O'Connor MN, Ryan C, Gallagher P. STOPP/START criteria for potentially inappropriate prescribing in older people: version 2. Age Ageing. 2015 Mar;44(2):213-8.

H1(vi): Collamati A, Martone AM, Poscia A, Brandi V, Celi M, Marzetti $E$, Cherubini $A$, Landi F. Anticholinergic drugs and negative outcomes in the older population: from biological plausibility to clinical evidence. Aging Clin Exp Res. 2016 Feb;28(1):25-35.

H1 (vii): Salahudeen MS, Duffull SB, Nishtala PS. Anticholinergic burden quantified by anticholinergic risk scales and adverse outcomes in older people: a systematic review. BMC Geriatr. 2015 Mar 25;15:31. doi: 10.1186/s12877-015-0029-9.

\section{J: Suplemanlar.}

J1. Kanama riski olan olgularda (antikoagülan kullanımı, NSAii kullanımı, anlamlı kanama öyküsü) gingko biloba ekstraktı kullanımı uygun değidir

${ }^{*}$ Gingko biloba ile birlikte aspirin kullanımında da kanama riski artar; kombine kullanılmamaları daha uygun olabilir

J1(i): Robert B S. Clinical use of ginkgo biloba. In: UpToDate, Post, TW (Ed), UpToDate, Waltham, MA, 2019 Son erişim tarihi 29 Ekim 2019.

J1(ii): Clinton B W. Treatment and prevention of vascular dementia. In: UpToDate, Post, TW (Ed), UpToDate, Waltham, MA, 2019 Son erişim tarihi 29 Ekim 2019.

J1(iii): Bent S, Goldberg H, Padula A, Avins AL. Spontaneous bleeding associated with ginkgo biloba: a case report and systematic review of the literature: a case report and systematic review of the literature. J Gen Intern Med 2005; 20:657.

J1 (iv): Rosenblatt M, Mindel J. Spontaneous hyphema associated with ingestion of Ginkgo biloba extract. N Engl J Med 1997; 336:1108.

J1(v): Rowin J, Lewis SL. Spontaneous bilateral subdural hematomas associated with chronic Ginkgo biloba ingestion. Neurology 1996; 46:1775.

J1 (vi): Gilbert GJ. Ginkgo biloba. Neurology. 1997 Apr;48(4):1137.

J1(vii): Vale S. Subarachnoid haemorrhage associated with Ginkgo biloba. Lancet. 1998 Jul 4;352(9121):36.

J1(viii): Pedroso JL, Henriques Aquino CC, Escórcio Bezerra ML, Baiense RF, Suarez MM, Dutra LA, Braga-Neto P, Povoas Barsottini OG. Ginkgo biloba and cerebral bleeding: a case report and critical review. Neurologist. 2011 Mar;17(2):89-90.

J2. Sarı kantaron'un (St. John's Wort) antidepresan kullanan hastalarda (özellikle SSRi ile serotonerjik sendrom riski) ve sitokrom p450 ile metabolize olan ilaç (örn. digoksin, teofilin, varfarin, karbamazepin, fenitoin, fenobarbital) kullanan hastalarda sistemik kullanımı uygun değildir (sarı kantaron sitokrom p450 aktivasyonu yapar)

J2(i): Robert B Saper. Clinical use of St. John's wort. In: UpToDate, Poat, TW(Ed), Waltham, MA, 2019 Son erişim tarihi 29 Ekim 2019.

J2(ii): Lantz MS, Buchalter E, Giambanco V. St. John's wort and antidepressant drug interactions in the elderly. J Geriatr Psychiatry Neurol. 1999;12(1):7.

J2(iii): Henderson L, Yue OY, Bergquist C, Gerden B, Arlett P. St John's wort (Hypericum perforatum): drug interactions and clinical outcomes. British Journal of Clinical Pharmacology. 2002;54(4):349-356. 
\#J3. Varfarin kullanan hastalarda supleman kullanımı uygun değildir (kanama riskinde olası artış nedeniyle)

*Oral olarak kullanılan birçok supleman (örn. ginseng, sarımsak, zerdeçal, zencefil, şeytan pençesi, sarı kantaron, koenzim 010, yeşil çay vb.) varfarin'in antikoagülan etkisini artırarak kanama riskinde artışa sebep olabilir.

J3(i): Ge B, Zhang Z, Zuo Z. Updates on the clinical evidenced herbwarfarin interactions. Evid Based Complement Alternat Med. 2014;2014:957362.

J3(ii): Holbrook AM, Pereira JA, Labiris R, McDonald H, Douketis JD, Crowther M, Wells PS. Systematic overview of warfarin and its drug and food interactions. Arch Intern Med. 2005 May 23;165(10):1095-106.

\#Uluslararası Delfi paneli çalışmasında konsensus sağlanmayan kriterler

\section{Kısaltmalar:}

AF: Atrial fibrilasyon

ACEi: Anjiotensin konverting enzim inhibitörleri

ARB: Anjiotensin reseptör blokerleri

ChEls:Asetilkolinesteraz inhibitörleri

DM: Diabetes mellitus

EF: Ejeksiyon fraksiyonu

eGFR: Estimated Glomerular Filtrasyon hızı

FDA: Food and Drug Administration
GIS: Gastrointestinal sistem

GiA: Geçici iskemik atak

GÖR: Gastroözofageal reflü

H1 receptor: Histamin 1 reseptör

HT: Hipertansiyon

INR: International Normalized Ratio

KOAH: Kronik obstrüktif akciğer hastalığı

LUTS: Alt üriner sistem semptomları

Mi: Miyokard infarktüsü

MSS: Merkezi sinir sistemi

NSAii: Non steroidal anti inflamatuar ilaçlar

NYHA: New York Heart Association

OAK: Oral antikoagülan

PMR: Post miksiyonel rezidü

$\mathrm{PO}_{2}$ : Parsiyel oksijen basıncı

PPI: Proton pompa inhibitörleri

OTc: düzeltilmiş OT Intervali

RAS: Renin anjiotensin sistem

SGLT-2: Sodium-glucose kotransporter-2

SNRIs: Serotonin-norepinefrin geri alım inhibitörleri

SSRIs: Selektif serotonin geri alım inhibitörleri

TSH: Tiroid stimulan hormon 


\section{TIME to START- YAŞLIDA BAŞLANMASI UYGUN OLAN ILAÇLAR}

Bu grup ilaçların, kriter içeriğindeki durumlarda kullanımının yaşıılarda endikasyonu ve potansiyel faydalanımı vardır ancak klinik pratikte sıklıkla gözden kaçabilmekte veya ileri yaş nedeniyle, geçerli ek bir sebep olmaksızın, verilmemektedir. Bu ilaçların kriter içeriğindeki durumda kullanılmaması "potansiyel uygunsuz ilaç kullanımı" olarak nitelendirilmektedirler. Klinisyenler hastanın tüm özellikleriyle ilacın hastasındaki potansiyel fayda ve zararını (kar-zarar dengesini), beklenen yaşam süresini ve hasta/bakımveren tercihleri doğrultusunda saptanan tedavi hedeflerini göz önünde bulundurarak karar vermelidir. Bu grup ilaçları klinisyenler bazı olgularda kullanmamayı uygun bulabilir.

Klinik kullanıma yardımo olması için bazı kriterlere eklenen açıklamalar kriterden hemen sonra italik karakterde ve önek * ile verilmiştir.

Referanslar; kriterle ilgili ve mevcut ise açıklamalar ile ilgili referansları içermektedir.

\section{TIME-to-START Kriterleri (referanslı ve açıklamalı)}

\section{A: Kardiyovasküler Sistem Kriterleri}

A1. Dökümante aterosklerotik koroner arter hastalığı (geçirilmiş akut koroner sendrom/koroner anjioplasti veya stentleme/ koroner arter bypass greftleme/abdominal aort anevrizması), dökümante aterosklerotik serebrovasküler hastalık (geçirilmiş iskemik inme/GiA/ geçirilmiş karotis endarterektomi veya stentleme) veya semptomatik alt ekstremite arter hastalığı olan hastalarda sekonder korunma amaçlı antiplatelet tedavi (aspirin veya klopidogrel) başlanması uygundur

*Primer kardiyovasküler korunma amaçlı aspirin başlanması çoğu olguda uygun değildir (intrakranial ve GiS kanama riskinde artış ve sınırlı faydalanım nedeniyle).

A1 (i): Zuckerman IH, Yin X, Rattinger GB, Gottlieb SS, SimoniWastila L, Pierce SA, Huang TY, Shenolikar R, Stuart B. Effect of exposure to evidence-based pharmacotherapy on outcomes after acute myocardial infarction in older adults. J Am Geriatr Soc 2012; 60(10): 1854-61.

A1(ii): Alonso-Coello $\mathrm{P}$, Bellmunt $\mathrm{S}$, McGorrian $\mathrm{C}$, Anand SS, Guzman R, Criqui MH, AkIEA, Olav Vandvik P, Lansberg MG, Guyatt GH, Spencer FA; American College of Chest Physicians. Antithrombotic therapy in peripheral artery disease: Antithrombotic Therapy and Prevention of Thrombosis, 9th ed: American College of Chest Physicians Evidence-Based Clinical Practice Guidelines. Chest 2012; 141(2Suppl): e669S-90S.

A1 (iii): Fleg JL, Aronow WS, Frishman WH. Cardiovascular drug therapy in the elderly: benefits and challenges. Nat Rev Cardiol 2011; 8(1): 13-28.
A1(iv): Vandvik PO, Lincoff AM, Gore JM, Gutterman DD, Sonnenberg FA, Alonso-Coello P,AkI EA, Lansberg MG, Guyatt GH, Spencer FA; American College of Chest Physicians. Primary and secondary prevention of cardiovascular disease: Antithrombotic Therapy and Prevention of Thrombosis, 9th ed: American College of Chest Physicians Evidence-Based Clinical Practice Guidelines. Chest 2012; 141(2Suppl): e637S-68S. Erratum in: Chest 2012; 141(4): 1129. Dosage error in article text.

A1(v): O'Mahony D, O'Sullivan D, Byrne S, O'Connor MN, Ryan C, Gallagher P. STOPP/START criteria for potentially inappropriate prescribing in older people: version 2. Age Ageing. 2015 Mar;44(2):213-8. doi: 10.1093/ageing/afu145. Epub 2014 Oct 16.

A1(vi): McNeil JJ, Wolfe R, Woods RL, Tonkin AM, Donnan GA, Nelson MR, Reid CM, Lockery JE, Kirpach B, Storey E, Shah RC, Williamson JD, Margolis KL, Ernst ME, Abhayaratna WP, Stocks $\mathrm{N}$, Fitzgerald SM, Orchard SG, Trevaks RE, Beilin $\amalg$, Johnston $\mathrm{Cl}$, Ryan J, Radziszewska B, Jelinek M, Malik M, Eaton CB, Brauer D, Cloud G, Wood EM, Mahady SE, Satterfield S, Grimm R, Murray AM; ASPREE Investigator Group. Effect of Aspirin on Cardiovascular Events and Bleeding in the Healthy Elderly. N Engl J Med. 2018 Oct 18;379(16):1509-1518.

A1(vii): ASCEND Study Collaborative Group, Bowman $L$, Mafham M, Wallendszus K, Stevens W, Buck G, Barton J, Murphy K, Aung T, Haynes R, Cox J, Murawska A, Young A, Lay $M$, Chen F, Sammons E, Waters $E$, Adler A, Bodansky J, Farmer A, McPherson R, Neil A, Simpson D, Peto R, Baigent C, Collins R, Parish $S$, Armitage J. Effects of Aspirin for Primary Prevention in Persons with Diabetes Mellitus. N Engl J Med. 2018 Oct 18;379(16):1529-1539.

A1(viii): Aboyans $V$, Ricco JB, Bartelink MEL, Björck $M$, Brodmann M, Cohnert T, Collet JP, Czerny M, De Carlo M, Debus $\mathrm{S}$, Espinola-Klein C, Kahan T, Kownator S, Mazzolai L, Naylor AR, Roffi M, Röther J, Sprynger M, Tendera M, Tepe G, Venermo M, Vlachopoulos C, Desormais I; ESC Scientific Document Group. 2017 ESC Guidelines on the Diagnosis and Treatment of Peripheral Arterial Diseases, in collaboration with the European Society for Vascular Surgery (ESVS): Document covering atherosclerotic disease of extracranial carotid and vertebral, mesenteric, renal, upper and lower extremity arteriesEndorsed by: the European Stroke Organization (ESO)The Task Force for the Diagnosis and Treatment of Peripheral Arterial Diseases of the European Society of Cardiology (ESC) and of the European Society for Vascular Surgery (ESVS). Eur Heart J. 2018 Mar 1;39(9):763-816.

A1(ix): Authors/Task Force Members:, Piepoli MF, Hoes AW, Agewall $S$, Albus $C$, Brotons $C$, Catapano AL, Cooney MT, Corrà U, Cosyns B, Deaton C, Graham I, Hall MS, Hobbs FDR, Løchen $M L$, Löllgen $H$, Marques-Vidal P, Perk J, Prescott E, Redon J, 
Richter DJ, Sattar N, Smulders Y, Tiberi M, Bart van der Worp H, van Dis I, Verschuren WMM. 2016 European Guidelines on cardiovascular disease prevention in clinical practice: The Sixth Joint Task Force of the European Society of Cardiology and Other Societies on Cardiovascular Disease Prevention in Clinical Practice (constituted by representatives of 10 societies and by invited experts) Developed with the special contribution of the European Association for Cardiovascular Prevention \& Rehabilitation (EACPR). Atherosclerosis. 2016 Sep;252:207-274.

A2. Dökümante aterosklerotik koroner arter hastalığı (geçirilmiş akut koroner sendrom/koroner anjioplasti veya stentleme/ koroner arter bypass greftleme/abdominal aort anevrizması), dökümante serebrovasküler hastalık (geçirilmiş iskemik inme/ GIA/geçirilmiş karotis endarterektomi veya stentleme) veya periferik arter hastalığı olan hastalarda sekonder korunma amaçlı statin tedavisi başlanması uygundur

*Yaşam beklentisi <2 yıl olan hastalarda, terminal demansı olanlarda, >85 yaş hastalarda statinden beklenen faydalanım düşüktür; statin yan etkileri (miyopati, karaciğer toksisitesi vb.) daha fazladır. *Bu olgularda, statin tedavisi kararı hasta/ hasta yakını bilgilendirmesi ve ortak karar verme ilkesi ile belirlenmelidir.

A2(i): Mills EJ, Wu P, Chong G, Ghement I, Singh S, Akl EA, Eyawo 0 , Guyatt $\mathrm{G}$, Berwanger 0 , Briel M. Efficacy and safety of statin treatment for cardiovascular disease: a network metaanalysis of 170,255 patients from 76 randomized trials. OJM 2011; 104(2): 109-24. Review.

A2(ii): Brugts JJ, Yetgin T, Hoeks SE, Gotto AM, Shepherd J, Westendorp RG, de CraenAJ, Knopp RH, Nakamura H, Ridker $P$, van Domburg $R$, Deckers JW. The benefits of statins in people without established cardiovascular disease but with cardiovascular risk factors: meta-analysis of randomised controlled trials. BMJ 2009; 338: b2376. Review

A2(iii): Amarenco P, Labreuche J. Lipid management in the prevention of stroke: review and updated meta-analysis of statins for stroke prevention. Lancet Neurol 2009; 8(5): 453-63. Review.

A2(iv): Onder $G$, Landi $F$, Fusco $D$, Corsonello $A$, Tosato $M$, Battaglia M, Mastropaolo S, Settanni S, Antocicco M, Lattanzio F. Recommendations to prescribe in complex older adults: results of the CRIteria to assess appropriate Medication use among Elderly complex patients (CRIME) project. Drugs Aging. 2014 Jan;31(1):33-45. Review.

A2(v): O'Mahony D, O'Sullivan D, Byrne S, O'Connor MN, Ryan C, Gallagher P. STOPP/START criteria for potentially inappropriate prescribing in older people: version 2. Age Ageing. 2015 Mar;44(2):213-8. doi: 10.1093/ageing/afu145. Epub 2014 Oct 16. Review.
A2(vi): Aboyans V, Ricco JB, Bartelink MEL, Björck M, Brodmann $M$, Cohnert T, Collet JP, Czerny M, De Carlo M, Debus $S$, Espinola-Klein C, Kahan T, Kownator $S$, Mazzolai L, Naylor AR, Roffi M, Röther J, Sprynger M, Tendera M, Tepe G, Venermo M, Vlachopoulos C, Desormais I; ESC Scientific Document Group. 2017 ESC Guidelines on the Diagnosis and Treatment of Peripheral Arterial Diseases, in collaboration with the European Society for Vascular Surgery (ESVS): Document covering atherosclerotic disease of extracranial carotid and vertebral, mesenteric, renal, upper and lower extremity arteriesEndorsed by: the European Stroke Organization (ESO)The Task Force for the Diagnosis and Treatment of Peripheral Arterial Diseases of the European Society of Cardiology (ESC) and of the European Society for Vascular Surgery (ESVS). Eur Heart J. 2018 Mar 1;39(9):763-816.

A2(vii): Authors/Task Force Members:, Piepoli MF, Hoes AW, Agewall $\mathrm{S}$, Albus $\mathrm{C}$, Brotons $\mathrm{C}$, Catapano AL, Cooney MT, Corrà U, Cosyns B, Deaton C, Graham I, Hall MS, Hobbs FDR, Løchen $M L$, Löllgen $H$, Marques-Vidal P, Perk J, Prescott E, Redon J, Richter DJ, Sattar N, Smulders Y, Tiberi M, Bart van der Worp H, van Dis I, Verschuren WMM. 2016 European Guidelines on cardiovascular disease prevention in clinical practice: The Sixth Joint Task Force of the European Society of Cardiology and Other Societies on Cardiovascular Disease Prevention in Clinical Practice (constituted by representatives of 10 societies and by invited experts) Developed with the special contribution of the European Association for Cardiovascular Prevention \& Rehabilitation (EACPR). Atherosclerosis. 2016 Sep;252:207-274.

A2(viii): Fleg JL, Forman DE, Berra K, Bittner V, Blumenthal JA, Chen MA, Cheng S, Kitzman DW, Maurer MS, Rich MW, Shen WK, Williams MA, Zieman SJ; American Heart Association Committees on Older Populations and Exercise Cardiac Rehabilitation and Prevention of the Council on Clinical Cardiology, Council on Cardiovascular and Stroke Nursing, Council on Lifestyle and Cardiometabolic He. Secondary prevention of atherosclerotic cardiovascular disease in older adults: a scientific statement from the American Heart Association. Circulation. 2013 Nov 26;128(22):2422-46.

A3. Sistolik kan basıncı sürekli olarak $>160 \mathrm{mmHg}$ ve/veya diastolik kan basıncı sürekli olarak $>90 \mathrm{mmHg}$ olan hastalarda antihipertansif tedavi başlanması uygundur

A3(i): Williams B, Poulter NR, Brown MJ, Davis M, Mclnnes GT, Potter JF, Sever PS, Thom SM; BHS guidelines working party, for the British Hypertension Society.British Hypertension Society guidelines for hypertension management 2004 (BHS-IV): summary. BMJ 2004; 328(7440):634-40. Erratum in: BMJ 2004; 328(7445): 926.

A3(ii): Papademetriou V, Farsang C, Elmfeldt D, Hofman A, Lithell H, Olofsson B, Skoog I, Trenkwalder P, Zanchetti A; 
Study on Cognition and Prognosis in the Elderly study group. Stroke prevention with the angiotensin II type 1-receptor blocker candesartan in elderly patients with isolated systolic hypertension: the Study on Cognition and Prognosis in the Elderly (SCOPE). J Am Coll Cardiol 2004; 44(6): 1175-80.

A3(iii): Bejan-Angoulvant $T$, Saadatian-Elahi $M$, Wright JM, Schron EB, Lindholm LH, Fagard R, Staessen JA, Gueyffier F. Treatment of hypertension in patients 80years and older: the lower the better? A meta-analysis of randomized controlled trials. J Hypertens 2010; 28(7): 1366-72.

A3(iv): George L B. Treatment of hypertension in patients with diabetes mellitus. In: UpToDate, Post, TW (Ed), UpToDate, Waltham, MA, 2019 Son erişim tarihi 23 Ekim 2019.

A3(v): Williams B, Mancia G, Spiering W, Agabiti Rosei E, Azizi M, Burnier M, Clement D, Coca A, De Simone G, Dominiczak A, Kahan T, Mahfoud F, Redon J, Ruilope L, Zanchetti A, Kerins M, Kjeldsen S, Kreutz R, Laurent S, Lip GYH, McManus R, Narkiewicz K, Ruschitzka F, Schmieder R, Shlyakhto E, Tsioufis K, Aboyans $V$, Desormais I. 2018 Practice guidelines for the management of arterial hypertension of the European Society of Hypertension (ESH) and the European Society of Cardiology (ESC). Blood Press. 2018 Dec;27(6):314-340.

A3(vi): Paul K. Whelton, Robert M. Carey, Wilbert S. Aronow, Donald E. Casey Jr., Karen J. Collins, Cheryl Dennison Himmelfarb, Sondra M. DePalma, Samuel Gidding, Kenneth A. Jamerson, Daniel W. Jones, Eric J. MacLaughlin, Paul Muntner, Bruce Ovbiagele, Sidney C. Smith Jr., Crystal C. Spencer, Randall S. Stafford, Sandra J. Taler, Randal J. Thomas, Kim A. Williams Sr., Jeff D. Williamson and Jackson T. Wright Jr. 2017 ACC/AHA/ AAPA/ABC/ACPM/ AGS/APhA/ASH/ ASPC/NMA/PCNA Guideline for the Prevention, Detection, Evaluation, and Management of High Blood Pressure in Adults A Report of the American College of Cardiology/American Heart Association Task Force on Clinical Practice Guidelines.. J Am Coll Cardiol 2018;71:e127-e248

A3(vii): O'Mahony D, O'Sullivan D, Byrne S, O'Connor MN, Ryan C, Gallagher P. STOPP/START criteria for potentially inappropriate prescribing in older people: version 2. Age Ageing. 2015 Mar;44(2):213-8. doi: 10.1093/ageing/afu145. Epub 2014 Oct 16. Review.

A4. Kronik non-valvüler AF varlığında, CHA2DS2-VASc skoru göz önüne alınarak, OAK (vitamin $\mathrm{K}$ antagonistleri, direkt trombin inhibitorleri veya faktor $\mathrm{Xa}$ inhibitörleri) başlanması uygundur

*Vitamin $K$ antagonistleri yerine non vitamin $K$ antagonisti'nin (YOAK) tercih edilmesi önerilir.

A4(i): Hughes M, Lip GY; Guideline Development Group, National Clinical Guideline forManagement of Atrial Fibrillation in Primary and Secondary Care, Nationallnstitute for Health and Clinical Excellence. Stroke and thromboembolism inatrial fibrillation: a systematic review of stroke risk factors, riskstratification schema and cost effectiveness data. Thromb Haemost 2008; 99(2): 295-304Review.

A4(ii): Dentali F, Riva N, Crowther M, Turpie AG, Lip GY, Ageno W. Efficacy and safetyof the novel oral anticoagulants in atrial fibrillation: a systematic review and meta-analysis of the literature. Circulation 2012; 126(20): 2381-91. Review.

A4(iii): Hart RG, Pearce LA, Aguilar MI. Meta-analysis: antithrombotic therapy to prevent stroke in patients who have non-valvular atrial fibrillation. Ann Intern Med 2007; 146(12): 857-67.

A4(iv): Aguilar MI, Hart R. Oral anticoagulants for preventing stroke in patients with non-valvular atrial fibrillation and no previous history of stroke or transient ischemic attacks. Cochrane Database of Systematic Reviews 2005, Issue 3. Art. No.: CD001927.

A4(v): Kirchhof $P$, Benussi $S$, Kotecha D, Ahlsson A, Atar D, Casadei B, Castella M, Diener HC, Heidbuchel H, Hendriks J, Hindricks G, Manolis AS, Oldgren J, Popescu BA, Schotten U, Van Putte B, Vardas P, Agewall S, Camm J, Baron Esquivias G,Budts W, Carerj S, Casselman F, Coca A, De Caterina R, Deftereos S, Dobrev D, Ferro JM, Filippatos G, Fitzsimons D, Gorenek B, Guenoun M, Hohnloser SH, Kolh P, Lip GY, Manolis A, McMurray J, Ponikowski P, Rosenhek R, Ruschitzka F, Savelieva I, Sharma S, Suwalski P, Tamargo JL, Taylor CJ, Van Gelder IC, Voors AA, Windecker S, Zamorano JL, Zeppenfeld K. 2016 ESC Guidelines for the management of atrial fibrillation developed in collaboration with EACTS. Eur J Cardiothorac Surg. 2016 Nov;50(5):e1-e88.

A4(vi): O'Mahony D, O'Sullivan D, Byrne S, O'Connor MN, Ryan C, Gallagher P. STOPP/START criteria for potentially inappropriate prescribing in older people: version 2. Age Ageing. 2015 Mar;44(2):213-8.

A5. Sistolik kalp yetersizliği $(\mathrm{EF}<=$ \%40) veya ST elevasyonlu Mi varlığında ACE inhibitörü tedavisi başlanması uygundur

A5(i): Fleg JL, Aronow WS, Frishman WH. Cardiovascular drug therapy in the elderly: benefits and challenges. Nat Rev Cardiol 2011; 8(1):13-28. Review.

A5(ii): Arif SA, Mergenhagen KA, Del Carpio RO, Ho C. Treatment of systolic heartfailure in the elderly: an evidence-based review. Ann Pharmacother 2010; 44(10): 1604-14. Review.

A5(iii): Lahoud R, Howe M, Krishnan SM, Zacharias $S$, Jackson EA. Effect of use of combination evidence-based medical therapy after acute coronary syndromes on long-term outcomes. Am J Cardiol 2012; 109(2): 159-64.

A5(iv): Ibanez B, James S, Agewall S, Antunes MJ, BucciarelliDucci $C$, Bueno H, Caforio ALP, Crea F, Goudevenos JA, Halvorsen $S$, Hindricks $G$, Kastrati $A$, Lenzen $M J$, Prescott $E$, Roffi $M$, Valgimigli M, Varenhorst C, Vranckx P, Widimský P. [2017 ESC 
Guidelines for the management of acute myocardial infarction in patients presenting with ST-segment elevation.]. Kardiol Pol. 2018;76(2):229-313.

A5(v): Marco Roffi, Carlo Patrono, Jean-Philippe Collet, Christian Mueller, Marco Valgimigli, Felicita Andreotti, Jeroen J. Bax, Michael A. Borger, Carlos Brotons, Derek P. Chew, Baris Gencer, Gerd Hasenfuss, Keld Kjeldsen, Patrizio Lancellotti, UIf Landmesser, Julinda Mehilli, Debabrata Mukherjee, Robert F. Storey, Stephan Windecker, ESC Scientific Document Group, 2015 ESC Guidelines for the management of acute coronary syndromes in patients presenting without persistent STsegment elevation: Task Force for the Management of Acute Coronary Syndromes in Patients Presenting without Persistent ST-Segment Elevation of the European Society of Cardiology (ESC), European Heart Journal, Volume 37, Issue 3, 14 January 2016, Pages 267-315.

A5(vi): Task Force Members, Montalescot G, Sechtem U, Achenbach S, Andreotti F, Arden C, Budaj A, Bugiardini R, Crea F, Cuisset T, Di Mario C, Ferreira JR, Gersh BJ, Gitt AK, Hulot JS, Marx N, Opie LH, Pfisterer M, Prescott E, Ruschitzka F, Sabaté M, Senior R, Taggart DP, van der Wall EE, Vrints CJ; ESC Committee for Practice Guidelines, Zamorano JL, Achenbach S, Baumgartner H, Bax JJ, Bueno H, Dean V, Deaton C, Erol C, Fagard R, Ferrari R, Hasdai D, Hoes AW, Kirchhof $P$, Knuuti J, Kolh P, Lancellotti P, Linhart A, Nihoyannopoulos P, Piepoli MF, Ponikowski P, Sirnes PA, Tamargo JL, Tendera M, Torbicki A, Wijns W, Windecker S; Document Reviewers, Knuuti J, Valgimigli M, Bueno H, Claeys MJ, Donner-Banzhoff N, Erol C, Frank H, Funck-Brentano C, Gaemperli O, Gonzalez-Juanatey JR, Hamilos M, Hasdai D, Husted S, James SK, Kervinen K, Kolh P, Kristensen SD, Lancellotti P, Maggioni AP, Piepoli MF, Pries AR, Romeo $F$, Rydén $L$, Simoons ML, Sirnes PA, Steg PG, Timmis A, Wijns W, Windecker S, Yildirir A, Zamorano JL. 2013 ESC guidelines on the management of stable coronary artery disease: the Task Force on the management of stable coronary artery disease of the European Society of Cardiology. Eur Heart J. 2013 Oct;34(38):2949-3003.

A5(vii): Fihn SD, Gardin JM, Abrams J, Berra K, Blankenship JC, Dallas AP, Douglas PS, Foody JM, Gerber TC, Hinderliter $A L$, King SB 3rd, Kligfield PD, Krumholz HM, Kwong RY, Lim MJ, Linderbaum JA, Mack MJ, Munger MA, Prager RL, Sabik JF, Shaw $\sqcup$, Sikkema JD, Smith CR Jr, Smith SC Jr, Spertus JA, Williams SV; American College of Cardiology Foundation; American Heart Association Task Force on Practice Guidelines; American College of Physicians; American Association for Thoracic Surgery; Preventive Cardiovascular Nurses Association; Society for Cardiovascular Angiography and Interventions; Society of Thoracic Surgeons. 2012 ACCF/AHA/ACP/AATS/ PCNA/SCAI/STS Guideline for the diagnosis and management of patients with stable ischemic heart disease: a report of the American College of Cardiology Foundation/American Heart Association Task Force on Practice Guidelines, and the American College of Physicians, American Association for Thoracic Surgery, Preventive Cardiovascular Nurses Association, Society for Cardiovascular Angiography and Interventions, and Society of Thoracic Surgeons. J Am Coll Cardiol. 2012 Dec 18;60(24):e44-e164.

A5(viii): O'Mahony D, O'Sullivan D, Byrne S, O'Connor MN, Ryan C, Gallagher P. STOPP/START criteria for potentially inappropriate prescribing in older people: version 2. Age Ageing. 2015 Mar;44(2):213-8. doi: 10.1093/ageing/afu145. Epub 2014 Oct 16. Review.

A6. Sistolik kalp yetersizliği $(E F<=\% 40)$ veya iskemik kalp hastalığı (kronik iskemik kalp hastalığında antianjinal etki/ Mi sonrası dönemde mortalite düşürücü etki nedeniyle) varlığında beta-bloker tedavi (sistolik KY'de bisoprolol/uzamış salınımlı metoprolol süksinat/karvedilol/nebivolol; iskemik kalp hastalığnda herhangi bir beta-bloker) başlanması uygundur

*Miyokard infarktüsünden 3 yıl sonra beta-bloker tedavi potansiyel kar-zarar dengesi göz önünde bulundurularak kesilebilir.

A6(i): Theo E M. Initial pharmacologic therapy of heart failure with reduced ejection fraction in adults. Son erişim tarihi 11 Kasım 2019.

A6(ii): Flather MD, Shibata MC, Coats AJ, et al. Randomized trial to determine the effect of nebivolol on mortality and cardiovascular hospital admission in elderly patients with heart failure (SENIORS). Eur Heart J 2005; 26:215.

A6(iii): van Veldhuisen DJ, Cohen-Solal A, Böhm M, et al. Betablockade with nebivolol in elderly heart failure patients with impaired and preserved left ventricular ejection fraction: Data From SENIORS (Study of Effects of Nebivolol Intervention on Outcomes and Rehospitalization in Seniors With Heart Failure). J Am Coll Cardiol 2009; 53:2150.

A6(iv): Veldhuisen DJ. Nebivolol in chronic heart failure: current evidence and future perspectives. Expert Opin Pharmacother. 2010 Apr;11(6):983-92.

A6(v): Ponikowski P, Voors AA, Anker SD, Bueno H, Cleland JGF, Coats AJS, Falk V,González-Juanatey JR, Harjola VP, Jankowska EA, Jessup $M$, Linde C, Nihoyannopoulos $P$, Parissis JT, Pieske B, Riley JP, Rosano GMC, Ruilope LM, Ruschitzka F, Rutten FH, van der Meer P; ESC Scientific Document Group. 2016 ESC Guidelines for the diagnosis and treatment of acute and chronic heart failure: The Task Force for the diagnosis and treatment of acute and chronic heart failure of the European Society of Cardiology (ESC)Developed with the special contribution of the Heart Failure Association (HFA) of the ESC. Eur Heart J. 2016 Jul 14;37(27):2129-2200. 
A6(vi): Joseph P K, Julian M A, Bernard J G. Stable ischemic heart disease: Overview of care. Son erişim tarihi 23 Ekim 2019.

A6(vii): Smith SC Jr, Benjamin EJ, Bonow RO, Braun LT, Creager MA, Franklin BA, Gibbons RJ, Grundy SM, Hiratzka LF, Jones DW, Lloyd-Jones DM, Minissian M, Mosca L, Peterson ED, Sacco RL, Spertus J, Stein JH, Taubert KA; World Heart Federation and the Preventive Cardiovascular Nurses Association. AHA/ACCF Secondary Prevention and Risk Reduction Therapy for Patients with Coronary and other Atherosclerotic Vascular Disease: 2011 update: a guideline from the American Heart Association and American College of Cardiology Foundation. Circulation. 2011 Nov 29;124(22):2458-73.

A6(viii): O'Mahony D, O'Sullivan D, Byrne S, O'Connor MN, Ryan C, Gallagher P. STOPP/START criteria for potentially inappropriate prescribing in older people: version 2. Age Ageing. 2015 Mar;44(2):213-8.

\section{B Santral Sinir Sistemi Kriterleri}

B1. Majör depresif bozukluk varlığında antidepresan tedavi başlanması uygundur

B1(i): Lebowitz BD, Pearson JL, Schneider LS, Reynolds CF 3rd, Alexopoulos GS, Bruce ML, Conwell Y, Katz IR, Meyers BS, Morrison MF, Mossey J, Niederehe G, ParmeleeP. Diagnosis and treatment of depression in late life.Consensus statementupdate. JAMA 1997; 278(14): 1186-90. Review.

B1(ii): Mottram P, Wilson K, Strobl J. Antidepressants for depressed elderly. Cochrane Database Syst Rev. 2006 Jan 25;(1):CD003491. Review.

B1(iii): O'Mahony D, O'Sullivan D, Byrne $S$, O'Connor MN, Ryan C, Gallagher P. STOPP/START criteria for potentially inappropriate prescribing in older people: version 2. Age Ageing. 2015 Mar;44(2):213-8. doi: 10.1093/ageing/afu145. Epub 2014 Oct 16. Review.

B1(iv): Charles F. Reynolds. Evidence-Based Treatment and Prevention of Major Depressive Episodes in Later Life in Hazzards Geriatric Medicine and Gerontology Seventh edition. Eds. Halter J B, Ouslander J G, Studenski S, High K P, Asthana S, Ritchie C S, Supiano M A,; 2017 page1487-1503.

B2. Fonksiyonelliği (işlevselliği) etkileyen persistan, ağır şiddette anksiyete varlı̆ı̆ında SSRi (SSRi kontrendike ise SNRi veya pregabalin) tedavisi başlanması uygundur

*Anksiyete tedavisinde, SSRillerden yararlanmayan veya SSRi'leri tolere edemeyen hastalarda, eşlik eden depresyon yok ise, buspiron monoterapisi kullanılabilir.

B2(i): Allgulander C, Hartford J, Russell J, Ball S, Erickson J, Raskin J, Rynn M. Pharmacotherapy of generalized anxiety disorder: results of duloxetine treatment from a pooled analysis of three clinical trials. Curr Med Res Opin 2007; 23(6): 1245-52.
B2(ii): National Institute for Health and Clinical Excellence. Generalized anxiety disorder and panic disorder (with or without agoraphobia) in adults. Clinical Guideline 113. 2011. http://guidance.nice.org.uk/CG113 (son erişim tarihi 12 Kasım 2019).

B2(iii): O'Mahony D, O'Sullivan D, Byrne S, O'Connor MN, Ryan C, Gallagher P. STOPP/START criteria for potentially inappropriate prescribing in older people: version 2. Age Ageing. 2015 Mar;44(2):213-8. doi: 10.1093/ageing/afu145. Epub 2014 Oct 16. Review.

B2(iv): Bystritsky A. Pharmacotherapy for generalized anxiety disorder in adults. In: UpToDate, Post, TW (Ed), UpToDate, Waltham, MA, 2019 Son erişim tarihi 11 Kasım 2019.

B2(v): Brawman-Mintzer O, Knapp RG, Rynn M, et al. Sertraline treatment for generalized anxiety disorder: a randomized, double-blind, placebo-controlled study. J Clin Psychiatry 2006; 67:874.

B2(vi): Dahl AA, Ravindran A, Allgulander C, et al. Sertraline in generalized anxiety disorder: efficacy in treating the psychic and somatic anxiety factors. Acta Psychiatr Scand 2005; 111:429.

B2(vii): Davidson JR, Bose A, Korotzer A, Zheng H. Escitalopram in the treatment of generalized anxiety disorder: double-blind, placebo controlled, flexible-dose study. Depress Anxiety 2004; 19:234.

B2(viii): Davidson JR, Bose A, Wang Q. Safety and efficacy of escitalopram in the long-term treatment of generalized anxiety disorder. J Clin Psychiatry 2005; 66:1441.

B2(ix): Goodman WK, Bose A, Wang Q. Treatment of generalized anxiety disorder with escitalopram: pooled results from doubleblind, placebo-controlled trials. J Affect Disord 2005; 87:161.

B2(x): Craske M, Bystritsky A. Approach to treating generalized anxiety disorder in adults. In: UpToDate, Post, TW (Ed), UpToDate, Waltham, MA, 2019 erişim tarihi 11 Kasım 2019

B2(xi): Baldwin DS, Anderson IM, Nutt DJ, Allgulander C, Bandelow B, den Boer JA, Christmas DM, Davies S, Fineberg N, Lidbetter N, Malizia A, McCrone P, Nabarro D, O'Neill C, Scott J, van der Wee N, Wittchen HU. Evidence-based pharmacological treatment of anxiety disorders, post-traumatic stress disorder and obsessive-compulsive disorder: a revision of the 2005 guidelines from the British Association for Psychopharmacology. J Psychopharmacol. 2014 May;28(5):403-39.

B2(xii): Lenze EJ, Rollman BL, Shear MK, Dew MA, Pollock BG, Ciliberti C, Costantino M, Snyder S, Shi P, Spitznagel E, Andreescu C, Butters MA, Reynolds CF 3rd. Escitalopram for older adults with generalized anxiety disorder: a randomized controlled trial. JAMA. 2009 Jan 21;301(3):295-303. 
B2(xiii): Andreescu C, Varon D. New research on anxiety disorders in the elderly and an update on evidence-based treatments. Curr Psychiatry Rep. 2015 Jul;17(7):53.

B2(xiv): Daniel D. Sewell, Steve Koh, Jeanne Maglione, Ryan Greytak, Laura Marrone, Dilip V. Jeste. General Topics in Geriatric Psychiatry, ANXIETY DISORDERS. in Hazzards Geriatric Medicine and Gerontology Seventh edition. Eds. Halter J B, Ouslander J G, Studenski S, High K P, Asthana S, Ritchie C S, Supiano M A,i 2017 pages 1532-36.

\#B3. Erken-orta evre Alzheimer hastalığında ChEi tedavisi başlanması uygundur

*Alzheimer hastalı̆ıında ChEi tedavisi başlanması için kanıt vardır.

*Erken-orta evre Alzheimer hastalığında her 3 kolinesteraz inhibitörü (donepezil, galantamin, rivastigmin) için kanıt vardır ve FDA onayı mevcuttur

*ileri evre Alzheimer hastalığında donepezil ile ilgili kanıt ve FDA onayı mevcuttur.

*Parkinson hastalığı demansında rivastigmin başlanması için kanıt vardır ve FDA onayı mevcuttur. Parkinson hastalığı demansında donepezilin yararlı olabileceğine dair çalışmalar vardır

*Diğer demans tiplerinden Lewy cisimcikli demans ve vasküler demansta ChEi kullanımına dair kesin kanıtlar yoktur ancak kullanılması önerilebilir.

*Lewy cisimcikli demansta donepezil ve rivastigminin yararlı olabileceğine dair çalışmalar vardır. Lewy cisimcikli demansta FDA onayı ChEi'lerinin hiçbiri için mevcut değildir

*Vasküler demansta kolinesteraz inhibitörlerinin yararlı olabileceğine dair çalışmalar vardır. Vasküler demansta FDA onayı ChEi'lerinin hiçbiri için mevcut değildir.

B3(i): Raina P, Santaguida P, Ismaila A, Patterson C, Cowan D, Levine $M$, Booker $L$, Oremus M. Effectiveness of cholinesterase inhibitors and memantine for treating dementia: evidence review for a clinical practice guideline. Ann Intern Med 2008; 148(5): 379-97. Review.

B3(ii): Birks J. Cholinesterase inhibitors for Alzheimer's disease. Cochrane Database Syst Rev 2006 Jan 25;(1):CD005593. Review.

B3(iii): Rolinski M, Fox C, Maidment I, McShane R. Cholinesterase inhibitors for dementia with Lewy bodies, Parkinson's disease dementia and cognitive impairment in Parkinson's disease. Cochrane Database Syst Rev 2012 Mar 14;3:CD006504.

B3(iv): O'Mahony D, O'Sullivan D, Byrne S, O'Connor MN, Ryan C, Gallagher P. STOPP/START criteria for potentially inappropriate prescribing in older people: version 2. Age Ageing. 2015 Mar;44(2):213-8. doi: 10.1093/ageing/afu145. Epub 2014 Oct 16. Review.
B3(v): Press D, Alexander M. Cholinesterase inhibitors in the treatment of dementia. In: UpToDate, Post, TW (Ed), UpToDate, Waltham, MA, 2019 Son erişim tarihi 11 Kasım 2019.

B3(vi): Press D, Alexander M. Treatment of dementia. In: UpToDate, Post, TW (Ed), UpToDate, Waltham, MA, 2019 Son erişim tarihi 11 Kasım 2019.

B3(vii): Farlow MR. Prognosis and treatment of dementia with Lewy bodies. In: UpToDate, Post, TW (Ed), UpToDate, Waltham, MA, 2019 Son erişim tarihi 11 Kasım 2019.

B3(viii): Efficacy of rivastigmine in dementia with Lewy bodies: a randomised, double-blind, placebo-controlled international study. McKeith I, Del Ser T, Spano P, Emre M, Wesnes K, Anand R, Cicin-Sain A, Ferrara R, Spiegel R Lancet. 2000;356(9247):2031;

B3(ix): Mori E, Ikeda M, Kosaka K, Donepezil-DLB Study Investigators. Donepezil for dementia with Lewy bodies: a randomized, placebo-controlled trial. Ann Neurol 2012; 72:41.

B3(x): Ikeda $M$, Mori $E_{1}$ Matsuo $K_{\text {, et al. Donepezil for }}$ dementia with Lewy bodies: a randomized, placebo-controlled, confirmatory phase III trial. Alzheimers Res Ther 2015; 7:4.

B3(xi): Emre M, Aarsland D, Albanese A, et al. Rivastigmine for dementia associated with Parkinson's disease. N Engl J Med 2004; 351:2509.;

B3(xii): Dubois B, Tolosa E, Katzenschlager R, Emre M, Lees AJ, Schumann G, Pourcher E, Gray J, Thomas G, Swartz J, Hsu T, Moline ML. Donepezil in Parkinson's disease dementia: a randomized, double-blind efficacy and safety study. Mov Disord. 2012 Sep 1;27(10):1230-8

B3(xiii): Malouf R, Birks J. Donepezil for vascular cognitive impairment. Cochrane Database Syst Rev. 2004;(1):CD004395. Review.

B3(xiv): Erkinjuntti T, Kurz A, Gauthier S, Bullock R, Lilienfeld $\mathrm{S}$, Damaraju CV. Efficacy of galantamine in probable vascular dementia and Alzheimer's disease combined with cerebrovascular disease: a randomised trial. Lancet. $2002 \mathrm{Apr}$ 13;359(9314):1283-90.

B3(xv): Auchus AP, Brashear HR, Salloway $S$, Korczyn AD, De Deyn PP, Gassmann-Mayer C; GAL-INT-26 Study Group. Galantamine treatment of vascular dementia: a randomized trial. Neurology. 2007 Jul 31;69(5):448-58.

B3(xvi): Birks J, McGuinness B, Craig D. Rivastigmine for vascular cognitive impairment. Cochrane Database Syst Rev. 2013 May 31;(5):CD004744. Review.

B3 (xvii): Ballard C, Sauter M, Scheltens $P, H e$ Y, Barkhof $F$, van Straaten EC, van der Flier WM, Hsu C, Wu S, Lane R. Efficacy, safety and tolerability of rivastigmine capsules in patients with 
probable vascular dementia: the VantagE study. Curr Med Res Opin. 2008 Sep;24(9):2561-74.

B3(xviii): Mok V, Wong A, Ho S, Leung T, Lam WW, Wong KS. Rivastigmine in Chinese patients with subcortical vascular dementia. Neuropsychiatr Dis Treat. 2007 Dec;3(6):943-8.

B3(xix): Narasimhalu K, Effendy S, Sim CH, Lee JM, Chen I, Hia SB, Xue HL, Corrales MP, Chang HM, Wong MC, Chen $\mathrm{CP}$, Tan EK. A randomized controlled trial of rivastigmine in patients with cognitive impairment no dementia because of cerebrovascular disease. Acta Neurol Scand. 2010 Apr;121(4):217-24.

B3(xx): U.S. Food and Drug Administration. Donepezil hydrochloride: Highlights of prescribing information by FDA. Available at: https://www.accessdata.fda.gov/drugsatfda_docs/ label/2012/020690s035,021720s008,022568s005lbl.pdf erişim tarihi 11 Kasım 2019.

B3(xxi): U.S. Food and Drug Administration. Rivastigmine tartrate: Highlights of prescribing information by FDA Available at: https://www.accessdata.fda.gov/drugsatfda_docs/ label/2006/020823s016,021025s008lbl.pdf erişim tarihi 11 Kasım 2019.

B3(xxii): U.S. Food and Drug Administration. Galantamine hydrobromide: Highlights of prescribing information by FDA Available at: https://www.acce ssdata.fda.gov/d rugsatf da docs/l abel/2017/021 1690rig 1s032,02 12240 ri g1s030,02161 50r ig1s023lbl.pdf erişim tarihi 11 Kasım 2019

B3(xxiii): Birks JS, Harvey RJ. Donepezil for dementia due to Alzheimer's disease. Cochrane Database Syst Rev. 2018 Jun 18;6:CD001190.

B3(xxiv): Birks JS, Grimley Evans J. Rivastigmine for Alzheimer's disease. Cochrane Database Syst Rev. 2015 Apr 10;(4):CD001191.

\#B4. Orta-ileri evre Alzheimer hastalığında memantin tedavisi başlanması uygundur

*Memantin'in vasküler demansta da etkinliği olabilir.

*Memantin, demansın davranışsal ve psikiyatrik semptomlarında (BPSD) faydalı olabilir.

B4(i): Memantine: Drug information, Lexicomp Online. Son erişim tarihi 22 Ekim 2019.

B4(ii): California ADS Tx guideline; Geldmacher DS. Treatment Guidelines for Alzheimer's Disease: Redefining Perceptions in Primary Care. Primary Care Companion to The Journal of Clinical Psychiatry. 2007;9(2):113-121

B4(iii): Press D, Alexander M. Treatment of dementia. In: UpToDate, Post, TW (Ed), UpToDate, Waltham, MA, 2019 Son erişim tarihi 11 Kasım 2019.
B4(iv): Reisberg B, Doody R, Stöffler A, Schmitt F, Ferris S, Möbius $\mathrm{HJ}$; Memantine Study Group. Memantine in moderate-to-severe Alzheimer's disease. N Engl J Med. 2003 Apr 3;348(14):1333-41.

B4(v): Howard R, McShane R, Lindesay J, Ritchie C, Baldwin A, Barber $R$, Burns $A$, Dening $T$, Findlay $D$, Holmes $C$, Hughes $A$, Jacoby $R$, Jones $R$, Jones $R$, McKeith I, Macharouthu A, O'Brien J, Passmore P, Sheehan B, Juszczak E, Katona C, Hills R, Knapp $M$, Ballard C, Brown R, Banerjee $S$, Onions C, Griffin M, Adams J, Gray R, Johnson T, Bentham P, Phillips P. Donepezil and memantine for moderate-to-severe Alzheimer's disease. N Engl J Med. 2012 Mar 8;366(10):893-903.

B4(vi): Chen R, Chan PT, Chu H, Lin YC, Chang PC, Chen CY, Chou KR. Treatment effects between monotherapy of donepezil versus combination with memantine for Alzheimer disease: A meta-analysis. PLoS One. 2017 Aug 21;12(8):e0183586.

B4(vii): Orgogozo JM, Rigaud AS, Stöffler A, Möbius HJ, Forette F. Efficacy and safety of memantine in patients with mild to moderate vascular dementia: a randomized, placebo-controlled trial (MMM 300). Stroke. 2002 Jul;33(7):1834-9.

B4(viii): Wilcock G, Möbius HJ, Stöffler A; MMM 500 group. A double-blind, placebo-controlled multicentre study of memantine in mild to moderate vascular dementia (MMM500). Int Clin Psychopharmacol. 2002 Nov;17(6):297-305.

B4(ix): Guidelines for the treatment of Alzheimer's disease. NHS Foundation Trust. Review Jan 2012. Available at: http:// www.humber.nhs.uk/Downloads/Services/Pharmacy/Guidelines/ Alzheimer\%20disease\%20treatment\%20guidelines.pdf (erişim tarihi 11 Kasım 2019)

B4(x): McShane R, Westby MJ, Roberts E, Minakaran N, Schneider L, Farrimond LE, Maayan N, Ware J, Debarros j. Memantine for dementia. Cochrane Database of Systemic Reviews 2019, Issue 3. Art. No: CD003154.

\#B5. Fonksiyonelliği (işlevselliği) etkileyen esansiyel tremoru olan hastalara propranolol veya pirimidon tedavisi başlanması uygundur

\section{*Pirimidon'un FDA onayı yoktur.}

*Pirimidon yan etkileri (sedasyon, vertigo ve bulantı) yaygındır. Kulanıldığında düşük dozda başlanıp yavaş doz artırımı yapılmalıdır.

B5(i): Zesiewicz TA, Evidence-based guideline update: treatment of essential tremor: report of the Quality Standards subcommittee of the American Academy of Neurology. Neurology. 2011 Nov 8;77(19):1752-5.

B5(ii): Reich SG. Essential Tremor. Med Clin North Am. 2019 Mar;103(2):351-356. doi: 10.1016/j.mcna.2018.10.016. Review. 
B5(iii): Haubenberger D, Hallett M. Essential Tremor. N Engl J Med. 2018 May 10;378(19):1802-1810. doi: 10.1056/ NEJMcp1707928. Review.

B5(iv): Primidone: Drug information, Lexicomp online. Son erişim tarihi 12 Kasım 2019.

B6. Fonksiyonel (işlevsel) bozukluk ve dizabiliteye sebep olan idiyopatik Parkinson hastalığı varlığında L-dopa tedavisi başlanması uygundur

B6(i): Marjama-Lyons JM, Koller WC. Parkinson's disease. Update in diagnosis and symptom management. Geriatrics 2001; 56(8): 24-5, 29-30, 33-5. Review.

B6(ii): Danisi F. Parkinson's disease. Therapeutic strategies to improve patient function and quality of life. Geriatrics 2002; 57(3): 46-50; quiz 52. Review.

B6(iii): O'Mahony D, O'Sullivan D, Byrne S, O'Connor MN, Ryan C, Gallagher P. STOPP/START criteria for potentially inappropriate prescribing in older people: version 2. Age Ageing. 2015 Mar;44(2):213-8. doi: 10.1093/ageing/afu145. Epub 2014 Oct 16. Review.

B6(iv): Ferreira JJ,Summary of the recommendations of the EFNS/MDS-ES review on therapeutic management of Parkinson's disease. Eur J Neurol. 2013 Jan;20(1):5-15

B6(v): Spindler MA, Tarsy D. Initial pharmacologic treatment of Parkinson disease. In: UpToDate, Post, TW (Ed), UpToDate, Waltham, MA, 2019 Son erişim tarihi 12 Kasım 2019.

B6(vi): Kotagal V, Bohnen NI. Parkinson Disease and Related Disorders in Hazzards Geriatric Medicine and Gerontology Seventh edition. Eds. Halter J B, Ouslander J G, Studenski S, High K P, Asthana S, Ritchie C S, Supiano M A,; 2017. Pages 1422-28.

B6(vii): Connolly BS, Lang AE. Pharmacological treatment of Parkinson disease: a review. JAMA. 2014 Apr 23-30;311(16):167083. doi: 10.1001/jama.2014.3654. Review.

B7. İdiyopatik Parkinson hastalarında açık-kapalı motor dalgalanmalar başladığında, L-dopa tedavisine MAO-B inhibitörü veya COMT inhibitörü eklenmesi uygundur

B7(i): Ferreira JJ, Summary of the recommendations of the EFNS/MDS-ES review on therapeutic management of Parkinson's disease. Eur J Neurol. 2013 Jan;20(1):5-15.

B7(ii): Kotagal V, Bohnen NI. Parkinson Disease and Related Disorders in Hazzards Geriatric Medicine and Gerontology Seventh edition. Eds. Halter J B, Ouslander J G, Studenski S, High K P, Asthana S, Ritchie C S, Supiano M A; 2017. Pages 1428-30.

B7(iii): Connolly BS, Lang AE. Pharmacological treatment of Parkinson disease: a review. JAMA. 2014 Apr 23-30;311(16):167083. doi: 10.1001/jama.2014.3654. Review.
B8. Demir eksikliği ve kronik böbrek yetersizliğinin dışlandığı huzursuz bacak sendromu olan hastalarda, semptomlar yaşam kalitesini olumsuz etkiliyorsa, alfa-2-delta kalsiyum kanal blokerleri (pregabalin, gabapentin) veya dopamin agonistleri (pramipeksol/ropinirol/rotigotin) başlanması uygundur

*L-dopa tedavisi (50-200 mg), özellikle intermitan semptomu olan olgularda uygun olabilir. Böbrek yetersizliği olan semptomatik olgularda da tercih edilebilir.

B8(i): Zintzaras E, Kitsios GD, Papathanasiou AA, Konitsiotis $S$, Miligkos M, Rodopoulou P, Hadjigeorgiou GM. Randomized trials of dopamine agonists in restless legs syndrome: a systematic review, quality assessment, and meta-analysis. Clin Ther 2010; 32(2): 221-37. Review.

B8(ii): Hansen RA, Song L, Moore CG, Gilsenan AW, Kim MM, Calloway MO, Murray MD. Effect of ropinirole on sleep outcomes in patients with restless legs syndrome: meta-analysis of pooled individual patient data from randomized controlled trials. Pharmacotherapy 2009; 29(3): 255-62.

B8(iii): Scholz H, Trenkwalder C, Kohnen R, Riemann D, Kriston $\mathrm{L}$, Hornyak M. Dopamine agonists for restless legs syndrome. Cochrane Database Syst Rev. 2011 Mar 16;(3):CD006009. doi: 10.1002/14651858.CD006009.pub2. Review.

B8(iv): Garcia-Borreguero D, Stillman P, Benes $H$, Buschmann $H$, Chaudhuri KR, Gonzalez Rodríguez VM, Högl B, Kohnen R, Monti GC, Stiasny-Kolster K, Trenkwalder C,Williams AM, Zucconi M. Algorithms for the diagnosis and treatment of restless legs syndrome in primary care. BMC Neurol. 2011 Feb 27;11:28

B8(v): O'Mahony D, O'Sullivan D, Byrne S, O'Connor MN, Ryan C, Gallagher P. STOPP/START criteria for potentially inappropriate prescribing in older people: version 2. Age Ageing. 2015 Mar;44(2):213-8. doi: 10.1093/ageing/afu145. Epub 2014 Oct 16. Review.

B8(vi): Silber MH. Treatment of restless legs syndrome and periodic limb movement disorder in adults. In: UpToDate, Post, TW (Ed), UpToDate, Waltham, MA, 2019 erişim tarihi 11 Kasım 2019

B8(vii): Trenkwalder C, Stiasny K, Pollmächer T, Wetter T, Schwarz $J$, Kohnen R, Kazenwadel J, Krüger HP, Ramm S, Künzel M, et al. L-dopa therapy of uremic and idiopathic restless legs syndrome: a double-blind, crossover trial. Sleep. 19950ct;18(8):681-8.

B8(viii): Garcia-Borreguero D, Silber MH, Winkelman JW, Högl B, Bainbridge J, Buchfuhrer $M$, Hadjigeorgiou G, Inoue $Y$, Manconi M, Oertel W, Ondo W, Winkelmann J, Allen RP. Guidelines for the first-line treatment of restless legs syndrome/WillisEkbom disease, prevention and treatment of dopaminergic augmentation: a combined task force of the IRLSSG, EURLSSG, and the RLS-foundation. Sleep Med. 2016 May;21:1-11. 
B8(ix): Winkelman JW, Armstrong MJ, Allen RP, Chaudhuri KR, Ondo W, Trenkwalder C, Zee PC, Gronseth GS, Gloss D, Zesiewicz T. Practice guideline summary: Treatment of restless legs syndrome in adults: Report of the Guideline Development, Dissemination, and Implementation Subcommittee of the American Academy of Neurology. Neurology. 2016 Dec 13;87(24):2585-2593.

\section{C: Gastrointestinal Sistem Kriterleri}

C1. Yaşam tarzı değişikliklerine (diyet-egzersiz) yanıtsız semptomatik konstipasyonu olan olgularda, fekal tıkaç dışlanarak, lif desteği (psilyum, metilselüloz, polikarbofil, buğday dekstrin) veya polietilenglikol başlanması uygundur

C1(i): Rao SSC. Constipation in the older adult.In: UpToDate, Post, TW (Ed), UpToDate, Waltham, MA, 2019 Son erişim tarihi 11 Kasım 2019

C1(ii): O'Mahony D, O'Sullivan D, Byrne S, O'Connor MN, Ryan C, Gallagher P. STOPP/START criteria for potentially inappropriate prescribing in older people: version 2. Age Ageing. 2015 Mar;44(2):213-8. doi: 10.1093/ageing/afu145. Epub 2014 Oct 16. Review.

C1 (iii): Emmanuel A, Mattace-Raso F, Neri MC, Petersen KU, Rey $E$, Rogers J.Constipation in older people: A consensus statement. Int J Clin Pract. 2017Jan;71(1).

C1(iv): Bharucha $A E$, Pemberton JH, Locke GR 3rd. American GastroenterologicalAssociation technical review on constipation. Gastroenterology. 2013Jan;144(1):218-38. doi:10.1053/j. gastro.2012.10.028. Review.

\section{D: Solunum Sistemi Kriterleri}

D1. Hafif-orta astım veya KOAH'ı olan hastalarda düzenli inhale beta2 agonist veya antikolinerjik tedavi başlanması uygundur

D1(i): Pauwels RA, Buist AS, Ma $P$, Jenkins CR, Hurd SS; GOLD Scientific Committee. Global strategy for the diagnosis, management, and prevention of chronic obstructive pulmonary disease: National Heart, Lung, and Blood Institute and World Health Organization Global Initiative for Chronic Obstructive Lung Disease (GOLD): executive summary. Respir Care 2001; 46(8): 798-825. Review.

D1(ii): Keating GM. Tiotropium bromide inhalation powder: a review of its use in the management of chronic obstructive pulmonary disease. Drugs 2012; 72(2):273-300. Review.

D1(iii): Yohannes AM, Hardy CC. Treatment of chronic obstructive pulmonary disease in older patients: a practical guide. Drugs Aging 2003; 20(3): 209-28. Review.

D1 (iv): McCrory DC, Brown CD. Anti-cholinergic bronchodilators versusbeta2-sympathomimetic agents for acute exacerbations of chronic obstructivepulmonary disease. Cochrane Database Syst Rev. 2002;(4):CD003900. Review.
D1(v): O'Mahony D, O'Sullivan D, Byrne S, O'Connor MN, Ryan C, Gallagher P. STOPP/START criteria for potentially inappropriate prescribing in older people: version 2. Age Ageing. 2015 Mar;44(2):213-8. doi: 10.1093/ageing/afu145. Epub 2014 Oct 16. Review.

D1(vi): Global Initiative For Chronic Obstructive Lung Disease. Global Strategy for the Diagnosis, Management, and Prevention of Chronic Obstructive Pulmonary Disease.2018 Report.Available at: https://goldcopd.org/wp-content/uploads/2017/11/GOLD2018-v6.0-FINAL-revised-20-Nov_WMS.pdf son erişim tarihi 23 October 2019.

D1(vii): Anderson GP1.Current issues with beta2-adrenoceptor agonists: pharmacology and molecular and cellular mechanisms. Clin Rev Allergy Immunol. 2006 Oct-Dec;31(2-3): 119-30.

D2. FEV1< \%50 olan ve oral steroid tedavisi gerektiren tekrarlayan alevlenmeleri olan orta-ağır astım veya KOAH hastalarında düzenli inhale kortikosteroid tedavisi başlanması uygundur

D2(i): Global Initiative For Chronic Obstructive Lung Disease. Global Strategy for the Diagnosis, Management, and Prevention of Chronic Obstructive Pulmonary Disease.2018 Report. Available at: https://goldcopd.org/wp-content/uploads/2017/11/GOLD2018-v6.0-FINAL-revised-20-Nov_WMS.pdf Son erişim tarihi 23 Ekim 2019.

D2(ii): O'Mahony D, O'Sullivan D, Byrne S, O'Connor MN, Ryan C, Gallagher P. STOPP/START criteria for potentially inappropriate prescribing in older people: version 2. Age Ageing. 2015 Mar;44(2):213-8. doi: 10.1093/ageing/afu145. Epub 2014 Oct 16. Review.

D3. Kronik hipoksemisi $\left(\mathrm{PO}_{2}<=55 \mathrm{mmHg}\right.$ veya $\left.\mathrm{SO}_{2}<=\% 88\right)$ olan hastalarda evde sürekli oksijen tedavisi başlanması uygundur

D3(i): Tiep BL, Carter R. Long-term supplemental oxygen therapy.In: UpToDate, Post, TW (Ed), UpToDate, Waltham, MA, 2019 erişim tarihi 11 Kasım 2019

D3(ii): O'Mahony D, O'Sullivan D, Byrne S, O'Connor MN, Ryan C, Gallagher P. STOPP/START criteria for potentially inappropriate prescribing in older people: version 2. Age Ageing. 2015 Mar;44(2):213-8. Doi: 10.1093/ageing/afu145. Epub 2014 Oct 16. Review.

D3(iii): Croxton TL, Bailey WC. Long-term oxygen treatment in chronic obstructive pulmonary disease: recommendations for future research: an NHLBI workshop report. Am J Respir Crit Care Med 2006; 174:373.

D3(iv): Sjöberg F, Singer M. The medical use of oxygen: a time for critical reappraisal. J Intern Med2013; 274:505.

D3(v): Global Initiative For Chronic Obstructive Lung Disease. Global Strategy ort he Diagnosis, Management, and Prevention 
of Chronic Obstructive Pulmonary Disease.2018 Report. Available at: https://goldcopd.org/wp-content/uploads/2017/11/GOLD2018-v6.0-FINAL-revised-20-Nov_WMS.pdf Son erişim tarihi 23 Ekim 2019.

\section{E: Kas İskelet Sistemi Kriterleri ve Analjezik Ilaçlar}

\#E1. Günlük diyetle vitamin D alımı <800-1000 iÜ veya elementer kalsiyum alımı <1000-1200 mg olan hastalarda replasman tedavisinin başlanması uygundur

E1(i): Cosman F, de Beur SJ, LeBoff MS, Lewiecki EM, Tanner $B$, Randall S, Lindsay R; National Osteoporosis Foundation. Clinician's Guide to Prevention and Treatment of Osteoporosis. Osteoporos Int. 2014 Oct;25(10):2359-81. doi:10.1007/s00198014-2794-2. Epub 2014 Aug 15. Erratum in: Osteoporos Int. 2015 Jul;26(7):2045-7.

E1(ii): Rosen HN. Calcium and vitamin D supplementation in osteoporosis. In: UpToDate, Post, TW (Ed), UpToDate, Waltham, MA, 2019 Son erişim tarihi 11 Kasım 2019.

E1(iii): O'Mahony D, O'Sullivan D, Byrne S, O'Connor MN, Ryan C, Gallagher P. STOPP/START criteria for potentially inappropriate prescribing in older people: version 2. Age Ageing. 2015 Mar;44(2):213-8. doi: 10.1093/ageing/afu145. Epub 2014 Oct 16. Review.

E1(iv): Camacho PM, Petak SM, Binkley N, Clarke BL, Harris ST, Hurley DL, Kleerekoper M, Lewiecki EM, Miller PD, Narula HS, Pessah-Pollack R, Tangpricha V, WimalawansaSJ, Watts NB. American Association Of Clinical Endocrinologists And Americancollege of Endocrinology Clinical Practice Guidelines for the Diagnosis and Treatment of Postmenopausal Osteoporosis - 2016. Endocr Pract. 2016 Sep2;22(Suppl 4):1-42.

E1(v): Heflin MT. Geriatric health maintenance. In: UpToDate, Post, TW (Ed), UpToDate, Waltham, MA, 2019 Son erişim tarihi 11 Kasım 2019.

E1(vi): Stephen R. Lord. Falls.in Hazzards Geriatric Medicine and Gerontology Seventh edition. Eds. Halter J B, Ouslander J G, Studenski S, High K P, Asthana S, Ritchie C S, Supiano M A, 2017 pages 1032-42.

E1(vii): Dennis H. Sullivan, Larry E. Johnson. Nutrition and Obesityin Hazzards Geriatric Medicine and Gerontology Seventh edition. Eds. Halter J B, Ouslander J G, Studenski S, High K P, Asthana S, Ritchie C S, Supiano M A,; 2017 page 723-24.

E2. Dökümante osteoporozu olan [frajilite fraktürü ve/veya kemik mineral dansitometri T skoru (femur total, femur boyun veya lomber < -2,5)] hastalarda anti-rezorptif (bifosfonat, denosumab) veya anabolik ajan (parathormon anoloğu) başlanması uygundur

*Tedavi aynı zamanda yeterli D vitamini ve elementer kalsiyum alımını da içermelidir.
E2(i): Cosman F, de Beur SJ, LeBoff MS, Lewiecki EM, Tanner B, Randall S, Lindsay R; National Osteoporosis Foundation. Clinician's Guide to Prevention and Treatment of Osteoporosis. Osteoporos Int. 2014 Oct;25(10):2359-81. doi: 10.1007/s00198014-2794-2. Epub 2014 Aug 15. Erratum in: Osteoporos Int. 2015 Jul;26(7):2045-7.

E2(ii): O'Donnell S, Cranney A, Wells GA, Adachi JD, Reginster JY. Strontium ranelate for preventing and treating postmenopausal osteoporosis. Cochrane Database SystRev. 2006 Jul 19;(3):CD005326. Review. Update in: Cochrane Database Syst Rev.2006;(4):CD005326.

E2(iii): Rosen HN, Drezner MK. Overview of the management of osteoporosis in postmenopausal women. In: UpToDate, Post, TW (Ed), UpToDate, Waltham, MA, 2019 Son erişim tarihi 11 Kasım 2019.

E2(iv): O'Mahony D, O'Sullivan D, Byrne S, O'Connor MN, Ryan C, Gallagher P. STOPP/START criteria for potentially inappropriate prescribing in older people: version 2. Age Ageing. 2015 Mar;44(2):213-8. doi: 10.1093/ageing/afu145. Epub 2014 Oct 16. Review.

E2(v): Camacho PM, Petak SM, Binkley N, Clarke BL, Harris ST, Hurley DL, Kleerekoper M, Lewiecki EM, Miller PD, Narula HS, Pessah-Pollack R, Tangpricha V, WimalawansaSJ, Watts NB. American Association of Clinical Endocrinologists and Americancollege of Endocrinology Clinical Practice Guidelines for the Diagnosis and Treatment of Postmenopausal Osteoporosis - 2016. Endocr Pract. 2016 Sep2;22(Suppl 4):1-42.

E2(vi): Eastell R, Rosen CJ, Black DM, Cheung AM, Murad MH, Shoback D. Pharmacological Management of Osteoporosis in Postmenopausal Women: An Endocrine Society*Clinical Practice Guideline. J Clin Endocrinol Metab. 2019 May 1;104(5):15951622.

E3. Uzun süreli (beklenen süre $\geq 3$ ay) sistemik kortikosteroid tedavisi başlanan hastalarda: i) $\geq 7,5 \mathrm{mg} / \mathrm{gün}$ prednizolon veya eşdeğer steroid tedavisi alacaklarda, ii) eğer T skoru $<-1$ ise dozdan bağımsız steroid tedavisi alacak tüm hastalarda, bifosfonat tedavisi başlanması uygundur

*>=70 yaş olgularda, dozdan bağımsız uzun süreli (>3 ay) steroid tedavisi alacak tüm hastalara da, bifosfonat tedavisi başlanması uygun olabilir.

*Tedavi aynı zamanda yeterli D vitamini ve temel kalsiyum alımını da içermelidir.

E3(i): Homik J, Suarez-Almazor ME, Shea B, Cranney A, Wells G, Tugwell P. Calcium and vitamin D for corticosteroid-induced osteoporosis. Cochrane Database Syst Rev 2000; (2): CD000952. Review. 
E3(ii): Iwamoto J, Takeda T, Sato Y. Effects of antifracture drugs in postmenopausal, male and glucocorticoid-induced osteoporosis--usefulness of alendronate and risedronate. Expert Opin Pharmacother 2007; 8(16): 2743-56. Review.

E3(iii): Glucocorticoid Induced Osteoporosis. Osteoporosis and metabolic bone disease diagnosis and treatment guidelines of the Society of Endocrinology and Metabolism of Turkey - 2018. Page 59-61. Available at: http://www.temd.org.tr/ admin/uploads/tbl_gruplar/20180517113533-2018-05-17tbl_ gruplar113531.pdf erişim tarihi 11 Kasım 2019. (Türkçe)

E3(iv): Allen CS, Yeung JH, Vandermeer B, Homik J. Bisphosphonates for steroid-induced osteoporosis. Cochrane Database Syst Rev. 2016 Oct 5;10:CD001347. Review.

E3(v): Rosen HN, Saag KG.Prevention and treatment of glucocorticoid-induced osteoporosis.In: UpToDate, Post, TW (Ed), UpToDate, Waltham, MA, 2019 Son erişim tarihi 11 Kasım 2019.

E3(vi): O'Mahony D, O'Sullivan D, Byrne S, O'Connor MN, Ryan C, Gallagher P. STOPP/START criteria for potentially inappropriate prescribing in older people: version 2. Age Ageing. 2015 Mar;44(2):213-8. doi: 10.1093/ageing/afu145. Epub 2014 Oct 16. Review.

E3(vii): Compston J, Cooper A, Cooper C, Gittoes N, Gregson C, Harvey N, Hope S, Kanis JA, McCloskey EV, Poole KES, Reid DM, Selby P, Thompson F, Thurston A, Vine N; National Osteoporosis Guideline Group (NOGG). UK clinical guideline for the prevention and treatment of osteoporosis. Arch Osteoporos. 2017 Dec;12(1):43.

E3(viii): Lekamwasam S, Adachi JD, Agnusdei D, Bilezikian J, Boonen S, Borgström F, Cooper C, Diez Perez A, Eastell R, Hofbauer LC, Kanis JA, Langdahl BL, Lesnyak O, Lorenc $R_{\text {, }}$ McCloskey E, Messina OD, Napoli N, Obermayer-Pietsch B, Ralston SH, Sambrook PN, Silverman S, Sosa M, Stepan J, Suppan G, WahI DA, Compston JE; Joint IOF-ECTS GIO Guidelines Working Group. A framework for the development of guidelines for the management of glucocorticoid-induced osteoporosis. Osteoporos Int. 2012 Sep;23(9):2257-76.

E4. En az iki doz denosumab tedavisi sonlandırılıktan sonra uzun etkili antirezorbtif tedavi başlanması uygundur (denosumab kesilmesini takiben rebound BTM'lerde artış, BMD kaybı ve vertebral fraktür riskinde artış olur)

*Rebound etki iki dozdan sonra denosumab tedavisi kesilen olgularda daha belirgindir.

E4(i): Eastell R, Rosen CJ, Black DM, Cheung AM, Murad MH, Shoback D. Pharmacological Management of Osteoporosis in Postmenopausal Women: An Endocrine Society* Clinical Practice Guideline. J Clin Endocrinol Metab. 2019 May 1;104(5):15951622.
E4(ii): TsourdiE et al. Discontinuation of denosumab therapy for osteoporosis: a systematic review and position statement by ECTS. Bone2017;105:11-17.

E4(iii): Horne AM, Mihov B, Reid IR. Bone loss after romosozumab/denosumab: effects of bisphosphonatesCalcif Tissue Int 2018;103:55-61.

E4(iv): Reid IR, Horne AM, Mihov B, Gamble GD. Bone loss after denosumab: only partial protection with zoledronateCalcif Tissue Int. 2017;101:371-374.

\#E5.Teriparatid tedavisi sonrası antirezorbtif tedavi başlanması uygundur

E5(i): Camacho PM, Petak SM, Binkley N, Clarke BL, Harris ST, Hurley DL, Kleerekoper M, Lewiecki EM, Miller PD, Narula HS, Pessah-Pollack R, Tangpricha V, WimalawansaSJ, Watts NB. American Association Of Clinical Endocrinologists and American College of Endocrinology Clinical Practice Guidelines for the Diagnosis and Treatment of Postmenopausal Osteoporosis 2016. Endocr Pract. 2016 Sep2;22(Suppl 4):1-42.

E5(ii): Meier C, Uebelhart B, Aubry-Rozier B, Birkhäuser $M$, Bischoff-Ferrari HA, Frey D, Kressig RW, Lamy O, Lippuner K, Stute P, Suhm N, Ferrari S. Osteoporosis drug treatment: duration and management after discontinuation. A position statement from the SVGO/ASCO. Swiss Med Wkly. 2017 Aug 16;147:w14484.

E5(iii): Eastell R, Rosen CJ, Black DM, Cheung AM, Murad MH, Shoback D. Pharmacological Management of Osteoporosis in Postmenopausal Women: An Endocrine Society ${ }^{*}$ Clinical Practice Guideline. J Clin Endocrinol Metab. 2019 May 1;104(5):15951622

E6. Kronik aktif romatolojik hastalık varlığında hastalığı modifiye edici tedavi başlanması uygundur

E6(i): Saag KG, Teng GG, Patkar NM, Anuntiyo J, Finney C, Curtis JR, Paulus HE,Mudano A, Pisu M, Elkins-Melton $M$, Outman R, Allison JJ, Suarez Almazor M,Bridges SL Jr, Chatham WW, Hochberg M, MacLean C, Mikuls T, Moreland LW, O'DellJ, Turkiewicz AM, Furst DE; American College of Rheumatology. American College of Rheumatology 2008 recommendations for the use of nonbiologic and biologic disease-modifying antirheumatic drugs in rheumatoid arthritis. Arthritis Rheum 2008; 59(6): 762-84.

E6(ii): Köller MD, Aletaha D, Funovits J, Pangan A, Baker D, Smolen JS. Response of elderly patients with rheumatoid arthritis to methotrexate or TNF inhibitors compared with younger patients. Rheumatology (0xford) 2009; 48(12): 1575-80.

E6(iii): Fleischmann R, Baumgartner SW, Weisman MH, Liu T, White B, Peloso P. Long term safety of etanercept in elderly subjects with rheumatic diseases. Ann Rheum Dis 2006; 65(3): 379-84. 
E6(iv): O'Mahony D, O'Sullivan D, Byrne S, O'Connor MN, Ryan C, Gallagher P. STOPP/START criteria for potentially inappropriate prescribing in older people: version 2. Age Ageing. 2015 Mar;44(2):213-8. doi: 10.1093/ageing/afu145. Epub 2014 Oct 16. Review.

E6(v): Smolen JS, Landewé R, Bijlsma J, Burmester G, Chatzidionysiou K, Dougados M, Nam J, Ramiro S, Voshaar M, van Vollenhoven $R$, Aletaha $D$, Aringer $M$, Boers $M$, Buckley $C D$, Buttgereit F, Bykerk V, Cardiel M, Combe B, Cutolo M, van EijkHustings Y, Emery P, Finckh A, Gabay C, Gomez-Reino J, Gossec $L$, Gottenberg JE, Hazes JMW, Huizinga $T$, Jani M, Karateev D, Kouloumas M, Kvien T, Li Z, Mariette X, McInnes I, Mysler E, Nash P, Pavelka K, Poór G, Richez C, van Riel P, RubbertRoth A, Saag K, da Silva J, Stamm T, Takeuchi T, Westhovens $R$, de Wit $M$, van der Heijde D. EULAR recommendations for the management of rheumatoid arthritis with synthetic and biological disease-modifying antirheumatic drugs: 2016 update. Ann Rheum Dis. 2017 Jun;76(6):960-977. doi: 10.1136/ annrheumdis-2016-210715. Epub 2017 Mar 6. Review.

E7. Metotreksat alan hastalarda folik asit desteği başlanması uygundur

E7(i): Visser K, Katchamart W, Loza E, Martinez-Lopez JA, Salliot C, Trudeau J,Bombardier C, Carmona L, van der Heijde D, Bijlsma JW, Boumpas DT, Canhao H,Edwards CJ, Hamuryudan V, Kvien TK, Leeb BF, Martín-Mola EM, Mielants H,Müller-Ladner U, Murphy G, Østergaard M, Pereira IA, Ramos-Remus C, Valentini G, Zochling J, Dougados M. Multinational evidence-based recommendations for the use of methotrexate in rheumatic disorders with a focus on rheumatoid arthritis: integrating systematic literature research and expert opinion of a broad international panel of rheumatologists in the $3 \mathrm{E}$ Initiative. Ann Rheum Dis 2009; 68(7): 1086-93.

E7(ii): Ortiz Z, Shea B, Suarez Almazor M, Moher D, Wells G, Tugwell $P$. Folic acid and folinic acid for reducing side effects in patients receiving methotrexate for rheumatoid arthritis. Cochrane Database Syst Rev 2000; (2):CD000951. Review.

E7(iii): O'Mahony D, O'Sullivan D, Byrne S, O'Connor MN, Ryan C, Gallagher P. STOPP/START criteria for potentially inappropriate prescribing in older people: version 2. Age Ageing. 2015 Mar;44(2):213-8. doi: 10.1093/ageing/afu145. Epub 2014 Oct 16. Review.

E7(iv): Shea, B., Swinden, M. V., Ghogomu, E. T., Ortiz, Z., Katchamart, W., Rader, T.,... \& Tugwell, P. (2014). Folic acid and folinic acid for reducing side effects in patients receiving methotrexate for rheumatoid arthritis. The Journal of rheumatology, 41(6), 1049-1060.

E7(v): British National Formulary vol. 76, September 2018-March 2019: p 993, 888-89.
E7(vi): Smolen JS, Landewé R, Bijlsma J, Burmester G, Chatzidionysiou K, Dougados M,Nam J, Ramiro S, Voshaar M, van Vollenhoven $R$, Aletaha $D$, Aringer $M$, Boers $M, B$ uckley $C D$, Buttgereit $F$, Bykerk V, Cardiel $M$, Combe B, Cutolo $M$, vanEijkHustings $Y$, Emery P, Finckh A, Gabay C, Gomez-Reino J, Gossec L, Gottenberg JE, Hazes JMW, Huizinga T, Jani M, Karateev D, Kouloumas M, Kvien T, Li Z,Mariette X, Mclnnes I, Mysler E, Nash P, Pavelka K, Poór G, Richez C, van Riel P,RubbertRoth A, Saag K, da Silva J, Stamm T, Takeuchi T, Westhovens $R$, de Wit $M$, van der Heijde D. EULAR recommendations for the management of rheumatoidarthritis with synthetic and biological disease-modifying antirheumatic drugs:2016 update. Ann Rheum Dis. 2017 Jun;76(6):960-977. doi:10.1136/ annrheumdis-2016-210715. Epub 2017 Mar 6. Review.

E8. Tekrarlayan gut atağı olan hastalarda ksantin oksidaz inhibitörü (öncelikle allopürinol) başlanması uygundur

E8(i): Fravel MA, Ernst ME. Management of gout in the older adult. Am J Geriatr Pharmacother 2011; 9(5): 271-85. Review.

E8(ii): Zhang W, Doherty M, Bardin T, Pascual E, Barskova V, Conaghan P, Gerster J,Jacobs J, Leeb B, Lioté F, McCarthy G, Netter P, Nuki G, Perez-Ruiz F, Pignone A,Pimentão J, Punzi L, Roddy E, Uhlig T, Zimmermann-Gòrska I; EULAR Standing Committee for International Clinical Studies Including Therapeutics. EULAR evidence based recommendations for gout. Part II: Management. Report of a task force of the EULAR Standing Committee for International Clinical Studies Including Therapeutics (ESCISIT). Ann Rheum Dis. 2006; 65(10): 1312-24. Review.

E8(iii): Tayar JH, Lopez-Olivo MA, Suarez-Almazor ME. Febuxostat for treating chronic gout. Cochrane Database Syst Rev. 2012 Nov 14;11:CD008653. Review.

E8(iv): O'Mahony D, O'Sullivan D, Byrne S, O'Connor MN, Ryan C, Gallagher P. STOPP/START criteria for potentially inappropriate prescribing in older people: version 2. Age Ageing. 2015 Mar;44(2):213-8. doi: 10.1093/ageing/afu145. Epub 2014 Oct 16. Review.

E8(v): British National Formulary vol. 76, September 2018-March 2019: p 1085-87.

E8(vi): Richette P, Doherty M, Pascual E, Barskova V, Becce F, Castañeda-Sanabria J, Coyfish M, Guillo $S$, Jansen TL, Janssens $H$, Lioté F, Mallen C, Nuki G, Perez-RuizF, Pimentao J, Punzi L, Pywell T, So A, Tausche AK, Uhlig T, Zavada J, Zhang W, Tubach F, Bardin T. 2016 updated EULAR evidence-based recommendations for themanagement of gout. Ann Rheum Dis. 2017 Jan;76(1):2942. doi:10.1136/annrheumdis-2016-209707. Epub 2016 Jul 25. Review.

E9. Orta-ağır düzeydeki ağrı tedavisinde diğer analjeziklerin (parasetamol, NSAii veya hafif opioidler) yeterli olmadığı durumlarda güçlü etkili opioid tedavisi başlanması uygundur 
E9(i): Papaleontiou M, Henderson CR Jr, Turner BJ, Moore AA, Olkhovskaya Y, Amanfo L,Reid MC. Outcomes associated with opioid use in the treatment of chronic non-cancer pain in older adults: a systematic review and meta-analysis. J Am Geriatr Soc 2010; 58(7): 1353-69. Review.

E9(ii): van Ojik $A L$, Jansen PA, Brouwers JR, van Roon EN. Treatment of chronic pain in older people: evidence-based choice of strong-acting opioids. Drugs Aging 2012; 29(8): 61525. Review.

E9(iii): O'Mahony D, O'Sullivan D, Byrne S, O'Connor MN, Ryan C, Gallagher P. STOPP/START criteria for potentially inappropriate prescribing in older people: version 2. Age Ageing. 2015 Mar;44(2):213-8. doi: 10.1093/ageing/afu145. Epub 2014 Oct 16. Review.

E9(iv): Guerriero F. Guidance on opioids prescribing for the management of persistent non-cancer pain in older adults. World J Clin Cases. 2017 Mar 16;5(3):73-81.

E9(v): Bruce A. Ferrell. Pain Management in Hazzards Geriatric Medicine and Gerontology Seventh edition. Eds. Halter J B, Ouslander J G, Studenski S, High K P, Asthana S, Ritchie C S, Supiano M A, 2017.

E10. Kronik ağrılı olan ve uzun etkili opioid kullanan hastalarda, kaçak ağrı varlığında (breakthrough pain: aralıklarla gelen şiddetli ağrılar) tedaviye kısa etkili opioidlerin eklenmesi uygundur (şiddetli ağrının kontrol edilememe riski)

E10(i): Portenoy RK, Mehta Z, Ahmed E. Cancer pain management with opioids: Optimizing analgesia. In: UpToDate, Post, TW (Ed), UpToDate, Waltham, MA, 2019 Son erişim tarihi 11 Kasım 2019.

E10(ii): O'Mahony D, O'Sullivan D, Byrne S, O'Connor MN, Ryan C, Gallagher P. STOPP/START criteria for potentially inappropriate prescribing in older people: version 2. Age Ageing. 2015 Mar;44(2):213-8. doi: 10.1093/ageing/afu145. Epub 2014 Oct 16. Review.

E10(iii): John G. Cagle, Eric W. Widera. Geriatrics and Palliative Care in Current Diagnosis and Treatment: Geriatrics Second edition. Eds. Brie Williams, Anna Chang, C. Seth Landefeld, Cyrus Ahalt, Rebecca Conant, Helen Chen.; 2014 page 65.

E10(iv): Bruce A. Ferrell. Pain Management in Hazzards Geriatric Medicine and Gerontology Seventh edition. Eds. Halter J B, Ouslander J G, Studenski S, High K P, Asthana S, Ritchie C S, Supiano M A,; 2017 page 1204-1211.

\section{F: Endokrin Sistem Kriterleri}

F1. Diabetes mellitus'lu hastalarda aşikar proteinüri (>300 mg/ gün) veya mikroalbuminüri ( $>30 \mathrm{mg} / \mathrm{gün}$ ) varlığında, ACEi veya ARB tedavisi başlanması uygundur
*Böbrek yetersizliği olan olgularda ACEi veya ARB tedavisinin başlangıç döneminde serum kreatinin düzeyinde artış beklenir.

*Bu artış \%30'dan az ise tedaviye devam edilmesi önerilir.

*ACEi veya ARB başlanması açısından mutlak kontrendike bir bazal kreatinin düzeyi olmamakla birlikte serum kreatinin düzeyi $>3,0 \mathrm{mg} / \mathrm{dl}$ olan hastalarda başlanmaması önerilebilir.

*Diabetes mellitus'lu hastalarda ACEI-ARB tedavisi başlangıcından sonraki 1-2 hafta içinde, her doz artışında ve en az yılda 1 defa serum kreatinin ve potasyum düzeyi monitörize edilmelidir (hiperpotasemi ve renal bozulma riski)

F1(i): Schmidt M, Mansfield KE, Bhaskaran K, Nitsch D, Sørensen HT, Smeeth L, Tomlinson LA. Serum creatinine elevation after renin-angiotensin system blockade and long term cardiorenal risks: cohort study. BMJ. 2017 Mar 9;356:j791.

F1(ii): Bakris GL, Weir MR. Angiotensin-converting enzyme inhibitor-associated elevations in serum creatinine: is this a cause for concern? Arch Intern Med. 2000 Mar 13;160(5):685-93.

F1(iii): Bicket DP. Using ACE inhibitors appropriately. Am Fam Physician. 2002 Aug 1;66(3):461-8. Review.

\section{G: Ürogenital Sistem Kriterleri}

\#G1. Prostatektominin endike olmadığı, orta-ağır (IPSS skoru) düzeyde semptomatik LUTS (alt uriner sistem semptomları) mevcut olan hastalarda alfa-1 reseptör blokeri kullanımı uygundur

G1(i): Lowe FC. Role of the newer alpha, -adrenergic-receptor antagonists in the treatment of benign prostatic hyperplasiarelated lower urinary tract symptoms. Clin Ther 2004; 26(11): 1701-13. Review.

G1(ii): Schwinn DA, Roehrborn CG. Alpha1-adrenoceptor subtypes and lower urinary tractsymptoms. Int J Urol. 2008 Mar;15(3):193-9. doi:10.1111/j.1442-2042.2007.01956.x. Review.

G1 (iii): Dunn CJ, Matheson A, Faulds DM. Tamsulosin: a review of its pharmacology and therapeutic efficacy in the management of lower urinary tract symptoms. Drugs Aging 2002; 19(2):13561. Review.

G1(iv): Cunningham GR, Kadmon D. Medical treatment of benign prostatic hyperplasia. In: UpToDate, Post, TW (Ed), UpToDate, Waltham, MA, 2019 Son erişim tarihi 11 Kasım 2019.

G1(v): O'Mahony D, O'Sullivan D, Byrne S, O'Connor MN, Ryan C, Gallagher P. STOPP/START criteria for potentially inappropriate prescribing in older people: version 2. Age Ageing. 2015 Mar;44(2):213-8. doi: 10.1093/ageing/afu145. Epub 2014 Oct 16. Review. 
G1(vi): S. Gravas (Chair), J.N. Cornu, M.J. Drake, M. Gacci, C. Gratzke, T.R.W. Herrmann, S. Madersbacher, C. Mamoulakis, K.A.O. Tikkinen Guidelines Associates: M. Karavitakis, I. Kyriazis, S. Malde, V. Sakkalis, R. Umbach. EAU Guidelines on Management of Non-Neurogenic Male Lower Urinary Tract Symptoms (LUTS), incl. Benign Prostatic Obstruction (BPO). European Association of Urology 2018. Page 17-18.

\#G2. Prostatektominin endike olmadığı orta-ağır (IPSS skoru) düzeyde semptomatik LUTS (alt uriner sistem semptomları) mevcut olan hastalarda, prostat hacmi $>30-40 \mathrm{~mL}$ ise, alfa-1 reseptör blokerine ek olarak 5-alfa redüktaz inhibitörü tedavisi başlanması uygundur

G2(i): Cunningham GR, Kadmon D. Medical treatment of benign prostatic hyperplasia. In: UpToDate, Post, TW (Ed), UpToDate, Waltham, MA, 2019 Son erişim tarihi 11 Kasım 2019.

G2(ii): O'Mahony D, O'Sullivan D, Byrne S, O'Connor MN, Ryan C, Gallagher P. STOPP/START criteria for potentially inappropriate prescribing in older people: version 2. Age Ageing. 2015 Mar;44(2):213-8. doi: 10.1093/ageing/afu145. Epub 2014 Oct 16. Review.

G2(iii): S. Gravas (Chair), J.N. Cornu, M.J. Drake, M. Gacci, C. Gratzke, T.R.W. Herrmann, S. Madersbacher, C. Mamoulakis, K.A.O. Tikkinen Guidelines Associates: M. Karavitakis, I. Kyriazis, S. Malde, V. Sakkalis, R. Umbach. EAU Guidelines on Management of Non-Neurogenic Male Lower Urinary Tract Symptoms (LUTS), incl. Benign Prostatic Obstruction (BPO). European Association of Urology 2018. Page 18-19.

G3. Semptomatik atrofik vajinitte, hormon-dışı tedaviler denendikten sonra, topikal vajinal östrojen tedavisi kullanımı uygundur

G3(i): Lynch C. Vaginal estrogen therapy for the treatment of atrophic vaginitis. J Womens Health (Larchmt) 2009; 18(10): 1595-606. Review.

G3(ii): Bachmann G, Bouchard C, Hoppe D, Ranganath R, Altomare C, Vieweg A, Graepel J, Helzner E. Efficacy and safety of low-dose regimens of conjugated estrogens cream administered vaginally. Menopause 2009; 16(4): 719-27.

G3(iii): Mainini G, Scaffa C, Rotondi M, Messalli EM, Quirino $L$, Ragucci $A$. Local estrogen replacement therapy in postmenopausal atrophic vaginitis: efficacy and safety of low dose 17beta-estradiol vaginal tablets. Clin Exp Obstet Gynecol 2005; 32(2): 111-3.

G3(iv): O'Mahony D, O'Sullivan D, Byrne S, O'Connor MN, Ryan C, Gallagher P. STOPP/START criteria for potentially inappropriate prescribing in older people: version 2. Age Ageing. 2015 Mar;44(2):213-8. doi: 10.1093/ageing/afu145. Epub 2014 Oct 16. Review.
G3(v): The use of vaginal estrogen in women with a history of estrogen-dependent breast cancer. Committee Opinion No. 659. American College of Obstetricians and Gynecologists. Obstet Gynecol 2016;127:e93-6.

G3(vi): The NAMS 2017 Hormone Therapy Position Statement Advisory Panel. The 2017 hormone therapy position statement of The North American Menopause Society.Menopause. 2017 Jul;24(7):728-753.

G3(vii): Bergendal A, Kieler $H$, Sundström A, Hirschberg $A L$, Kocoska-Maras L. Risk ofvenous thromboembolism associated with local and systemic use of hormone therapy in peri- and postmenopausal women and in relation to type and route ofadministration. Menopause. 2016 Jun;23(6):593-9.

G3(viii): Calle EE, Feigelson HS, Hildebrand JS, Teras LR, Thun MJ, Rodriguez C. Postmenopausal hormone use and breast cancer associations differ by hormone regimen and histologic subtype. Cancer 2009; 115(5): 936-45. Erratum in: Cancer 2009; 115(7): 1587.

G3(ix): Diergaarde B, Potter JD, Jupe ER, Manjeshwar S, Shimasaki CD, Pugh TW, Defreese DC, Gramling BA, Evans I, White E. Polymorphisms in genes involved in sex hormone metabolism, estrogen plus progestin hormone therapy use, and risk of postmenopausal breast cancer. Cancer Epidemiol Biomarkers Prev 2008; 17(7): 1751-9.

\section{H: Aşılar.}

H1. Yıllık influenza aşısı yapılması uygundur

*Trivalan yüksek doz ve tetravalan influenza aşılarının yaşlıda etkinlikleri standart doz trivalan aşıya göre daha fazladır, tercih edilebilir.

* Tetravalan, trivalan ve yüksek doz trivalan influenza aşılarının FDA onayı vardır.

H1(i): Hibberd PL. Seasonal influenza vaccination in adults. In: UpToDate, Post, TW (Ed), UpToDate, Waltham, MA, 2019 erişim tarihi 11 Kasım 2019

H1(ii): O'Mahony D, O'Sullivan D, Byrne S, O'Connor MN, Ryan C, Gallagher P. STOPP/START criteria for potentially inappropriate prescribing in older people: version 2. Age Ageing. 2015 Mar;44(2):213-8. doi: 10.1093/ageing/afu145. Epub 2014 Oct 16. Review.

H1(iii): U.S. Food and Drug Administration. Vaccines Licensed for Use in the United States. Content current as of: 05/09/2019. Available at: https://www.fda.gov/vaccines-blood-biologics/ vaccines/vaccines-licensed-use-united-states (erişim tarihi 10 Kasım 20192019)

H1(iv): Grohskopf LA, Alyanak E, Broder KR, Walter EB, Fry AM, Jernigan DB. Prevention and Control of Seasonal Influenza with 
Vaccines: Recommendations of the Advisory Committee on Immunization Practices - United States, 2019-20 Influenza Season. MMWR Recomm Rep 2019;68(No. RR-3):1-21.

H2. 65 yaşından sonra Pnömokok aşısı (13 valan konjuge ve 23 valan polisakkarit aşıdan herbiri için bir doz) yapılması uygundur

i) Daha önce pnömokok aşısı yapılmamış bireylerde ilk doz aşı olarak 13 valan konjuge aşı, takiben en az 1 yıl sonra 23 valan polisakkartd aşı uygulanmalıdır.

ii) Daha önce 23 valan polisakkarit aşı yapılmış bireylerde 1 yıl sonra 13 valan konjuge aşı yapılmalıdır.

*23 valan polisakkarit aşı 65 yaş öncesinde uygulanmışsa, 65 yaş üstünde ilk aşıdan en az 5 yıl sonra tekrarlanmalıdır

*23 valan polisakkarit aşının 65 yaş üzeri 10 yılda bir tekrarlanması önerilebilir

H2(i): Advisory Committee on Immunization Practices. Recommended Adult Immunization Schedule, United States, 2019.Centers for Disease Control and Prevention. Available at: https://www.cdc.gov/vaccines/schedules/downloads/adult/ adult-combined-schedule.pdf. (erişim tarihi 10 Kasım 2019 2019)

H2(ii): An Advisory Committee Statement (ACS) National Advisory Committee on Immunization (NACl). Update on the use of 13-valent pneumococcal conjugate vaccine (PNEU-C-13) in addition to 23-valent pneumococcal polysaccharide vaccine (PNEU-P-23) in immunocompetent adults 65 years of age and older - Interim Recommendation. Date published: October 2016. Available at: https://www.canada.ca/en/public-health/ services/publications/healthy-living/update-use-of-13-valentpneumococcal-conjugate-vaccine-pneu-c-13-in-additionto-23-valent-pneumococcal-polysaccharide-vaccine-pneup-23-immunocompetent-adults-65-years-and-older-interimrecommendation.html (erişim tarihi 10 Kasım 2019)

H2(iii): O'Mahony D, O'Sullivan D, Byrne S, O'Connor MN, Ryan C, Gallagher P. STOPP/START criteria for potentially inappropriate prescribing in older people: version 2. Age Ageing. 2015 Mar;44(2):213-8. doi: 10.1093/ageing/afu145. Epub 2014 Oct 16. Review.

H2(iv): U.S. Food and Drug Administration. Vaccines Licensed for Use in the United States. Content current as of: 05/09/2019. Available at: https://www.fda.gov/vaccines-blood-biologics/ vaccines/vaccines-licensed-use-united-states (Son erişim tarihi 10 Kasım 2019.)

H2(v): Heflin MT. Geriatric health maintenance. In: UpToDate, Post, TW (Ed), UpToDate, Waltham, MA, 2019 Son erişim tarihi 11 Kasım 2019.

H3. Herpes zoster aşısı yapılması uygundur (zona infeskiyonu riskinde ve postherpetik nevralji riskinde azalma sağlar)
*Daha önce zona infeksiyonu veya su çiçeği geçirmiş olguların da aşılanması önerilir.

*RZV, ZVL'den daha fazla koruma sağlar.

*RZV, ZVL'ye tercih edilir.

*RZV intramüsküler olarak iki dozda uygulanır. ikinci doz, ilk dozdan 2-6 ay sonra verilmelidir. Bu program, önceden herpes zoster öyküsü olanlar ve daha önce ZVL almış olanlar dahil tüm hastalar için kullanılmalıdır.

*Zona infeksiyonu geçiren olgularda aşılama en erken 6-12 ay sonra önerilir.

H3(i): Oxman MN, Levin MJ, Shingles Prevention Study Group. Vaccination against Herpes Zoster and Postherpetic Neuralgia. J Infect Dis 2008; 197 Suppl 2:S228.

H3(ii): Albrecht MA, Levin MJ. Vaccination for the prevention of shingles (herpes zoster).In: UpToDate, Post, TW (Ed), UpToDate, Waltham, MA, 2019 erişim tarihi 10 Kasım 2019

H3(iii): Oxman MN, Levin MJ, Johnson GR, Schmader KE, Straus SE, Gelb LD, Arbeit RD,Simberkoff MS, Gershon AA, Davis LE, Weinberg A, Boardman KD, Williams HM, Zhang JH, Peduzzi PN, Beisel CE, Morrison VA, Guatelli JC, Brooks PA, Kauffman CA,Pachucki CT, Neuzil KM, Betts RF, Wright PF, Griffin MR, Brunell P, Soto NE,Marques AR, Keay SK, Goodman RP, Cotton DJ, Gnann JW Jr, Loutit J, Holodniy M,Keitel WA, Crawford GE, Yeh SS, Lobo Z, Toney JF, Greenberg RN, Keller PM,Harbecke R, Hayward AR, Irwin MR, Kyriakides TC, Chan CY, Chan IS, Wang WW,Annunziato PW, Silber JL; Shingles Prevention Study Group. A vaccine to preventherpes zoster and postherpetic neuralgia in older adults. N Engl J Med. 2005 Jun 2;352(22):2271-84.

H3(iv): Heflin MT. Geriatric health maintenance. In: UpToDate, Post, TW (Ed), UpToDate, Waltham, MA, 2019 erişim tarihi 11 Kasım 2019

H3(v): Kimberlin DW, Whitley RJ. Varicella-zoster vaccine for the prevention ofherpes zoster. N Engl J Med. 2007 Mar 29;356(13):1338-43. Review.

H3(vi): Curran D, Patterson BJ, Van Oorschot D, Buck PO, Carrico J, Hicks KA, Lee B,Yawn BP. Cost-effectiveness of an adjuvanted recombinant zoster vaccine in older adults in the United States who have been previously vaccinated with zostervaccine live. Hum Vaccin Immunother. 2019;15(4):765-771. doi:10.1080/216 45515.2018.1558689. Epub 2019 Feb 20.

H3(vii): U.S. Food and Drug Administration. Vaccines Licensed for Use in the United States. Content current as of: 05/09/2019. Available at: https://www.fda.gov/vaccines-blood-biologics/ vaccines/vaccines-licensed-use-united-states (erişim tarihi 10 Kasım 2019) 
H3(viii): An Advisory Committee Statement (ACS) National Advisory Committee on Immunization (NACl). Updated Recommendations on the Use of Herpes Zoster Vaccines. Date published: 2018-08-30.

H4. 10 yılda bir Td (tetanoz-difteri toksoidi) yapılması uygundur

*Pertusis aşısı 1 yaşından büyük infantlarla yakın teması olan yaşlılarda (dede, nine gibi) önerilebilir. Bu durumda tek doz TdaP şeklinde uygulanabilir

H4(i): Recommended Adult Immunization Schedule for ages 19 years or older. https://www.cdc.gov/vaccines/schedules/ downloads/adult/adult-combined-schedule.pdf. erişim tarihi 23 Ekim 2019

H4(ii): Ridda I, Yin JK, King C, Raina MacIntyre C, McIntyre P. The importance ofpertussis in older adults: a growing case for reviewing vaccination strategy in the elderly. Vaccine. 2012 Nov 6;30(48):6745-52.

H4(iii): Centers for Disease Control and Prevention (CDC). Updated recommendations for use of tetanus toxoid, reduced diphtheria toxoid and acellular pertussis (Tdap) vaccine from the Advisory Committee on Immunization Practices, 2010. MMWR Morb Mortal Wkly Rep 2011; 60:13.

H4(iv): Heflin MT. Geriatric health maintenance. In: UpToDate, Post, TW (Ed), UpToDate, Waltham, MA, 2019 erişim tarihi 11 Kasım 2019

H4(v): Liang JL, Tiwari T, Moro P, Messonnier NE, Reingold A, Sawyer M, Clark TA. Prevention of Pertussis, Tetanus, and Diphtheria with Vaccines in the UnitedStates: Recommendations of the Advisory Committee on Immunization Practices(ACIP). MMWR Recomm Rep. 2018 Apr 27;67(2):1-44.

H4(vi): Diphtheria, tetanus toxoids, and acellular pertussis vaccine (DTaP and Tdap): Drug information, Lexicomp online. erişim tarihi 11 Kasım 2019.

\#H5. Hacca gidecek olgulara meningokok aşısı yapılması uygundur

*Hacdan en az 10 gün önce önerilir.

*5 yıldan sonra tekrar seyahat edilecekse doz tekrarlanmalıdır.

H5(i): Recommended Adult Immunization Schedule for ages 19 years or older. https://www.cdc.gov/vaccines/schedules/ downloads/adult/adult-combined-schedule.pdf. erişim tarihi 23 Ekim 2019

H5(ii): David O F, Karin L. Immunizations for travel. In: UpToDate, Post, TW (Ed), UpToDate, Waltham, MA, 2019 erişim tarihi 10 Kasım 2019

H5(iii): Kim DK, Riley LE, Hunter P; Advisory Committee on Immunization Practices. Recommended Immunization Schedule for Adults Aged 19 Years or Older, United States, 2018. Ann Intern Med. 2018 Feb 6;168(3):210-220.

\section{I: Suplemanlar.}

I1. Malnütrisyon (MN) veya malnütrisyon riski (MNR) olan yaşıılarda beslenme danışmanlığı ve besin takviyesi diyetle alımı artırmak ve beslenme hedeflerine ulaşmak için yeterli değil ise oral nütrisyonel suplemanların (ONS) başlanması uygundur

*Kronik hastalığı olan yaşılıarda ONS başlanması ile ilgili daha çok kanıt vardır.

${ }^{*}$ ONS içeriğinin günlük en az $400 \mathrm{kcal}$ enerji ve $30 \mathrm{~g}$ protein içermesi ve ONS'nin en az 1 ay devam edilmesi önerilir.

${ }^{*}$ ONS verilen olguların ayda 1 değerlendirilmesi uygundur.

*Tedavide rehberlik etmesi açısından yaşlı bireylerde enerji alımı için tavsiye edilen değer $30 \mathrm{kcal} / \mathrm{kg} / \mathrm{gün}$ 'dür.

*Sağıılı yaşsı bireylerde protein alımı 1,0-1,2 g/kg/gün önerilmektedir

*Akut veya kronik hastalığı olan yaşı bireyler için protein alımı 1,2-1,5 g/kg/gün önerilmektedir.

${ }^{*}$ Ciddi hastalığı, yaralanma veya malnütrisyonu olan yaşlı bireyler için protein alımının 1,5 g/kg/gün'ün üzerine 2,0 g/kg/ gün'e kadar çıkarılması gerekebilir.

I1(i): LLLnutrition Topic 8. Approach to Oral and Enteral Nutrition in Adults. Module 8.1. Indications, Contraindications, Complications and Monitoring of EN. Zanetti M. Available at: https://IInutrition.com/mod/page/view.php?id=2654; $\quad$ (erişim tarihi 10 Kasım 2019.)

I1 (ii): Norman K, Pichard C, Lochs H, Pirlich M. Prognostic impact of disease-related malnutrition. Clin Nutr 2008; 27: 5-15.

I1(iii): Stratton RJ, Green CJ, Elia M. Disease-related malnutrition: an evidence-based approach to treatment. First Edition. CABI; First edition (January 30, 2003)

I1(iv): Guest JF, Panca $M$, Baeyens JP, de Man $F_{1}$ Ljungqvist O, Pichard C, Wait $S$, Wilson L. Health economic impact of managing patients following a community-based diagnosis of malnutrition in the UK. Clin Nutr. 2011; 30: 422-429.

I1(v): Illnutrition: Topic 36. Nutrition in OlderAdults. Module 36.1 Epidemiology, Aetiology and Consequences of Malnutrition in Older Adults: Cederholm T. Available at: https://IIInutrition. $\mathrm{com} / \mathrm{mod} /$ page/view.php?id=2685\#u361p4 (erişim tarihi 10 Kasım 2019)

I1(vi): Volkert D, Beck AM, Cederholm T, Cruz-Jentoft A, Goisser S, Hooper L, Kiesswetter $E_{1}$ Maggio M, Raynaud-Simon A Sieber CC, Sobotka L, van Asselt D, Wirth R, Bischoff SC. ESPEN guideline on clinical nutrition and hydration in geriatrics. Clin Nutr. 2018 Jun 18.pii: S0261-5614(18)30210-3. 
12. Hastanede yatan MN veya MNR olan yaşılıarda oral nutrisyonel suplemanların (ONS) başlanması uygundur (besin alımı ve vücut ağırlığını artırır, komplikasyon ve tekrar başvuru riskini azaltır)

*Spontan oral enerji alımı akut hastane yatışı olan yaşıılarda genellikle düşüktür ve gereksinimleri karşılamamaktadır.

*Hastaneden çıktıktan sonra çoğu olguda ONS kullanımına devam etmek uygun olabilir.

I2(i): Volkert D, Beck AM, Cederholm T, Cruz-Jentoft A, Goisser S, Hooper L, Kiesswetter E, Maggio M, Raynaud-Simon A, Sieber CC, Sobotka L, van Asselt D, Wirth R, Bischoff SC. ESPEN guideline on clinical nutrition and hydration in geriatrics. Clin Nutr. 2018 Jun 18.pii: S0261-5614(18)30210-3.

13. Kalça kırığı olan yaşlı hastalara postoperatif dönemde ONS başlanması (nütrisyonel durumundan bağımsız olarak) uygundur (besin alımını iyileştirir ve komplikasyon riskini azaltır)

*Spesifik bir ONS (standart veya yüksek proteinli) önerisi yoktur.

*ONS'nin en az 1 ay verilmesi uygun olabilir. Çalışmalarda, kalça kırığı sonrası ONS 1-6 ay arası kullanılmıştır.

*Preoperatif başlanması da düşünülebilir.

I3(i): Volkert D, Beck AM, Cederholm T, Cruz-Jentoft A, Goisser $S$, Hooper L, Kiesswetter E, Maggio M, Raynaud-Simon A, Sieber CC, Sobotka L, van Asselt D, Wirth R, Bischoff SC. ESPEN guideline on clinical nutrition and hydration in geriatrics. Clin Nutr. 2018 Jun 18.pii: S0261-5614(18)30210-3.

14. Bası yarası mevcut olan hastalarda yeterli protein ve enerji alımını sağlamak için 1,2-2 g/kg/gün protein, 30-35 kcal/kg / gün enerji hedeflenerek ONS başlanması uygundur

*Bası yarası olan malnütre hastalarda, arjinin, çinko ve antioksidanlarla zenginleştirilmiş yüksek protein ve enerji içeriğine sahip ONS kullanımı daha faydalı olabilir.

*Bası yarası olan hastalarda beslenme ürünlerine arjinin, glutamin ve HMB eklenmesinin olumlu sonuçları olabilir.

14(i): Gomes F, Schuetz P, Bounoure L, Austin P, BallesterosPomar M, Cederholm T, Fletcher J, Laviano A, Norman K, Poulia KA, Ravasco P, Schneider SM, Stanga Z, Weekes CE, Bischoff SC. ESPEN guidelines on nutritional support for polymorbid internal medicine patients. Clin Nutr. 2018 Feb;37(1):336353.

I4(ii): Volkert D, Beck AM, Cederholm T, Cruz-Jentoft A, Goisser $S$, Hooper L, Kiesswetter E, Maggio M, Raynaud-Simon A, Sieber CC, Sobotka L, van Asselt D, Wirth R, Bischoff SC. ESPEN guideline on clinical nutrition and hydration in geriatrics. Clin Nutr. 2018 Jun 18.pii: S0261-5614(18)30210-3.

14(iii): Stratton RJ, Ek AC, Engfer M, Moore Z, Rigby P, Wolfe R, Elia M. Enteralnutritional support in prevention and treatment of pressure ulcers: a systematic review and meta-analysis. Ageing Res Rev. 2005 Aug;4(3):422-50. Review.

I4(iv): Volkert D, Berner YN, Berry E, Cederholm T, Coti Bertrand P, Milne A, Palmblad J, Schneider S, Sobotka L, Stanga Z; DGEM (German Society for Nutritional Medicine), LenzenGrossimlinghaus R, Krys U, Pirlich M, Herbst B, Schütz T, Schröer W, Weinrebe W, Ockenga J, Lochs $H$; ESPEN (European Society for Parenteral and Enteral Nutrition). ESPEN Guidelines on Enteral Nutrition: Geriatrics. Clin Nutr. 2006 Apr;25(2):330-60.

14(v): Cereda E, Klersy C, Serioli M, Crespi A, D'Andrea F; OligoElement Sore Trial Study Group. A nutritional formula enriched with arginine, zinc, and antioxidants for the healing of pressure ulcers: a randomized trial. Ann Intern Med. 2015 Feb 3;162(3):167-74. doi: 10.7326/M14-0696. Erratum in: Ann Intern Med. 2015 Dec 15;163(12):964.

14(vi): Liu P, Shen WQ, Chen HL. Efficacy of arginine-enriched enteral formulas for the healing of pressure ulcers: a systematic review. J Wound Care. 2017 Jun 2;26(6):319-323.

14(vii): Wong A, Chew A, Wang CM, Ong L, Zhang SH, Young S. The use of a specialised amino acid mixture for pressure ulcers: a placebo-controlled trial. J Wound Care. 2014 May;23(5):25960, 262-4, 266-9.

\section{Kısaltmalar:}

ACEI: Anjiotensin konverting enzim inhibitörleri

ARB: Anjiotensin reseptör blokerleri

BTM: Kemik turnover belirteçleri

ChEi: Asetilkolinesteraz inhibitörleri

COMT: Catechol-0-methyltransferase

EF: Ejeksiyon fraksiyonu

eGFR: Estimated Glomerular Filtrasyon hızı

FDA: Food and Drug Administration

FEV1: Zorlu ekspiratuvar volüm

GiS: Gastrointestinal sistem

IPSS: Uluslararası Prostat Semptom Skoru

KOAH: Kronik obstrüktif akciğer hastalığı

KMD: Kemik mineral dansitesi

LUTS: Alt üriner sistem semptomları

MAO-B: Monoamine oxidase-B

Mi: Miyokard infarktüsü

MN: Malnürisyon

MNR: Malnütrisyon riski 
NSAii: Non steroidal anti inflamatuar ilaçlar

OAK: Oral antikoagülan

ONS: Oral nütrisyonel supleman

RZV: Rekombinant zoster aşıSI

$\mathrm{SaO}_{2}$ : Oksijen saturasyonu

SNRIs: Serotonin-norepinefrin geri alım inhibitörleri

SSRIs: Selektif serotonin geri alım inhibitörleri
TdaP: Tetanoz, difteri, and aselüler pertussis

ZVL: Canlı zoster aşıII

\#Uluslararası Delfi paneli çalışmasında konsensus sağlanmayan kriterler 